University of Louisville

ThinkIR: The University of Louisville's Institutional Repository

Electronic Theses and Dissertations

$12-2018$

\title{
Student voices: African American high school seniors' perception of culturally responsive teaching.
}

\author{
Whitney M. Stewart \\ University of Louisville
}

Follow this and additional works at: https://ir.library.louisville.edu/etd

Part of the Bilingual, Multilingual, and Multicultural Education Commons, Curriculum and Instruction Commons, Educational Leadership Commons, Educational Methods Commons, Elementary and Middle and Secondary Education Administration Commons, Indigenous Education Commons, Junior High, Intermediate, Middle School Education and Teaching Commons, Other Education Commons, Other Teacher Education and Professional Development Commons, Secondary Education Commons, Secondary Education and Teaching Commons, and the Urban Education Commons

\section{Recommended Citation}

Stewart, Whitney M., "Student voices: African American high school seniors' perception of culturally responsive teaching." (2018). Electronic Theses and Dissertations. Paper 3081.

https://doi.org/10.18297/etd/3081

This Doctoral Dissertation is brought to you for free and open access by ThinkIR: The University of Louisville's Institutional Repository. It has been accepted for inclusion in Electronic Theses and Dissertations by an authorized administrator of ThinkIR: The University of Louisville's Institutional Repository. This title appears here courtesy of the author, who has retained all other copyrights. For more information, please contact thinkir@louisville.edu. 


\title{
STUDENT VOICES: AFRICAN AMERICAN HIGH SCHOOL SENIORS' PERCEPTION OF CULTURALLY RESPONSIVE TEACHING
}

\author{
By \\ Whitney M. Stewart \\ B.S., University of Louisville, 2010 \\ M.Ed., University of Louisville, 2011

\begin{abstract}
A Dissertation
Submitted to the Faculty of the

College of Education and Human Development of the University of Louisville In Partial Fulfillment of the Requirements

for the Degree of
\end{abstract} \\ Doctor of Education \\ In Educational Leadership and Organizational Development \\ Department of Educational Leadership, Evaluation and Organizational Development \\ University of Louisville \\ Louisville, Kentucky
}

December 2018 
Copyright 2018 by Whitney M. Stewart

All rights reserved 



\title{
STUDENT VOICES: AFRICAN AMERICAN HIGH SCHOOL SENIORS' PERCEPTION OF CULTURALLY RESPONSIVE TEACHING
}

\author{
By \\ Whitney M. Stewart \\ B.S., University of Louisville, 2010 \\ M.Ed., University of Louisville, 2011 \\ A Dissertation Approved on
}

November 12, 2018

By the following Dissertation Committee:

Dr. Mary Brydon-Miller, Dissertation (Co-Chair)

Dr. Detra Johnson, Dissertation (Co-Chair)

Dr. Derrick Brooms

Dr. W. Blake Haselton 


\section{DEDICATION}

This dissertation is dedicated to my Heavenly Father. "For I know the plans I have for you," declares the Lord, "plans to prosper you and not to harm you, plans to give you hope and a future." (Jeremiah 29:11) I would also like to dedicate this dissertation to my father, Mr. Robert L. Stewart for his inspiration, motivation and unyielding love and to the memory of my beloved brother, Jonathan Chadwick (Chad) Stewart (deceased). 


\section{ACKNOWLEDGEMENTS}

In high school I wrote an award-winning essay about overcoming adversity that opened with, " If I had to select a quote that described my life, in a small summary, it would be, "To whom much is given, much is expected." The quote lifted from scripture in Luke 12:48 has been actualized again and again in my life. As the essay continues, any reader can clearly see that I've always had a special calling on my life. Even as a child, I knew that I was different and I always have been. I am set apart. I am destined for greatness. Therefore, first and most importantly, I would like to give all glory and honor to the Lord, my God, my Creator, who is the source and the strength of my life. All glory and honor is due to Him. Before I started this doctoral journey, I made a vow to God that this degree would belong to Him and that I would give Him all of the praise, glory and honor that is due to Him. I want to humbly thank God for everything He has given me

privilege and access to see, do, and experience. I am beyond grateful that He would select and use me to further His kingdom and His mission. Thank You, God. You are intentional. You are strategic. You have a purpose-filled plan just for me and I thank You.

I would like to thank my dissertation co-chairs, Dr. Mary Brydon-Miller and Dr. Detra Johnson for their mentorship, encouragement, and support throughout my doctoral journey. Thank you both for always seeing the potential in me and for pushing me to chase after it. I would also like to thank Dr. Blake Haselton and Dr. Derrick Brooms for their critical feedback, direction, and guidance as members of my dissertation committee. I would like to extend a deep appreciation to Dr. Alexander, Dr. Blackman, Dr. 
Carpenter, Dr. D. Compton, Dr. T. Compton, Dr. Howell, Dr. King, Dr. Pentecost, Ms. Bledsoe, and Mrs. Dockery-Brooks for the integral role they each played in helping me begin, and complete, this doctoral journey.

I would like to thank my ancestors, known and unknown; for I was birthed from greatness and here I stand on the shoulders of greatness. I would like to thank my father, Robert L. Stewart for his encouragement, support, patience, and understanding from the very beginning of this process. I would not have done this without your constant urgings, words of wisdom, and support, especially when I felt weary. I would like to thank my immediate family, Lena, Yonbretta, Kourtney, Willie, and Jonathan (deceased). I would like to thank my loving and supportive extended family, from my aunts, uncles, cousins, play cousins, my Godmother, my God-sisters, and my best friends Faith and Deanna, who prayed with, over, and for me. I would like to thank my church family, friends, colleagues, Pastor, Master Life classmates, special friends, and others who have continuously lifted me up in prayer and encouraged me in various ways. Whether through hot meals, in-person visits, text messages, video messaging, and/or phone calls, it meant the world to me when you checked in on me and it filled my spirit. Thank you. I am forever grateful.

I would like to thank my \#Block18 classmates for their reflective insight, engaging dialogue, support, and encouragement. I would like to especially thank my two writing partners, Dr. Ronda George and Dr. DeNay Speaks. Oh, how I am so thankful that our paths crossed at the same appointed time in the fall of 2015. I am so thankful to have you as my doctoral sisters. We made it! I would like to thank all of my study buddies - Quisha, Tamekka, Angela, and Dr. Candice Johnson. We held each other 
accountable for the goals we set and we cheered for one another once they were accomplished. Thank you.

Lastly, but certainly not least, I want to thank the village that raised me. You have been speaking life, love, and positivity into me since I was young child up until this present day. You planted seeds deep within my heart and mind that are now manifesting. What was once buried is now blossoming beyond expectations. When we speak into a child's life, we may never know what or who they will become, therefore let this dissertation speak love, life, and positivity into my "Littles"—Za'Nasia, Jathan, Jonathan, Leonardo, Brandon, Triniti, Makayla, and for future generations of Black and brown students to come. 


\title{
ABSTRACT \\ STUDENT VOICES: AFRICAN AMERICAN HIGH SCHOOL SENIORS' PERCEPTION OF CULTURALLY RESPONSIVE TEACHING
}

\author{
Whitney M. Stewart
}

November 12, 2018

This dissertation examined African_American high school seniors' perceptions of culturally responsive teaching in one public high school within a large urban publicschool district in the southeastern region of the United States. It begins with a brief historical overview on the plight of African-Americans in the US public education system and how public school educators have failed to leverage Afrocultural learning orientations as an asset to educate and increase the academic achievement of AfricanAmerican students in classrooms. The Philosophical Aspects of Cultural Difference Framework (Nichols, 1986, 1995) will guide this dissertation study. The latter part of the dissertation reveals that a critical examination of Afrocultural learning orientations, specifically communalism, verve, and movement (music), and achievement has potential to improve performance, engagement, and motivation of African-American students in US public-school classrooms.

This study is divided into five chapters. Chapter 1 begins with a current snapshot of African-American students' academic achievement and outcomes in the US publicschools system. Chapter 1 connects current trend data of African-American students' 
academic achievement and outcomes to the purpose and analytical strategy of this research study. Chapter 1 also provides a definition of terms and lays out the organization of the research study. Chapter 2 gives a historical overview of African-Americans in the US educational system, reviews current literature on culturally responsive teaching and how the use of Afrocultural learning orientations has produced academic successfulness for African-American students. Chapter 3 focuses on the methodological approach used for this research. Chapter 4 focuses on research findings from the purposeful sampling of nine African-American high school seniors who were recruited through a Demographic Survey to participate in one-on-one interviews, a focus group interview, and who completed a Participant Profile sheet. Chapter 5 discusses the findings, and links the findings to implications and suggestions for future research. 


\section{TABLE OF CONTENTS}

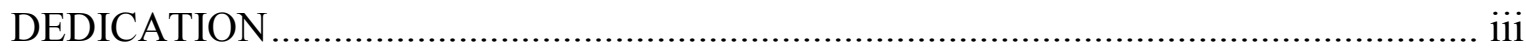

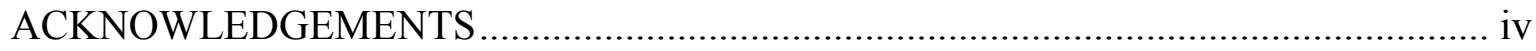

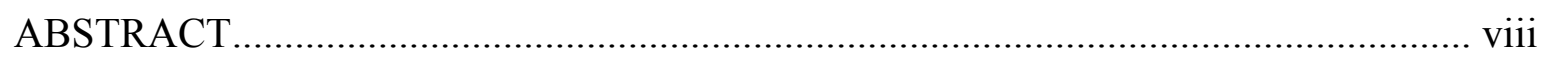

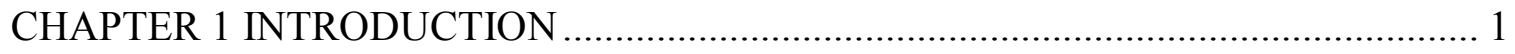

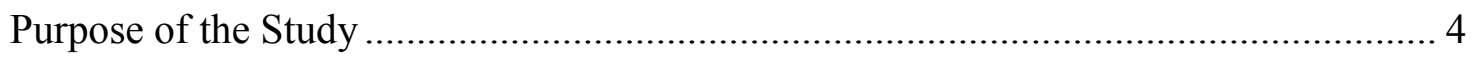

Analytical Strategy

Definition of Terms

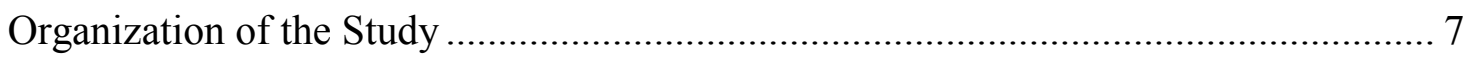

Summary

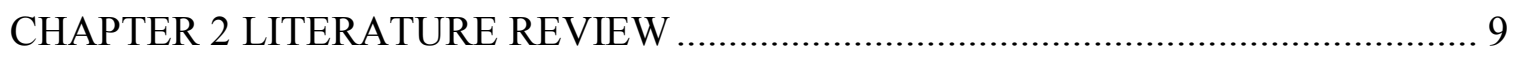

The Plight of African-Americans in the US Education System ................................... 9

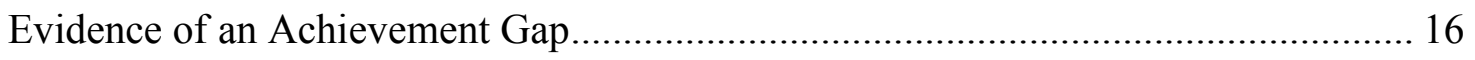

Federal and State Policies to Address Achievement Gap ......................................... 20

Culturally Responsive Pedagogy (CRP) and Educators' Disposition Alignment .... 24

Philosophical Aspects of Cultural Difference Framework and Its Application ........... 30

Relevant Research on Afrocultural Themes in Learning and Achievement................. 35

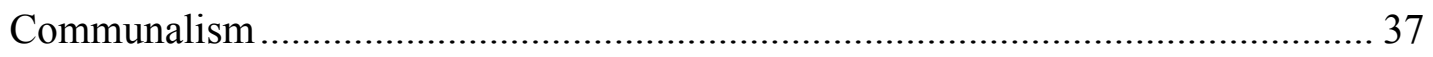

Verve

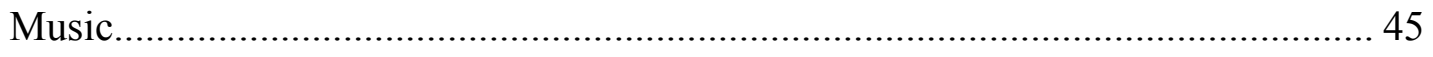

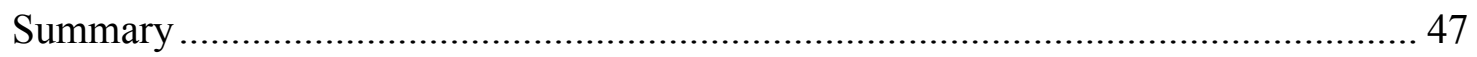




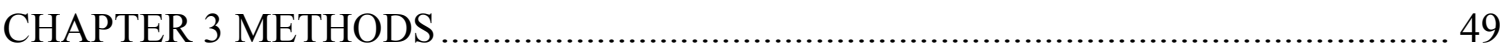

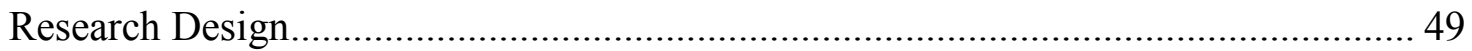

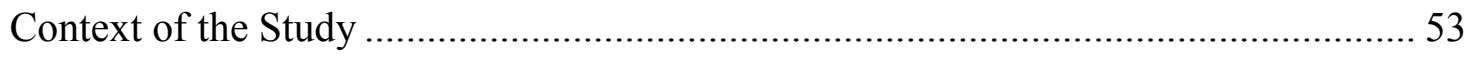

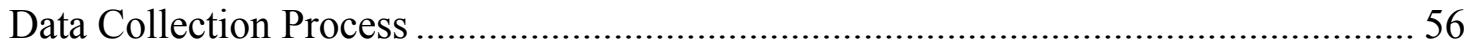

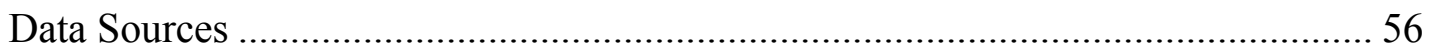

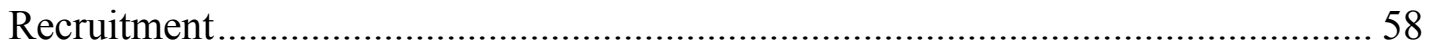

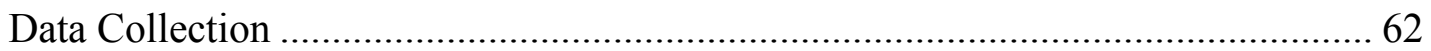

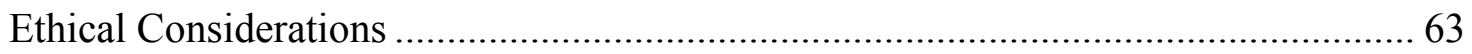

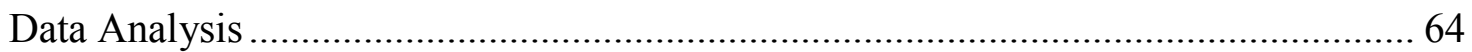

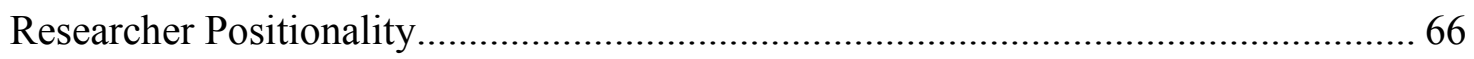

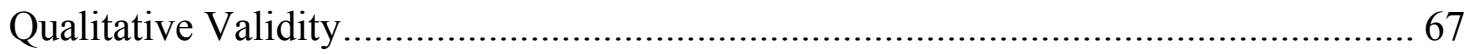

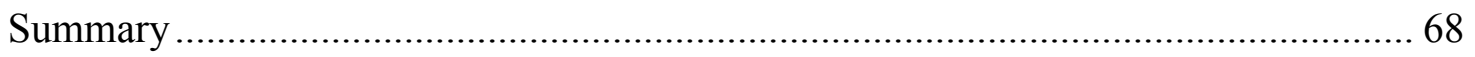

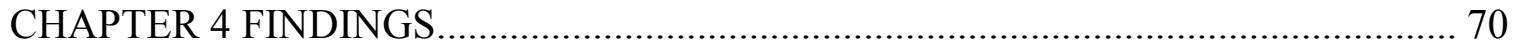

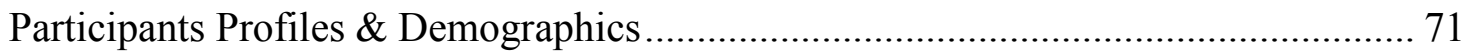

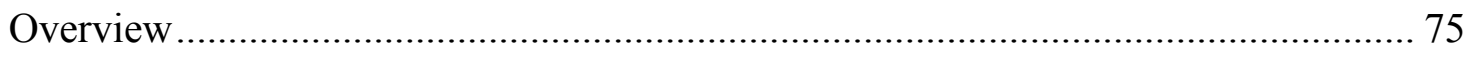

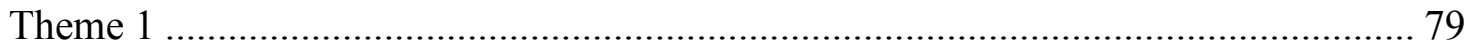

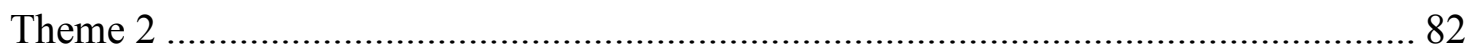

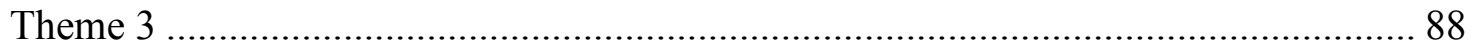

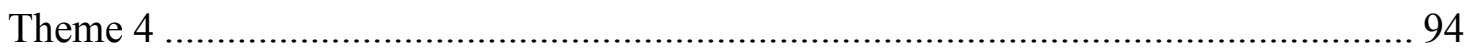

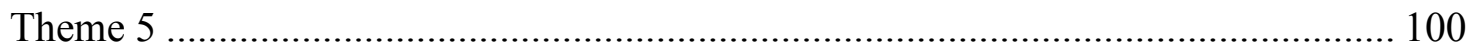

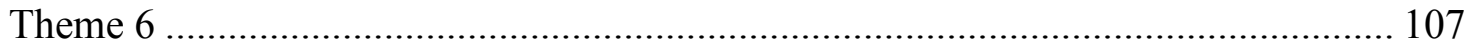




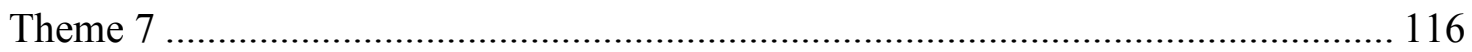

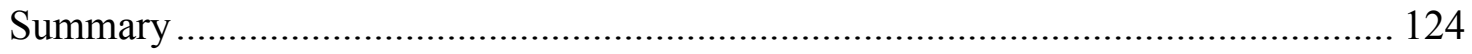

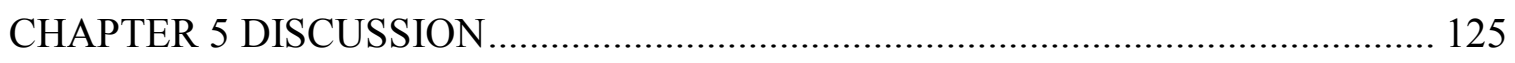

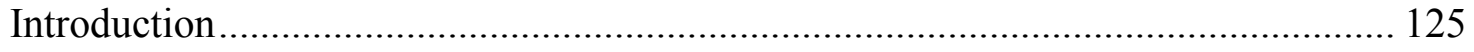

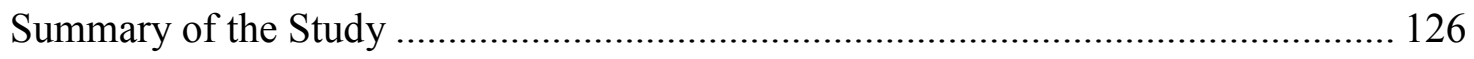

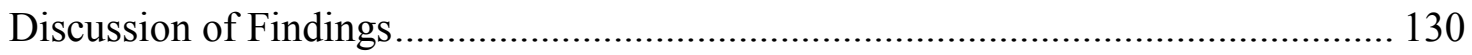

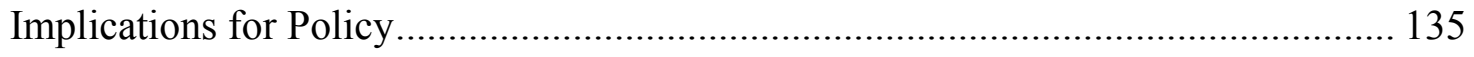

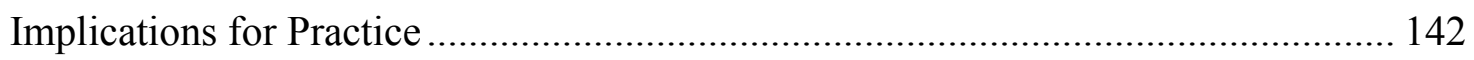

Recommendations for Future Research ........................................................... 147

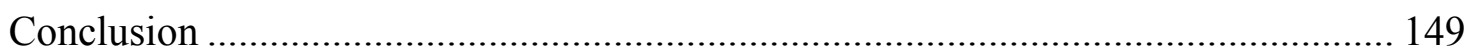

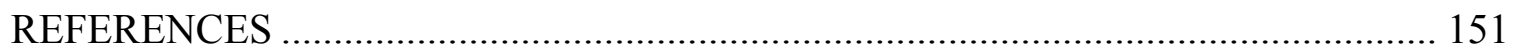

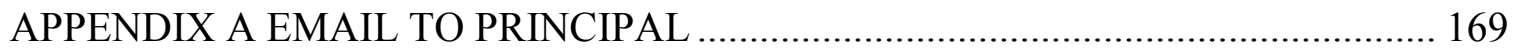

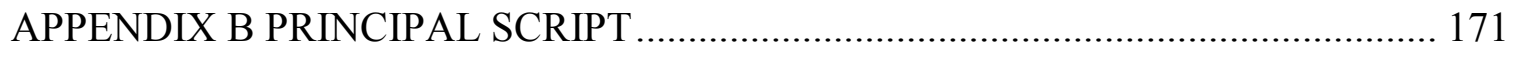

APPENDIX C STUDENT RECRUITMENT EMAIL................................................ 172

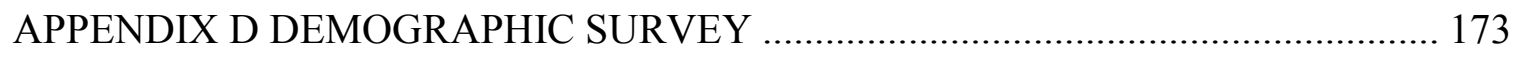

APPENDIX E PARENTAL/GUARDIAN CONSENT FORM ……………………...... 175

APPENDIX F 18 YEARS OR OLDER CONSENT FORM......................................... 180

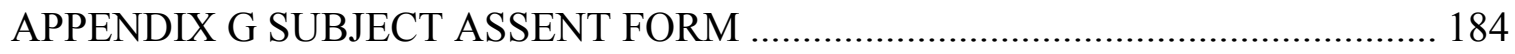

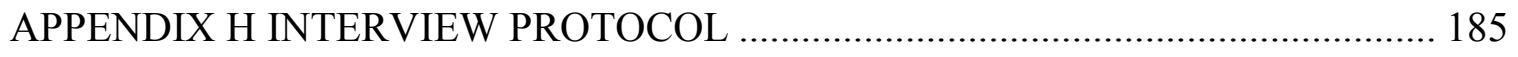

APPENDIX I PARTICIPANT PROFILE SHEET .................................................... 188

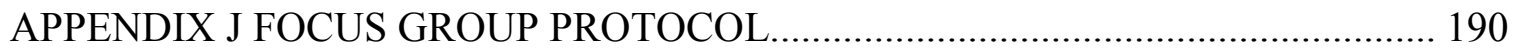

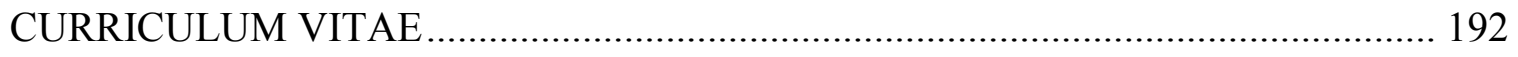




\section{CHAPTER 1}

\section{INTRODUCTION}

Since the inception of public schooling in the United States, African-American students have struggled to demonstrate academic success in the classroom. In multiple measures of achievement and performance outcomes, African-American students have consistently performed lower than their peers in academic outcomes such as test scores, graduation rates, dropout rates, college enrollment and career earnings (Kena et al., 2016). African-American students scored lower than their White peers in Grades 4, 8, and 12 on math and reading assessments for the last 25 years (Kena et al., 2016). Equally, the national average ACT and SAT score for graduating African-Americans has also been lower than the national average for their White peers (American College Testing, 2016; Scholastic Aptitude Test, 2016). Though improvements have been made in the graduation rate for African-American youth, disparities between African-American students and their White peers have stubbornly persisted (Kena et al., 2016). Adding insult to injury, not only do disparities exist between African-American students and White students in K12 settings, they also exist post-graduation as well. For the last 10 years, AfricanAmericans' college enrollment rates have remained nearly the same since 2004 (Kena et al., 2016). Salary and wage disparities exist as well. According to the National Center for Educational Statistics (2016), "Black young adults who worked full time, year-round also 
earn less than their White peers in a majority of occupations" (p. xxxi). Lastly, in addition to the achievement gap, it is important to note that African-American students are also substantially underrepresented in gifted education services (Grissom \& Redding, 2016), but overrepresented in special education services (Reynolds et al., 2009; Vasquez, 2005). After decades of trend data that follows well-established race and class patterns, efforts to close, or at least reduce, the achievement gap between White and African-American students remains a priority. To address this achievement gap, researchers have begun to examine the impact of culture on the cognitive performance of African-American students.

For decades, scholars have struggled to pinpoint the link between AfricanAmerican culture and cognitive performance. Some researchers (Ogbu, 1986; Ogbu \& Simons, 1998) have argued that school failure among African-American students was the result of their understandably negative attitudes toward U.S. educational institutions and their accompanying rejection of high achievement. Ogbu suggests there is a sub-culture among African-American students that rejects education in general and high academic achievement as a consequence of their "involuntary or castelike minority" heritage in schools $(1990$, p. 145). On the other hand, Fordham $(1988,1999)$ contends that school failure among African-American students is the result of critiques by their peers for “acting White” or selling out, (1999, p. 286). In other words, Fordham believes that school failure among African-American students occurs because they feel alienated as a result of complex interplay between school expectations and their own African-American culture. 
Other researchers have suggested another possible connection between AfricanAmerican students' culture and cognitive performance. Researchers (Boykin, 1986, 1995; Ladson-Billings, 2001; Marryshow, Hurley, Allen, Tyler, \& Boykin, 2005; Sankofa, Hurley, Allen \& Boykin, 2005) have shown that a cultural divergence between the instructional practices in public schools and the learning preferences of AfricanAmerican students may be the reason African-American students are underperforming. The cultural divergence between instructional practices and learning preferences of African-American students does not corroborate the age-old adage that African-American students reject education and high achievement for fear of "acting White" (Fordham, 1999, p. 286). Rather, the cultural divergence between instructional practices and learning preferences of African-American students shifts more attention to the response of educational leaders to disrupt racial disparities in classrooms by appropriately adjusting their teaching pedagogy to meet the needs of their African-American student clientele. If African-American students' underachievement is due to the cultural divergence between instructional practices and their learning preferences, then educational leaders may need to reassess the popular assumption that African-American students reject education and high achievement. Instead, educators should consider the potential of culturally responsive teaching as a solution to the achievement gap.

Culturally responsive teaching practices, specifically those rooted in AfricanAmerican cultural and learning norms, have proven to be an effective way to engage African-American students (Boykin \& Allen, 2003; Gay, 2000; Ladson-Billings, 1994; Muhammad, 2003; Murrell, 2002). Given the powerful potential of culturally responsive teaching, this study seeks to better equip educational leaders with the knowledge of how 
to serve African-American students while ultimately decreasing the racial achievement gap. Identifying culturally responsive teaching practices that contribute to the academic successfulness of African-American students in this study can help educational leaders replicate these elements across multiple settings.

\section{Purpose of the Study}

This study seeks to answer the following overarching research question: How do African-American high school seniors perceive culturally responsive teaching in their classrooms? There were three purposes for this study. First, the purpose of this study was to highlight culturally responsive teaching practices that African-American students perceived as contributing to their academic success. Second, the purpose of this study was to help identify if a cultural divergence exists between the instructional practices in U.S. public schools and the learning preferences previously established by AfricanAmerican students within their homes and communities and if it has any bearing on their academic achievement. Thirdly, the purpose of this study was to offer valuable insight on how to replicate African-American high school students' learning preferences to increase their academic achievement. By answering the research question, this study will also help to fill gaps in the literature as well as better equip educational leaders with knowledge of how to better serve African-American students while decreasing the achievement gap. This study's collection of African-American students' perceptions will add to the literature on culturally responsive teaching and Afrocultural learning orientations, such as the works of Boykin (1986, 1995, \& 2001), Hurley (1999), Ladson-Billings (2009), Marryshow et al. (2005), and Sankofa et al. (2005). Research focused on capturing the voices of African-American students is limited (Howard, 2001, 2002; Irving \& Hudley, 
2008; Ladson-Billings, 1994; Serpell, Boykin, Madhere, \& Nasim, 2006). Ultimately, this study will provide knowledge on how African-American high school seniors' perceive educators' efforts to be culturally responsive in their classrooms and its impact on their academic achievement.

\section{Analytical Strategy}

In order to understand African-American students' perception of culturally responsive teaching, this study will use a qualitative research approach, specifically a phenomenological research design. Creswell (2014) notes that, "Phenomenological research is a design of inquiry coming from philosophy and psychology in which the researcher describes the lived experiences of individuals about a phenomenon as described by participants. This description culminates in the essence of the experiences for several individuals who have all experienced the phenomenon" (p. 14). A phenomenological research design was selected because of its ability to capture the meaning of the experience (culturally responsive teaching) to the informants (AfricanAmerican high school seniors) (Creswell, 2014). This phenomenological research design will explore and describe if African-American students' attitudes and perceptions towards teaching styles are more consistent with either a mainstream cultural orientation (individualistic and competitive) or with an Afro-cultural orientation (communalism, verve, and music).

\section{Definition of Terms}

The following terms will be used in this study:

Achievement Gap: When one group of students (such as, students grouped by race/ethnicity, gender) outperforms another group of students. 
African-American: A Black American with African ancestry. Black or African American may be used interchangeably with this term.

Afro-Cultural Learning Orientation: The nine dimensions derived from West African beliefs, values and traditions are spirituality, harmony, movement (music), affect, verve, communalism, expressive individualism, social time perspective, and orality (Boykin, 1983). Afrocultural learning orientation, Afrocultural learning norms, Black cultural ethos, or Black culture may be used interchangeably with this term.

Communalism: "A fundamental focus on sharing and interdependence" (Boykin, Coleman, Lilja, Tyler, 2004, p. 1).

Culture: "The system of shared beliefs, values, customs, behaviors, and artifacts that the members of society use to cope with their world and with one another, and that is transmitted from generation to generation through learning" (Littlebear, 2009, p. 90). Culturally Responsive Practices: The implementation of policies, rules and consequences that embraces the sociocultural realities and histories of students and that reflects the communities where students develop and grow. Very similar to culturally responsive teaching however encompasses a wider scope of the educational/schooling experience other than teaching.

Culturally Responsive Teaching: "a pedagogy that embraces the sociocultural realities and histories of students through the presentation of what and how material is taught creating a classroom culture that reflect the communities where students develop and grow" (Kozleski, 2011, p. 1). Culturally responsive pedagogy may be used interchangeably with this term. 
Deficit Thinking: The belief that those who are culturally different are culturally deprived or disadvantaged (Ford, Harris, Tyson, \& Frazier Trotman, 2001)

Equity Mindset: The belief that the intelligence, ability, and capacity of people from different backgrounds are equally valuable and can produce equally beneficial outcomes (Dweck, 2010; Ramaley, 2014).

Verve: "having energy, being intense, and having expressive body language, which also implies a propensity to remain stimulating and lively" and "a tendency to attend to several concerns at once and to shift focus among them rather than to focus on a single concern or series of concerns in a rigidly sequential fashion.” (Carter, Hawkins, \& Natesan, 2008, p. 31)

\section{Organization of the Study}

Chapter 1 is organized as follows: the introduction, background of the study, purpose of the study, analytical strategy, definition of terms, and the organization of the study. The remainder of this study is organized into four chapters and a reference section. Chapter 2 presents a critical synthesis of literature on the plight of African-Americans in the US educational system and discusses efforts to address academic achievement gaps for African-American students. The literature review will also discusses culturally responsive teaching pedagogy, the conceptual framework and examine relevant research on Afrocultural learning norms. Chapter 3 describes the research design and an explanation of the research methods used, data collection, and procedures of this study. An analysis of the data and a discussion of findings are presented in Chapter 4. Finally, Chapter 5 discusses major findings in the study as well as includes recommendations for future research and implications for policy. 


\section{Summary}

Chapter 1 sets the course for this phenomenological research study. This research study is situated in a larger discourse about the relationship between the cultural aspects of students' learning styles and its impact on cognitive performance. Purposely, not only does this study examine how high school African-American seniors perceive culturally responsive teaching in their classroom. But it also speaks to how high school AfricanAmerican seniors perceive the connection between their Afrocultural learning orientation and their academic achievement. In the next chapter, a review of literature will examine how U.S. public schools have historically denied and discriminated against the education of African-American students. The literature review will also provide further details how current educational practices and policies, as well as education practitioners, have inadvertently, and intentionally, failed to address the academic achievement for AfricanAmerican students in public schools. 


\section{CHAPTER 2}

\section{LITERATURE REVIEW}

The overarching research question guiding this research inquiry is: How do African-American high school seniors perceive culturally responsive teaching in their classrooms? This literature review will give a brief overview on the plight of AfricanAmericans in the US educational system, provide evidence of an achievement gap, and discuss federal and state efforts to address academic achievement gaps for AfricanAmerican students. The review of literature also synthesizes previous research on how culturally responsive pedagogy and educators' disposition can either exacerbate or mitigate student achievement gaps for African-American students. The literature review will conclude by discussing the conceptual framework for the study and by examining relevant research on Afrocultural learning orientations. Relevant research on Afrocultural learning orientations will focus on the following three dimensions: (1) communalism, (2) verve, and (3) music. Ultimately, this literature review will frame a qualitative research study that is designed to explore if African-American students' attitudes and perceptions towards teaching styles are more consistent with either a mainstream cultural orientation (individualistic and competitive) or with an Afro-cultural orientation (communalism, verve, and music).

\section{The Plight of African-Americans in the US Education System}

The word plight is an apt descriptor for understanding the historical, political, and current relationship between African-Americans and the US educational system. As early 
as the 1600 s at the beginning of the trans-Atlantic slave trade, enslaved Africans, and their descendants, who would later be identified as African-Americans, suffered abuse and cruelty from the hands of White men if even suspected of communicating or acquiring knowledge (Span, 2005). As written in South Carolina's Negro Act of 1740, and in other similarly adopted state laws of the time period, was a legal acknowledgement that, “...having of slaves taught to write, or suffering them to be employed in writing, may be attended with great inconveniences," and furthermore established a law with punishable consequences for doing so (Duhaime, 2013). For instance, the state of Georgia imposed fines, public whippings, and/or imprisonment of anyone caught teaching enslaved or free African-Americans literacy skills (SambolTosco, 2004). At the time, Southern slaveholders saw literacy among slaves as a threat to the financially lucrative slave trade system, which relied heavily on slave labor and slave dependency on their masters (Span, 2005).

Despite legalized educational exclusion and oppression, African-Americans continued pursuing education in the United States. Under legal constraints and fear of punishment, African-American slaves often found alternative pathways to teaching and learning. Negro spirituals and hymns became popular and inconspicuous ways to transfer knowledge, family history, and routes to freedom (Library of Congress, n.d.). Some Christian groups and abolitionists, fueled by moral and religious convictions, also assisted in the teaching African-American slaves to read and write (Span, 2005). Even some slaveholders had practical needs for literate African-American slaves, so they taught their slaves to read in order to perform specific plantation tasks and crafts. 
In the years following the Antebellum period up until the historic 1954 court case between Brown v. Board of Education, African Americans still continued their educational pursuits in the face of inequitable educational opportunities (Harris, Brown, Ford \& Richardson, 2004). Although laws eventually became a little less restrictive and public opinion on African-American personhood and education shifted, AfricanAmericans seeking to obtain basic literacy skills were still met with additional challenges from the opposition. For example, in Mississippi, Missouri, and Maryland public assemblage of African-Americans for educational purposes was barred and Whites assisting African-Americans was strongly discouraged (Span, 2005). The legalized forbidden gathering of African-Americans made attending school, church and even small group meetings a challenge; yet African-Americans still found creative ways to seek and transfer knowledge.

Nevertheless, African-Americans continued learning to read and write in secret under oppressive laws and blatant exclusion. With minimal resources, African-Americans continued learning in secrecy by building schools for themselves, studying signs, studying names on doors, sketching on barrels and barns, exchanging goods and services for instructional lessons, from slave mistresses, and by playing competitive games involving the alphabet and writing (Span, 2005). In addition to learning secretively, African-Americans also pursued education while on their run to freedom via the Underground Railroad and through the eventual establishment of segregated or dual school systems for White and African-American students (Span, 2005). Separate school facilities were created through the establishment of private schools funded by AfricanAmerican church communities and private home schools ran by White and free African- 
American abolitionists (Span, 2005). During this time period, African-Americans experienced a more progressive, yet still segregated, education.

During the Progressive era, the relationship between African-Americans and the US educational system became highly politicized as the fight for education equality led to monumental court cases and rulings. Roberts v. City of Boston (1850) sought to end racially segregated schools but rather established the doctrine of separate but equal education. The Plessy v. Ferguson (1896) court decision upheld racial segregation and expanded the separate but equal doctrine to include public facilities as well as schools. Later, a string of court cases in higher education highlighted that inadequate and separate facilities designated for African-Americans were unequal. Court cases in higher education such as Missouri ex. rel. Gaines v. Canada (1938), Sweatt v. Painter (1950), and McLaurin v. Oklahoma State Regents (1950) helped pave the way for the unanimous ruling in Brown v. the Board of Education (1954), which stated that racial segregation of children in public schools violated the Equal Protection Clause of the Fourteenth Amendment (Harris et al., 2004).

Although the civil rights victory achieved through Brown v. Board of Education (1954) increased educational opportunities for all children, residual effects and trends still plague the current relationship between the African-American community (students, parents, and educators) and the US educational system today (Harris et al., 2004). Given the previously discussed historical and political past of African-Americans' pursuit of education within the US, the current relationship can be characterized as unfortunate at best. In spite of significant gains in high school completion among African American youth, academic outcomes of African American students still lag behind their White 
counterparts in multiple measures (Kena et al., 2016). Further research in the areas of special education, gifted/talented education, and discipline has also shown that African American students experience school failure in other areas as well.

Within the special education setting, there is an overrepresentation of students of color (Arum \& LaFree, 2008; U.S. Department of Education, Office of Special Education and Rehabilitative Services, Office of Special Education Programs, 2016). AfricanAmerican students were the second highest (15 percent) of students served under the Individuals with Disabilities Education Act (IDEA) (Kena et al., 2016). Even within special education supports, African-American students receiving special education services still faired worst than their White counterparts, and all other racial groups too. According to National Center for Education Statistics, "Of the students ages 14-21 served under IDEA who exited school, the percentage who graduated with a regular high school diploma was highest among White students (72 percent) and lowest among Black students (55 percent)" (Kena et al., 2016, p. 99).

In contrast to special education, within the gifted and talented educational setting, African-American students are underrepresented relative to White students (Ford, Grantham, \& Whiting, 2008; Grissom \& Redding, 2016). Grissom and Redding (2016) uncovered evidence that shows "identification of gifted students depends, in part, on factors having little to do with student performance or ability" but rather on the basis of race and ethnicity (p. 14). In particular, Grissom and Redding (2016) found evidence that, "Black students in classrooms with non-Black teaches are systematically less likely to receive gifted services" (p. 14). In fact, Toldson and Lewis (2012) found that AfricanAmerican males are 2.5 times less likely to be enrolled in gifted and talented programs, 
even if their prior achievements reflect their ability to succeed, and three times more likely to be suspended or expelled from school than their White peers.

In student disciplinary research, African-American students are disproportionately subjected to harsher disciplinary actions (Annamma et al., 2016; Blake et al., 2011; Crenshaw et al., 2015, Epstein, Blake, \& Gonzalez, 2017, Morris \& Perry, 2016). As a consequence, African-American students miss valuable learning time, which contributes to their lower likelihood of graduating from high school in four years than their White peers and makes them more susceptible to dropping out of high school at a rate twice that of their White peers (Toldson \& Lewis, 2012). Not only are there racial disparities within disciplinary actions, but there are also gender disparities within disciplinary actions for African-American students. For example, school-aged African-American girls are punished far more harshly than their peers for the same behaviors when referred to the disciplinary office and African-American girls are also more likely to be disciplined for subjective infractions (Annamma et al., 2016; Blake et al., 2011; Crenshaw et al., 2015, Epstein, Blake, \& Gonzalez, 2017, Morris \& Perry, 2016).

Moreover, the African-American educator workforce is yet another lens through which African-Americans' plight in the US educational system can be examined. Historically, the teaching profession has always provided a significant means of upward mobility for African-Americans who completed bachelor degrees. The teaching profession provided stable income, secure job opportunities, prestige and status from peers within the African American community (Irvine, 1988). However, the implementation of the 1954 Brown v. Board of Education decision resulted in adverse employment decisions such that many in the African-American educator workforce were 
fired or transferred after desegregation. In fact, estimates of nearly 40,000 of 82,000 African-American teachers and administrators lost their jobs (Ethridge, 1979; Hawkins, 1994; Holmes, 1990). "The mass dismissal of thousands of Black teachers and principals was a result of consolidation of Black and White schools to meet school desegregation mandates" (Cook \& Dixson, 2013, p. 1239). Consequently, the African-American educator workforce was dramatically reduced despite the suggested benefits of desegregation.

Unfortunately, civil rights advocates' priority to desegregate schools did not include Black teachers, Black teachers' experiences, protection of Black teachers' jobs, "knowledge of Black children held by Black teachers," nor the "educational needs of Black children" other than equality (Cook \& Dixson, 2013, pp. 1239-1240). As a result, the reduction of the African-American educator workforce post-desegregation established a trend of low racial diversity within the teaching workforce that persists to this present day. According to summary findings from the US Department of Education's State of Racial Diversity in the Educator Workforce report, "Elementary and secondary school educators in the United States are relatively homogenous racially" (2016, p. 3). This White, racially homogenous workforce has hardly changed in more than 15 years according to data from a similar survey conducted by the Department of Education in 2000 that found 84 percent of public school teachers identified as White (U.S. Department of Education, 2016). Along the same lines, the pushing out of AfricanAmerican educators for the teaching workforce, coupled with the failure to re-recruit them into the profession, is yet another example in which African-Americans' have experienced plight within the US educational system. 
Even beyond public schools, African Americans and Latinos continue to suffer from a lack of access to good jobs, persistently high unemployment rates, low weekly earnings, and the lowest inflation-adjusted median household incomes when compared to the White population (Weller, Ajinkya \& Farrell, 2012). Furthermore, economic outcomes reveal that African-American young adults who worked full time, year round also earned less than their White peers in a majority of occupations (Kena et al., 2016). Inspired by education's transformative potential and undeterred by the overtly oppressive conditions of the past and unequal outcomes of the present, African Americans still continue their quest to acquire some level of education in spite of insurmountable odds. Hence, in the face of educational plight, efforts to address African-American student achievement gaps can become a leveraging tool needed to level the rigged historical, political, social, and economic playing field for African-American students.

\section{Evidence of an Achievement Gap}

No nation can enslave a race of people for hundreds of years, set them free bedraggled and penniless, pit them, without assistance in a hostile environment, against privileged victimizers, and then reasonably expect the gap between the heirs of the two groups to narrow. Lines, begun parallel and left alone, can never touch. (Randall Robinson, 2000, p. 74)

The effectiveness of the public education system in the United States has most often been based on student performance and outcomes in several key areas such as standardized assessments, dropout rates, overall educational attainment, and economic outcomes (Deming \& Figlio, 2016). Although comparing results has been challenging, and is impossible at times, expectations to do so have increased since the passing of the 
Brown v. Board of Education (1954) decision. Despite the challenges in comparing student performances and outcomes, one truth has remained over time-certain groups, specifically African-Americans, have repeatedly scored below their White peers in multiple measures. The unbalanced distribution of educational results and benefits of students, given equitable public schooling and instruction, is known as the achievement gap. The achievement gap between African-American students and their White peers is well documented. For example, current trend data reveals that at Grades 4, 8, and 12 the average 2015 reading scores for African-American were lower than their White peers and were not measurably different from the corresponding scores in 2013 (Kena et al., 2016). However, at grade 12, the average 2015 reading scores for African-Americans (266) was lower than the 1992 score (273) but was not measurably different from the 2013 score (Kena et al., 2016). Additionally, at Grades 4, 8, and 12 the average 2015 math scores for African-American were lower than their White peers and were not measurably different from the corresponding scores in 2013 (Kena et al., 2016).

Moving beyond reading and math to standardized national assessments, the national average composite ACT score for African-American students in 2016 was 17.3, lower than the national average of 20.9 and that of White students 22.1 (American College Testing, 2016). Even the ACT composite score five-year trend data for graduating African-American students is lower than the national average and the average for White students (American College Testing, 2016). In the years 2012-2016, the average five-year composite ACT score for African-American students' was 17.0, 16.9, 17.0, 17.1, and 17.0, respectively (American College Testing, 2016). The average fiveyear ACT composite score for the nation during the same years were 21.1, 20.9, 21.0, 
21.0, and 20.8, respectively, while the average five-year composite ACT score for White students was 22.4, 22.2, 22.3, 22.4, and 22.2 (American College Testing, 2016). Although most students take the ACT, for those who took the SAT, total mean scores for African-American students in reading, math, and writing are lower than the national average and that of White students (Scholastic Aptitude Test, 2016). Achievement gaps between African-American and White students can also be found within disproportionate dropout rates. For instance, during the period from 1990 to 2014, the status dropout rate was lower for White youth (9.0 to 5.2 percent) than for Black youth (13.2 to 7.4 percent) (Kena et al., 2016). "Although the dropout rate for White and African-American youth declined from 1990 to 2014, rates in 2014 did not differ measurably from the gap between the rates in 1990" (Kena et al., 2016, p. 191). Additionally, each year between 1990 and 2014 the measured dropout status rate for African-American youth was still higher than their White peers (Kena et al., 2016).

In other comparisons, such as overall educational attainment and economic outcomes, African-Americans have also repeatedly faired far worse than their White peers (Kena et al., 2016). The percentage of African-American students who met ACT college readiness benchmarks scores in all four categories was $6 \%$ compared to their White peers 34\% (American College Testing, 2016). In other words, African-American ACT test-takers are more likely to enter post-secondary institutions underprepared for college-level work. When students have not met ACT college readiness benchmarks, they might delay their college career, choose a less rigorous institution, and/or be required to start their college careers in remedial, non-college credit bearing classes, incurring additional costs and delays in matriculation (American College Testing, 2016; Welton \& 
Martinez, 2014). A college education is expensive and the costs are rising yearly (College Board, 2017). Therefore, it stands to reason that the longer students are enrolled, the more costs accrued. These economic outcomes add to additional disadvantages many AfricanAmerican young adults experience post-graduation. The 2016 Condition of Education further documents the complications of the achievement gap when it noted that, "Black young adults who worked full time, year round also earn less than their White peers in a majority of occupations" (p. xxxi). In essence, post-secondary educational attainment also leaves an achievement gap between African-Americans and their White counterparts in economic outcomes too.

The trends in the achievement gap between African-American and White students have persisted over the last 25 years in predictable and disturbing patterns (Kena et al., 2016). The nation's efforts to address the achievement gap between African-American and White students have a long and well-documented history. Despite efforts to narrow the achievement gap, data reveals that certain groups, specifically African-Americans, repeatedly lag behind their White peers in multiple measures. Given the clear historical and political context between African-Americans and the U.S. educational system, it is easy to connect the plight that has been endured, and that which still endures into today. Hence_-"Lines, begun parallel and left alone, can never touch" (Robinson, 2000, p. 74). In short, the educational trajectory of African-American students and their White peers never had the same starting line. Therefore, it is unreasonable to expect the outcomes of the oppressed to mirror that of their oppressors without addressing their origins. 


\section{Federal and State Policies to Address Achievement Gap}

As early as the 1960s, efforts to address the achievement gap between students of color and White students have been at the center of federal and state educational policies. According the U.S. Department of Education website, "The Elementary and Secondary Act (ESEA) was signed into law in 1965 by President Lyndon Baines Johnson, who believed that 'full educational opportunity' should be our nation's first goal" (US Department of Education, n. d.). With its rich history as a longstanding national education law and for its commitment to equal opportunity for all students, ESEA was contextually situated as a civil rights law. As part of President Johnson's "War on Poverty" campaign (also known as the Economic Opportunity Act), ESEA sought to address the different challenges that specific subgroups of students (i.e., Free/Reduced Lunch, students of color, and disabled) brought into American classrooms that consciously and unconsciously governed their assessment performance and academic outcomes. Through the passing of the ESEA legislation, efforts to address achievement gaps between African-American and White students resulted in the establishment and funding of Head Start and Title I programming. The creation and expansion of Head Start programming provided disadvantaged children access to a child development program in hopes that it would break the cycle of poverty in low-income communities. While through Title I funding the government sought to combat poverty to, "Provide financial assistance to local educational agencies (LEAs) and schools with high numbers or high percentages of children from low-income families" (US Department of Education, n. d.).

A year later, the Equality of Educational Opportunity Report of 1966, nicknamed the "Coleman Report" after its committee chairperson, was published. The Coleman 
Report brought national attention to the state of educational equality in public schools across the United States during the era post-Brown vs Board of Education (1954). The Coleman Report detailed the availability of equal opportunities in public schools for students and teachers of color, chronicled the degree of segregation, assessed education quality, and warned of future desegregation implications (Coleman et al., 1966). The most notable finding was that African-American (Negro) students and teachers are largely and unequally segregated from their White counterparts, and that the average minority student (pupil) achieves less and is more affected by the quality of his school than the average White student (pupil) (Coleman et al., 1966). Not only did the Coleman Report bring attention to educational inequality for students of color twelve-years postdesegregation, but it also set the precedence for collection of assessment data which spurred researchers to further investigate educational quality and achievement gaps for student subgroups.

Propelled by the publication of the Coleman Report, the National Center for Education Statistics (NCES) created its first national assessment in 1969 (National Center for Education Statistics, n. d.). Known as the "nation's report card," National Assessment of Educational Progress (NAEP) is an annual report mandated by the U.S. Congress to report the nation's assessment scores and to track changes in the achievement gap (National Center for Education Statistics, n. d., p. 1). The annual educational report spotlights progress in education, important topics, and trends in education (National Center for Education Statistics, n. d.). Every year since 1990, NAEP has produced an annual report to policymakers and the general public about the progress of education in 
the United States. NAEP has helped to provide a fuller picture of persistent achievement gaps between African-American and White students despite efforts to address the gaps.

The next federal attempt to address achievement gaps came on August 26, 1981 when the Secretary of Education, T.H. Bell, created the National Commission on Excellence in Education and directed a report on the quality of education in America (U. S. Department of Education, 1983). David Gardner (1983) and others would later publish what would become known as another seminal educational piece, A Nation At Risk: The Imperative For Educational Reform (1983). The report investigated the declining state of the educational system in America by comparing American students to other nations, identified specific problem areas, and offered multiple recommendations for improvement (U. S. Department of Education, 1983). The five major recommendations spoke to content, standards and expectations, time, teaching, leadership and fiscal support. Overall the report sought to advocate for an increase in standards, extend valuable learning time, and improve teacher preparedness (U. S. Department of Education, 1983).

During the 1990s, federal and state policies focused on two specific tasks, the 1994 reauthorization of the Elementary and Secondary Education Act (ESEA) to support state's standards-based reform efforts and the launching of mass data collection from schools and staff (Hurst, Tan, Meek \& Sellers, 2003). Other than these two efforts, relatively little was done to close African-American achievement gaps during the 1990s (Hurst et al., 2003). It was not until No Child Left Behind (NCLB) was signed into law in 2001 under President George W. Bush, did targeted efforts to address achievement gaps return to focus (US Department of Education, n. d.). NCLB sought to address the 
academic achievement gaps amongst traditionally underserved student subgroups and persistently low achieving schools through strict accountability measures (Deming \& Figlio, 2016). Heretofore, NCLB was the apex of federal involvement in public education, a power that is not given explicitly to the federal government and thus left to the people or the states. The pendulum has started to swing back with the recent reauthorization of ESEA (as ESSA). In sum, the bulk of responsibility is and has been with the states, but federal policies shaped state and local provision heavily through response to federal legislation. As a result, the effective implementation of NCLB became increasingly difficult because of lofty, unattainable long-term goals. For instance, NCLB's goal was to reach 100 percent proficiency rates in reading and math by 2014 (Deming \& Figlio, 2016). Although NCLB was well intentioned, because of prior oversight by states to decrease achievement gaps, NCLB became too restrictive and relied too heavily on assessment scores.

In 2012, President Obama began granting flexibility to states regarding specific NCLB requirements. As a replacement for high-stakes test scores, rigorous and comprehensive state-developed plans designed to close academic achievement gaps superseded (US Department of Education, n. d.). The dire need for a more long-term solution to the needed flexibility to NCLB led to efforts to revise the law. On December 10, 2015, the most recent reauthorization of ESEA, the Every Student Succeeds Act (ESSA), was signed into law, replacing No Child Left Behind (US Department of Education, n. d.).

With the election of a new and controversial U.S. president and his equally controversial appointment of Betsy Devos, as the new Secretary of Education, there are 
now outspoken advocates for charter schools. It remains to be seen how these shifts in party dominance will shape education policy moving forward, but we do have some clear signals. Devos has voiced support for more state decision-making power, a trend that had already begun with ESSA in 2015. The legislation contracted the federal role in education. A clear example of this is the educator evaluation mandates specified in the legislation. ESSA now permits states and districts to develop and implement evaluation systems without proscription from the U.S. Department of Education as to the specific characteristics or measures of effectiveness that states must use in their evaluation systems, but requires that states with evaluation systems make public the criteria used in the evaluations (US Department of Education, n. d.).

Secretary Devos also clearly signaled her intention to expand school choice options through charter schools, school voucher programs, and tax credit scholarships. Regardless of possible changes in education policy that may, or may not occur, policymakers and educational leaders need to continue efforts to address the AfricanAmerican achievement gap. Given the history of failed federal and state efforts to address persistent achievement gaps, attention needs to be shifted to a more equitable educational opportunity for African-American students.

\section{Culturally Responsive Pedagogy (CRP) and Educators' Disposition Alignment}

Currently, the United States of America is becoming browner (Kena et al., 2016). Nearly half of all public-school students are considered racially diverse (i.e., non-White) (U.S. Department of Education, 2016, p. 1). Yet, teacher demographics have remained fairly consistent with 82 percent of public elementary and secondary school educators identifying as White (U.S. Department of Education, 2016, p. 1). These demographic 
changes, and many others like them, have important implications for the institution of public schooling and cannot be ignored. Particularly, the demographic shift in the cultural backgrounds of students has led to increasingly diverse learning orientations, values, attitudes, beliefs, and behaviors displayed in public-school classrooms. As a result, the student demographic shift has led to cultural incongruences that can complicate the learning transactions between students and their teachers.

An underlying premise of this research study is that culturally responsive teaching is the solution to better serving African-American students' academic achievement while decreasing the racial achievement gap. A second premise is that all students, including African-African students, have cultural assets that can be leveraged through instructional practices to enhance their academic performance. Taken all together, culturally responsive teaching seems to be an ideal solution to academic underachievement. But, what is culturally responsive pedagogy? First, culture is, "The system of shared beliefs, values, customs, behaviors, and artifacts that the members of society use to cope with their world and with one another, and that is transmitted from generation to generation through learning" (Littlebear, 2009, p. 90). Secondly, to be responsive means to attend to, to respond, to notice, to be proactive when possible, and reactive without delay when necessary. As Kozleski (2011) states, educators' responsiveness is embraced "through the presentation of what and how material is taught" with thoughtful consideration to "the communities where students develop and grow" (p. 1). And lastly, pedagogy is the art of how to transmit knowledge, or teaching. As a whole, culturally responsive teaching requires teachers to transcend their own cultural biases and preferences to establish and 
develop patterns for learning and communicating that engage and sustain student participation and achievement (Kozleski, 2011).

Any simple Google or scholarly search of culturally responsiveness teaching will yield many different definitions and educational pedagogies. However, there can be no discussion of culturally responsive education without mentioning the two leading educational researchers in culturally responsiveness, Dr. Geneva Gay and Dr. Gloria Ladson-Billings. Dr. Gay's research focuses on culturally responsive teaching, while Dr. Ladson-Billings' research focuses on culturally relevant teaching (Gay, 2013). Early on, Gay argued less about instruction but advocated for the inclusion of, "accurate content about and comprehensive portrayals of ethnically and racially diverse groups and experiences in various subject matter curricula" (Gay, 2013, p. 49). However, over years of research, Gay's views have shifted to focus more on connecting "in-school learning to out of school living" by promoting "educational equity and excellence," creating "community among individuals from different cultural, social, and ethnic backgrounds," and by developing "students' agency, efficacy, and empowerment" (Gay, 2013, p. 49).

Whereas Ladson-Billings' view is built on three propositions, "Students must experience academic success, develop and/or maintain contact and competence with their primary cultural heritages, and learn how to critique, challenge, and transform inequities, injustices, oppressions, exploitations, power, and privilege" (Gay, 2013, p. 51). For the purposes of this study, the researcher will operate under both Gay and Ladson-Billings' views. Specifically, the researcher defines, and advocates, that culturally responsive teaching must connect in-school learning to out of school living and create community among diverse students by providing students with an opportunity to experience 
academic success, and develop and/or maintain contact and competence with their primary cultural heritage. Furthermore, educators should continuously address, critique, challenge, and transform inequities, injustices, oppressions, exploitations, power, and privilege within the structure and institution of school for all students. Therefore, for the focus of this study the term "culturally responsive teaching" will be used in an effort to emphasize the researcher's hybrid definition from Gay and Ladson-Billings to help disrupt the disparities currently happening within classrooms and in schools across the country due to a cultural misalignment between students and educators. It should also be noted for this study that "culturally responsive teaching" is all encompassing of and may be referred to by others or used interchangeably as "culturally responsive pedagogy," "culturally relevant," "culturally congruent instruction," or "culturally compatible instruction." Furthermore, cultural competence is a continuum of levels for cultural responsiveness (Mason, 1993).

While many educators believe culturally responsive pedagogy is essential to working with diverse student populations, many lack examples and tools to effectively implement culturally responsive pedagogy in their daily practice (Fiedler et al., 2008; Ford \& Kea, 2009, Phuntsog, 2001). However, culturally responsive educators must, "establish and develop patterns for learning and communicating" (Kozleski, 2011). This means that the teacher must submit to being a student in order to properly respond to unfamiliar culture. All things considered, a student-centered, and/or a student-focused, approach is at the heart of culturally responsive teaching. In a student-centered approach, an emphasis on, and recognition of, the importance of including all students' cultural references in all aspects of learning is key (Ladson-Billings, 1994). 
Teachers practicing a culturally responsive pedagogy meet student needs with understanding, respect, and support. Studies have shown that perceived social support from teachers' influence motivation and academic achievement in students (Reeve \& Jang, 2006; Wentzel, 1998). When students feel supported by their teachers, they are more likely to feel a sense of connection to school and are more likely to be academically successful (Taliaferro \& DeCuir-Gunby, 2008). In addition, teacher expectations impact student achievement (Kuklinski \& Weinstein, 2001). If teachers have high expectations, their students will be more motivated to succeed. Likewise, if teachers have low expectations, their students will be less motivated to succeed. In fact, teachers often have lower expectations of African-American students, particularly African-American boys (Garibaldi, 1992).

However, low teacher expectations only help to explain a portion of AfricanAmerican student achievement gaps. On the other hand, African-American students need positive teacher/student relationships. Educators aligned with culturally responsive pedagogy keenly focus on building relationships with others. Such relationships are essential to helping African-American students feel as though they belong (Taliaferro \& DeCuir-Gunby, 2008). Unfortunately, U.S. public schools and educators in the past, and present, have held a deficit mind-set approach about African-American students and the causes behind the persistent achievement gap. Deficit thinking, or a deficit mind-set, is the belief that those who are culturally different are culturally deprived or disadvantaged (Ford, Harris, Tyson, \& Frazier Trotman, 2001). Educators who possess a deficit thinking approach focus on "fixing" or "changing" students to acclimate them to public schooling norms, rather than acknowledging their strengths and addressing long-standing 
stereotypes and discriminatory attitudes of African-American students (Tucker \& Herman, 2002, p.767).

As Holme, Diem, and Welton (2014) stated, "Normative change, therefore involves changing "deep culture" of schools by challenging deficit views of nondominant cultures and non-dominant cultural capital views" (Holme, Diem, \& Welton, 2014, p. 39). Therefore, an equity mind change is also essential for culturally responsive educators. An equity mindset is the belief that the intelligence, ability, and capacity of people from different backgrounds are equally valuable and can produce equally beneficial outcomes (Dweck, 2010; Ramaley, 2014). Having an equity mind change will require culturally responsive teachers to adopt an "additive approach" to understanding the home culture of students, with an explicit value for the "non-dominant" forms of cultural capital that students possess (Holme et al., 2014). Simply stated, an equity mind change will involve confronting and altering individual needs, feelings, prejudices, skills and limitations to improve outcomes for traditionally marginalized populations. To address African-American student achievement gaps, schools and educators cannot afford to adopt a colorblind ideology that minimizes the cultural values of non-dominant cultures nor acknowledge differences through a deficit mind-set approach (Constantine, 2007; Tucker \& Herman, 2002). According to Constantine (2007), colorblindness "refers to the denial, distortion, or minimization of race and racism" (p.2). Instead, culturally responsive educators take uncomfortable risks to create an inclusive environment that helps facilitate equitable learning that serves all children well.

Teaching strategies and practices that are limited only to mainstream cultural norms in education, among other things, lead African-American students to question their 
place in American public schools. For African-American students, and other students of color, academic success is often too contingent upon the acceptance of mainstream values, which are at times incongruent with the culturally rooted value systems that African-American students learn at home and in their communities (Boykin \& Allen, 2003). Consequently, as African-American students continue to matriculate through American public schools, many find it necessary to suppress their own Afrocultural orientation practices and behaviors to accommodate mainstream schooling practices (Boykin, Miller, \& Tyler, 2005; Cole \& Boykin, 2008). Perhaps, African-American students' perpetual suppression of culture and identity within public schools at the cost of being "successful" contributes to the achievement gap. In short, educators' failure to embrace and reward a wider range of cultural values and behaviors in schools will continually result in failed efforts to address African-American student achievement gaps. In sum, culturally responsive disposition and pedagogy, when used correctly by educators, can positively impact efforts to address African-American student achievement.

\section{Philosophical Aspects of Cultural Difference Framework and Its Application}

To properly frame this study, and to describe efficacious culturally responsive teaching practices when working with African-American students, I ground this study in Nichols' $(1986,1995)$ philosophical aspects of cultural difference framework. Nichols' $(1986,1995)$ Philosophical Aspects of Cultural Difference framework is the idea and understanding that culture cannot be dismissed in the human setting (Jones \& Nichols, 2013). Philosophical aspects of cultural difference framework helps to shape discussion about how racial and ethnic groups grew and thrived throughout human history with 
respect to the development of value systems and understandings about geography and the environment, as well as the creation and transmission of knowledge for survival (Jones \& Nichols, 2013). Furthermore, Nichols (1986) contends that humans tend to hold a natural instinct to survive and thrive, which in turn promotes a sense of belonging and intergenerational continuity in social traditions, practices and beliefs within racial and ethnic groups.

The central pillar of philosophical aspects of cultural difference is that culture cannot be dismissed in the human setting. According to Gutierrez and Rogoff (2003), culture is a not a biological trait but rather a repertoire of practices that are developed, refined, and transformed through an individuals' prolonged participation in their cultural community. In other words, students entering American public-school classrooms are not tabula rasa or "blank slates" as philosopher John Locke suggested. But rather, students are vessels, full of rich and unique experiences that are valuable and cannot be easily discharged, suppressed or restrained. Every day, students enter public school classrooms with a developed, refined, and transformed repertoire of practices engrained in them from their home lives. And at the end of each and every school day, students return back to their first classroom, their cultural community and home. As a result, this reoccurring cycle of time between home and school further demonstrates that culture cannot be easily dismissed because a student's culture is reaffirmed daily in the home and in their community. Seven hours inside a classroom does not magically erase the seventeen hours spent outside of school. In sum, culture matters and it is deeply rooted. Culture is how one identifies their self (Jones \& Nichols, 2013). Culture is not like an article of clothing 
that can be taken off and put on, but rather it is etched or engraved and is difficult to remove.

Furthermore, Jones and Nichols' (2013) theory that culture cannot be dismissed is extremely useful because it sheds insight on the relationship between culture and identity. Although culture and identity are different, they are intimately interconnected. According to Jones and Nichols (2013), "Culture includes the unifying beliefs of any group of people of similar religion, values, attitudes, ritual practices, family structure, language or mode of social organization" (p. 33-34). More so, culture and identity are interconnected because one's culture is informed by their identity. A person's sense of belonging with, or membership within a specific race, ethnicity, sex, age, sexual orientation, physical ability, shared history, and common traditions or practices that span across several generations refers to one's identity. Hence, culture cannot be easily dismissed because it is fluid and is woven throughout all aspects of one's life. Culture is informed by identity and identity is the essence of personhood.

Additionally, the philosophical aspect of cultural difference framework further explains how racial and ethnic groups grew and thrived throughout human history. The framework employs three human-related categories-- axiology, epistemology, and logic to explore how racial and ethnic groups grew and thrived over time. Axiology is defined as the study of values, epistemology is defined as how one applies, demonstrates, and transmits knowledge, and logic is defined as procedures for argumentation and reasoning (Jones \& Nichols, 2013, pp. 35-36). The axiology, epistemology, and logic of each racial and ethnic group has been developed, refined and transformed with respect to each groups' value system, geographical origins, environment and transmission of knowledge 
over thousands of years (Jones \& Nichols, 2013). Consequently, educators must pay special attention and acknowledge that all students are not the same. Subscribing to the "colorblind" philosophy in which all students are the same is unintentionally equivalent to erasing one's individual personhood (Jones \& Nichols, 2013). As mentioned earlier, colorblindness "refers to the denial, distortion, or minimization of race and racism" (Constantine, 2007, p.2). Therefore, educators must assent to the philosophy that each student's personhood is rooted in their identity and culture, which is impacted, by their racial and ethnic groups' axiology, epistemology, and logic. Failure to understand philosophical aspects of cultural difference among students has serious classroom implications.

Another facet of Nichols' (1986) Philosophical Aspects of Cultural Difference framework contends that humans tend to hold a natural instinct to survive and thrive, which in turn promotes a sense of belonging and intergenerational continuity in social traditions, practices and beliefs within racial and ethnic groups. Along the same lines, a number of studies have suggested and support the notion that coordinated group of people (racial and ethnic groups) need to relate to others. For example, when an individual feel that his or her identity is linked to a setting, he or she is more engaged and learns more (Nasir, 2006; Wortham, 2006). Other studies have shown that students often associate with other students who belong to the same racial group (Kunjufu, 1988; Tatum, 1997). This need to associate is culturally supportive for them and helps with their sense of cultural and racial identity.

Philosophical Aspects of Cultural Differences Framework has received vast scholarly attention among Fortune 500 Corporations, foreign governments, national 
government agencies, associations, health and mental health systems (Jones \& Nichols, 2013). In a wide variety of settings, this framework has demonstrated the important connection between racial and ethnic groups and their historical development of value systems, creation and transmission of knowledge (Jones \& Nichols, 2013). This framework has also demonstrated how different groups - particularly traditionally underserved groups — have interacted, and many times conflicted, with European and Euro-American values and culture in the past and present. In the context of education, philosophical aspects of cultural difference suggest that a student's axiology, epistemology and logic are employed by culturally based ethnic differences. Also, this framework suggests that each of us has a philosophy of life that consists of a set of beliefs and values within our racial and ethnic group that consciously and unconsciously governs our actions (Jones \& Nichols, 2013). Each philosophy about life has beliefs and values that are rooted in how our racial and ethnic ancestors viewed the world.

Philosophical aspects of cultural difference framework supports the notion that each student comes to school with an array of cultural backgrounds, histories, and experiences, which have implications for how educators should develop curriculum and engage in teaching and instruction (Jones \& Nichols, 2013). The framework also supports the argument that African American students, like students identified in other racial and ethnic groups, bring a unique cultural asset (collaborative acts) into American classrooms daily that consciously and unconsciously governs their actions, learning and transmission of knowledge (Jones \& Nichols, 2013). However, like other conceptual frameworks, the Philosophical Aspect of Cultural Differences Framework does not intend to be an all- 
inclusive racial and ethnic group description. Rather it intends to demonstrate how differences based on group experience contributes to and reinforces group culture.

Implications for educators using this framework can be found in how educators implement instruction and structure classroom practices with respect to their students' culture. As stated earlier, 82 percent of public elementary and secondary school educators are White (U.S. Department of Education, 2016, p. 1), yet nearly half of all public-school students are considered racially diverse (i.e., non-White). Consequently, teacher involvement is especially critical for racially and ethnically diverse students with respect to their ancestors' ethnic worldview and/or their own current worldview. Taken all together, in classrooms and schools governed by dominant/mainstream (White) values, students of color may find it necessary to endorse conflicting values, while devaluing their own (Sankofa et al., 2005). Therefore, it is especially critical that the educators do not further marginalize students of color by only sanctioning and rewarding mainstream values nor become desensitized to the cultural values of others. Instead, educators need to acknowledge, affirm and incorporate the varied worldviews and values of the students in their classroom and practices.

\section{Relevant Research on Afrocultural Themes in Learning and Achievement}

Public school education in the United States was originally created to serve three specific purposes: (1) the political goal of educating future citizens to participate in a democratic republic, (2) the social goal of controlling the behaviors of the masses, and (3) the economic goal of socializing workers into industry (Milner \& Lomotey, 2013). In its original design, consumers (students) of public school education were primarily economically-privileged, White males who were also racially, ethnically, and religiously 
homogeneous (Labaree, 2012). Therefore, it can be reasonably assumed that public schools and educators operated solely on the mainstream cultural ideals, values and teaching pedagogies aligned with their clientele. As a consequence, American public schools have a longstanding history for setting up policies and rewards for behaviors that are consistent and compliant with mainstream precepts, while punishing those that are not (Boykin, 1995).

Nevertheless, recent research documents that the United States' is currently growing more racially and ethnically diverse in our population and in our public school systems (Kena et al., 2016). According to the National Center for Education Statistics (2016), nearly half of all public-school students are considered racially diverse (i.e., nonWhite). Population predictions anticipate that the diversification trend and growth in nonWhite student populations will only increase over time (Kena et al., 2016). Trend data further reveals that existing achievement gaps in public school assessment results, educational attainment, and economic outcomes have persisted for several decades in predictable patterns as well (Kena et al., 2016). Given the changes occurring in the racial and ethnic demographics of public schools and the persistent achievement gaps, careful examination and considerations should be given to the current pedagogy, culture, climate, and instruction in classrooms across the country.

Therefore, American public schools can no longer afford to continue utilizing pedagogy merely founded on mainstream cultural ideas and values when today's education consumers (students) have changed. In an effort to respond to our country's shifting demographics as well as close the achievement gap between students of color and their White peers, one potential solution is to examine the cultural ideas and values of 
other ethnic groups. In alignment with this study's purpose and targeted demographic of students, an examination of Afrocultural themes in learning and achievement will be the focus. Critically examining relevant research on Afrocultural orientation themes in learning and achievement has potential to improve performance, engagement, and motivation of African-American students in public school classrooms across America. Although there are nine Afro-cultural orientations, this research study will focus only on the use of communalism, verve, and music as Afro-cultural learning orientation themes to support the culturally responsive teaching of African-American students. The researcher has chosen to focus on communalism, verve and music as the three Afro-cultural orientations because their incorporation into instructional contexts results in observable changes. The researcher also believes practicing educators working with AfricanAmerican students are experientially most familiar with the manifestations of these three Afro-cultural values rather than the remaining six.

\section{Communalism}

African American students, like students identified in other racial and ethnic groups, bring unique cultural assets into American classrooms daily that consciously and unconsciously govern their actions, learning and transmission of knowledge. Jones and Nichols' (2013) philosophical aspect of cultural difference identifies collaborative acts as the normative behavior for African culture. Surprisingly, the psychological orientations and behavioral inclinations of today's African Americans were inherited from their African cultural heritage and have remained sufficiently insulated from the forces of enculturation (Hurley, Boykin \& Allen, 2005). Therefore, one cultural asset many African-American students generally experience in their homes and communities during 
their formative years is communalism. A communal orientation is marked by "a commitment to social interconnectedness which includes an awareness in which social bonds and responsibilities transcend individual privileges" (Boykin, 1986, p. 61). The four dimensions of communalism are social orientation, group duty, identity, and sharing (Hurley, 1999). Social orientation places premium value in the relationship with others, group duty places group needs before individual needs, and identity places group membership as the core to sense of belonging (Boykin, Lilja, \& Tyler, 2004; Hurley, 1999). Social orientation, group duty, and identity are also three dimensions of communalism that clearly align with the axiological views of Africans, AfricanAmericans, Latinos, and Arabs (Jones \& Nichols, 2013). According to Jones and Nichols' (2013) framework, Africans, African-Americans, Latinos, and Arabs share a common "member-member axiological focus" (p. 42). With a member-member axiological focus, members view themselves as a collaborative part in the phenomenal world, placing the "highest cultural value on the development and promotion of human relationships," resulting in a "high value placed on the notion of community" (Jones \& Nichols, 2013, p. 42). The fourth dimension, sharing, uses pooled resources from individuals to benefit the group rather than self (Boykin, Lilja, \& Tyler, 2004; Hurley, 1999). Altogether, the four dimensions of communalism foster authentic collaboration, familism, community, and community interconnectedness (Jones \& Nichols, 2013). In the context of education, communalism is the most consistently studied Afrocultural orientation theme on African-American students' academic performance (Serpell et al., 2006). On a wide range of academic tasks, African-American students perform better after learning under communal conditions than they do under 
individualistic conditions that permeate most American classrooms (Allen \& Boykin, 1991; Boykin \& Bailey, 2000; Boykin et al., 2004; Hurley, Boykin \& Allen, 2005; Hurley, Allen, \& Boykin, 2009; Jagers, 1987; Serpell et al., 2006). Like any other student sub-group, it should be cautioned that African-American students are not monolithic; not all African-American students exhibit communalism to the same extent. Yet decades of findings have still concluded that African-American students gain more under communal learning conditions than their White peers (Johnson \& Johnson, 1985; Lucker, Rosenfield, Sikes, \& Aronson, 1976; Slavin, 1983). African-American students who studied communally were also more likely than their White counterparts to report satisfaction with the group interaction, enjoyment of the task, sharing of ideas, and liking their group members (Garibaldi, 1979; Hurley, Boykin, \& Allen, 2005). Additionally, African-American students who participate in communal learning conditions tend to place a higher importance on group work than rewards (Albury, 1993).

Unfortunately, despite the beneficial evidence of communalism and other Afrocultural orientation themes in learning and achievement for African-American students, they are not frequently employed in American classrooms. Instead, typical American classrooms tend to be over saturated with individualism and competition, which are European and Euro-American norms (Spence, 1985; Staton-Salazar, 1997). Consequently, research has found that many African American students reject mainstream cultural ideas and values because they are, at times, incongruent with the culturally rooted value systems that African American students learn in their home lives and in their communities (Boykin \& Allen, 2003; Sankofa et al., 2005). Subsequently, 
African American students experience little confirmation, value or relevance of their own Afrocultural lives, identities, and values in their normative-based classrooms and schools.

Although the exclusion of Afrocultural orientation themes in learning and achievement may seem trivial, it is in fact crucial in terms of today's efforts to address African-American student achievement gaps. A widely held misconception by many is that African-American students reject academic achievement in education (Fordham, 1988, 1999; Ogbu, 1986; Ogbu \& Simons, 1998). Over the years, it has become common amongst educators to dismiss the underachievement of African-American students as personal shortcomings in effort rather than address the continued efforts of systematic and institutional oppression (Marryshow et. al, 2005). Seminal findings from researcher Ogbu (1986) argue that school failure among African-American students is the result of their understandably negative attitudes toward U. S. educational institutions and their accompanying rejection of achievement. At the time, Ogbu believed African-American students underachievement was rooted in the idea that African-American people were systematically denied full access to the mechanisms of socioeconomic mobility in the United States. As a result, African-American students came to reject publicly adopted routes to prosperity because they were unattainable and irrelevant to their lives. Later, researcher Fordham's $(1988,1999)$ findings revealed that African-American students criticized their African-American peers who expressed positive attitudes toward achievement for "acting White" or "selling out" (Marryshow et al., 2005, p. 604).

However, one important variable was omitted from consideration in both conclusions--the influence of culture. Much of the work done on academic achievement of African-American students focused on causes and cures of underachievement 
(Marryshow et al., 2005). It was not until later that Boykin $(1986,1995)$ found that the behaviors observed in the Ogbu $(1986)$ and Fordham $(1988,1999)$ work might not reflect a rejection of achievement per se but rather a rejection of the specific modes of academic success available in mainstream educational institutions. Specifically, Boykin reasoned that the "negative attitudes toward achievement observed among African-American students may be the result of Black students' resistance to the mainstream cultural demands of schooling rather than a show of disdain for academic achievement in general" (Marryshow et al., 2005, p.604). Marryshow (1992) supported the theory that African-American students only rejected achievement via mainstream cultural modes (individualism and competition). In Marryshow's (1992) study, achievement modes that mirrored Afrocultural orientation behaviors (communalism and verve) found in the home and community experiences of African-American students were rated significantly more socially desirable (Sankofa et al., 2005). Furthermore, African-American students predicted their parents and African-American peers would prefer the same AfricanAmerican culturally oriented achievement (Sankofa et al., 2005) yet expected their teachers to embrace mainstream achievement and reject Afrocultural themed achievement (Marryshow et al., 2005).

Conceivably, the rejection of education by African-American students should be justified considering how American classrooms lack confirmation of Afrocultural values. But rather than focusing our attention on how to better equip African-American students to successfully negotiate the rigors and challenges posed by the American educational system, perhaps educators should adopt more culturally responsive teaching practices that positively address African-American student achievement gaps. Rather than discuss 
achievement difficulties, educators should draw more attention to the connection between culture and cognition. Using the appropriate pedagogical accommodations such as communalism can leverage African-American students' achievement by using their prior background knowledge and abilities to build new ones. As previously stated, African American students, like other students, bring unique cultural assets into American classrooms daily that consciously and unconsciously govern their actions, learning and transmission of knowledge (Rogoff, 1993; Serpell et al., 2006). However, disconnect occurs when schools and educators fail to acknowledge any value in the home-life and cognitive development of African-American students outside of schools (Rogoff, 1993; Wertsch, 1991). Perhaps, once educators begin using existing competencies acquired through communalism from the home-life and communities of African-American students, will we see the academic fate of African-American students shift and change.

\section{Verve}

Prior to public school enrollment, all students are exposed to new content, learning, and life experiences through familial childrearing practices. For many AfricanAmerican children, vervistic home environments and practices are natural, daily occurrences; however, in most public schools, pedagogical practices remain primarily geared towards European American norms (Boykin \& Cunningham, 2001). Verve can best be described as a person's preferred level of intensity for having energy, expressive body language, facial expressions, voice inflictions, pitch and tone, and the propensity to remain stimulated and lively (Boykin, 1983; Carter, Hawkins, \& Natesan, 2008). Among African-Americans, verve may also take the form of multiple activities taking place concurrently in the same space, including overlapping conversations and music playing 
during other daily activities and a tendency to attend to several concerns at once rather than focusing solely on one (Carter, Hawkins, \& Natesan, 2008; Marryshow et al., 2005). Evidence of well-developed vervistic learning style taught at home for relatively young African-Americans can be found in Guttentag's (1972) observation of African-American preschool children (three- and four- year- olds) who displayed a more varied and active movement style than their European American counterparts. Given the gaps in academic performance across different racial groups on a range of measures, research reveals that the idea of vervistic stimulation could be well suited for improving the academic performance of African-American students because it uses existing competencies in the service of attaining new ones.

Like communalism, verve is another specific aspect of African-American culture that impacts the academic achievement of students (Boykin, 1983; Boykin \& Bailey, 2000; Carter, Hawkins, \& Natesan, 2008; Marryshow et al., 2005). Verve is also rooted in normative behavior for African cultural heritage. In 1983, researcher Boykin identified verve as one of the nine dimension of African-American culture that have roots in West Africa that encompasses the essence of African-American experiences and interactions (Neal, Davis McCray, Webb-Johnson, \& Bridgest, 2003). In efforts to capitalize on the cultural assets of African-American students, vervistic instructional techniques should be considered to enhance academic performance.

According to Boykin and Bailey (2000), African-American students reported higher levels of verve at home and preferred vervistic contexts. Because AfricanAmerican students have much higher levels of stimulation compared to mainstream American culture, educators have a unique opportunity to build on African-American 
students' cultural integrity to enhance educational outcomes (Boykin \& Toms, 1985; Carter, Hawkins, \& Natesan, 2008; Guttentag, 1972; Morgan, 1990; Muhammad, 2003). However, the patterning of vervistic stimulation in the formative experience of AfricanAmerican students cultivates a special receptiveness to heightened variability that is often at odds with values and norms in public school classrooms. Research has found that students who display higher levels of verve are often negatively labeled by teachers (Breinin, 1981; Neal, Davis McCray, \& Webb-Johnson, 2001), are frequently punished (Carter \& Larke, 2003; Hale-Benson, 1986; Muhammad, 2003) or are referred to special education services (Vasquez, 2005). Too often public-school classrooms are too structured with monotonous, repetitious tasks that demand student conformity. Whereas, classrooms with high levels of vervistic instruction might look like, "excessive talking, students asking other students for help, students regularly asking assistance from the teacher, or students trying to work on more than one assignment at a time" (Carter, Hawkins, \& Natesan, 2008, p.34). Vervistic classrooms might also be characterized as noisy working environments, students preferring group work rather than individual work, students preferring hands-on, interactive learning tasks, joking, teasing and playing while doing classwork (Carter, Hawkins, \& Natesan, 2008). Ironically, students displaying vervistic characteristics within a classroom setting are often in sharp contrast with acceptable student behavior.

In academic settings, studies have found vervistic learning environments to be beneficial in increasing performance outcomes for African-American students (Bailey \& Boykin, 2001; Boykin \& Bailey, 2000). Boykin and Bailey (2000) found that the overall academic performance of African-American students was significantly higher when the 
academic tasks were presented in higher vervistic contexts. Similarly, significantly higher academic performance in vocabulary, mathematics, and picture-sequencing, and substantially higher performance in spelling were found in high verve contexts too (Boykin \& Bailey, 2000). Also, Boykin and Bailey (2000) also found African-American students' highest problem-solving performance was obtained in high vervistic context with background music while their lowest performance was obtained in low vervistic contexts without background music. Bailey and Boykin (2001) found African-American students to have greater motivation in high vervistic conditions versus low vervistic conditions. All things considered, utilizing verve as a culturally responsive approach to instruction might prove to be a valuable tool in leveraging student performance and addressing African-American achievement gaps.

\section{Music}

Musical inclination is positioned within African-American culture as a rich tradition, inherited from West African ancestors, that permeates the daily life of many African-American students. Perhaps, that's why African-Americans involvement in music making over the years has influenced and created so many different musical genres. Nevertheless, in an effort to address African-American achievement gaps, building a bridge between musical inclinations at home and in the community to classroom instruction might positively influence academic achievement. To support this notion, researchers Allen and Boykin (1991) found that learning contexts that included music and the opportunity for movement significantly enhanced the learning of many African-American children (Carter, Hawkins, \& Natesan, 2008). Boykin and Mungai (1997) later added that music is an extension of the African-American culture, and 
African-Americans tend to place the interconnectedness of music and movement in high esteem. Thus, many African-American communities have a high affinity to music and movement and view both as important to their individual, and collective, well-being and ancestral history.

Considering music's positive influence on the academic performance of AfricanAmerican students, the inclusion of music into daily classroom instruction is a culturally responsive innovation that could be used to address the achievement gap. Research has shown optimal learning performance for African-American students when the Afrocultural themes of music and movement in learning and achievement have been used (Allen \& Boykin, 1991; Boykin \& Allen, 1988; Boykin \& Bailey, 2000; Cole \& Boykin, 2008). Educators capitalizing on African-American students' cultural assets of music and movement might use instructional techniques such as: (a) communication infused with rhythmic language; (b) encouraging gestures with many instances of repetition; (c) call and response; (d) figurative language or catchy phrases; (f) singing; (g) background music; (h) beat making; (i) clapping; and (j) the patting of feet or hands (Carter, Hawkins, \& Natesan, 2008). In efforts to experiment with the creation of effective learning conditions for African-American students, educators should look to regularly incorporate music and movement into daily classroom instruction.

After all, Cole and Boykin (2008) and Boykin and Bailey (2000) found that African-American students performed the highest on academic tasks in which conditions contained music and provided highly expressive movement. Contrarily, their White peers' performance was hindered in the presence of music and movement, and their performance was enhanced without it (Boykin \& Bailey, 2000; Cole \& Boykin, 2008). 
Despite added academic and emotional benefits for African-American students (Boykin \& Bailey, 2000; Cole \& Boykin, 2008), the traditional culture of many American public schools is primarily void of music and movement. It leads one to wonder if evidence suggests that African-American students experience increased engagement, positive affect, and higher performance when music and movement are incorporated into instruction, then why are educators not rushing to capitalize on these students' cultural assets to boost student performance? Although there is no one clear answer, one has to wonder if education's move towards a more prescriptive pedagogy that aligns with standardized testing is the reason.

\section{Summary}

In efforts to address African-American student achievement gaps this study aims to understand African-American students' perception of culturally responsive teaching. The qualitative research design of this study will explore if African-American students' perceptions towards teaching styles are more consistent with either a mainstream cultural orientation (individualistic and competitive) or with an Afro-cultural orientation (communalism, verve, and music). The overarching research question guiding this research inquiry is: How do African-American high school seniors perceive culturally responsive teaching in their classrooms? Through the review of literature, light could be shed on matters of cultural responsive practices and cultural misalignment in classrooms serving African-American students. The results from this study may uncover that culturally responsive pedagogy might be one important tool that enhances AfricanAmerican student achievement. 
In conclusion, this literature review has given a brief overview on the plight of African-Americans in the US educational system and discussed efforts to address academic achievement gaps for African-American students. The review of literature has also discussed the philosophical aspects of cultural difference conceptual framework for the study and examined relevant research on Afrocultural learning norms of communalism, verve, and music and how each has influenced African-American student achievement. To summarize the available research, it is clear culturally responsive pedagogy positively influences African-American student achievement. Yet it is still underutilized within many schools and classrooms across the United States. Taken together, home, school and community contexts are fundamental during the formative years for all students. It is important that educational leaders help facilitate culturally responsive environments in American public schools so that all students, even AfricanAmericans, can actualize their fullest potential. 


\section{CHAPTER 3}

\section{METHODS}

The purpose of this qualitative study is to understand African-American high school seniors' perceptions of culturally responsive teaching in their classrooms. To guide this study, the researcher sought to answer the following research question: How do African-American high school seniors perceive culturally responsive teaching in their classrooms? In this chapter, the researcher provided a rationale for the selection of a qualitative research design as well as discussed the phenomenological methods of the study. Chapter 3 also defined the context of the study, identified data sources, and outlined the data collection, ethical considerations, data analysis, and qualitative validity used to conduct this study. The chapter concludes with a summary.

\section{Research Design}

The philosophical worldview proposed in this study was social constructivism. Social constructivism is the belief that, "individuals seek understanding of the world in which they live and work. Individuals develop subjective meanings of their experiences - meanings directed toward certain objects or things" (Creswell, 2014, p. 8). A social constructivist worldview best supported and shaped this study because the participants had subjective meanings of their experiences as students in public school classrooms. In this particular study, each participant's meaning (or experience) had been formed through their interaction with others (teachers and other adults within public 
schools) and negotiated through social, historical, and cultural contexts because of their identity as an African-American in the United States. Therefore, this study relied on the African-American high school seniors' perceptions of instruction and practices in their classrooms to construct the meaning of culturally responsive teaching and how it impacted African-American students' learning. The social constructivist worldview was connected to the methods because participants constructed their meaning of culturally responsive teaching and interpreted it within the context of a classroom.

The research approach used for this study was qualitative. According to Creswell (2014), a qualitative research approach calls for, "exploring and understanding the meaning of individuals or groups ascribed to a social or human problem" (Creswell, 2014, p. 4). The qualitative research approach aligned to the purpose of this study because a deep and detailed understanding of participants' (African-American high school students') perceptions of culturally responsive teaching in American public schools was explored. The qualitative research approach involved emerging questions and procedures, collecting data in the participants' setting, analyzing data inductively to generate themes, and making interpretations of the meaning of the data (Creswell, 2014). The benefit of using a qualitative research approach was to raise awareness of the instructional preferences of African-American students. Qualitative data gathered in this study showed how to reverse the academic underachievement of African-American students using instructional practices that African-American students preferred and identified as useful and impactful to their learning.

Researcher Creswell (2014) explained that there are several types of qualitative inquiry approaches such as narrative research, phenomenological research, grounded 
theory, ethnography, and case studies. All of these qualitative inquiry approaches as Merriam and Tisdell (2015) stated are, "based on the belief that knowledge is constructed by people in an ongoing fashion as they engage and make meaning of an activity, experience, or phenomenon" (p. 23). However, for this qualitative study, a phenomenological inquiry approach was most appropriate. According to Creswell (2014), "Phenomenological research is a design of inquiry coming from philosophy and psychology in which the researcher describes the lived experiences of individuals about a phenomenon as described by participants" (p. 14). Phenomenological inquiry was most appropriate for this study because the researcher sought to capture African-American students' voices on their lived experiences with culturally responsive teaching (the phenomenon) and how the experience transformed into the consciousness of AfricanAmerican students. Furthermore, this study utilized a phenomenological inquiry for two key reasons--First, a phenomenological inquiry best helped the researcher understand the lived experiences of the study's participants. A phenomenological inquiry was superior to other commonly used qualitative inquiry approaches for this study because it described the lived experiences as described by the participants. With a phenomenological approach, the researcher gave voice to participants by allowing their description of the lived experience to frame the essence of the experience. A phenomenological approach gave rich descriptions of the first-hand accounts of their experience with the phenomenon, rather than the researcher's.

Secondly, prior research on culturally responsive teaching, cultural divergence on cognitive performance, and research on the learning preferences of African-American students suggests that a phenomenological inquiry approach should be explored in future 
research to fill gaps in how to best support African-American student learners. Dating back to the early works of culturally responsive teaching from Ladson-Billings (1994) and Howard (2001, 2002), scholars have advocated for a need of much more research on African-American students and the practices of successful teachers of African-American students. Literature and studies on culturally responsive teaching and African-American students is limited. This phenomenological study seeks to add to the body of knowledge on culturally responsive teaching of African-American students by collecting data from student interviews which will, "Culminate in the essence of the experiences for several individuals who have all experienced the phenomenon" (Creswell, 2014, p. 14).

Furthermore, studies of cultural divergence and culture and cognitive performance (Boykin, 1986; Boykin, Coleman, Lilja \& Tyler, 2004; Hurley, Allen \& Boykin, 1991; Marryshow et. al, 2005; Serpell \& Cole, 2008) have suggested that future research should further assess the credibility of the notion of incompatibility between the cultural identities of African-American students and public school classrooms. Finally, studies on the learning preferences of African-American students (Boykin, 1986; Boykin et al., 2004; Cole, 2000; Cole \& Boykin, 2008) also justified the utilization of a phenomenological inquiry to gather the nuances, specification and dynamics of AfricanAmerican students' learning preferences. In conclusion, a phenomenological inquiry was used to conduct semi-structured, individual interviews and a focus group as the primary sources of data collection.

Utilization of an open coding design in this phenomenological approach permitted participants' voices to guide and construct meaning to the phenomenon of culturally responsive teaching as experienced by African-American students. Creswell (2014) 
defines coding as, "The process of organizing the data by bracketing chunks (or text or image segments) and writing a word representing a category in the margins" (pp. 197198). Open coding, a general procedure in analyzing phenomenological data, is a highly inductive reasoning approach to data analysis that builds on the essence of participants' experiences. To get at the essence of the experiences, the researcher in this study used open coding from the phenomenological interviews with African-American high school students to construct their perception of culturally responsive teaching in the classroom in their own words. Next, during axial coding, African-American student voices captured during data collection were segmented into categories with labels developed from the language of the students. Then, during selective coding, data collected from this phenomenological study were interpreted to reveal further understanding into AfricanAmerican students' perception of culturally responsive teaching, highlight culturally responsive teaching exemplars, identify students' learning preferences, and uncover if a cultural divergence had any bearing on their academic achievement.

\section{Context of the Study}

This study was conducted in a large urban public-school district in the southeastern region of the United States. This district was chosen for two reasons. First, this district was the largest public school district in the state. The selected district is home to 48 different high schools. Of the 48 high schools, 21 are considered regular education high schools. Regular education high schools are part of the school choice system in which students can apply and attend a high school of their choice. The remaining 27 high schools are a combination of schools or residential facilities specializing in specific developmental, learning, behavioral, and/or medical needs. Conducting research in such a 
large district allowed the researcher to seek out unique perspectives, experiences, and diversity of thought. Secondly, with such a large group of schools within the selected school district, the researcher had an opportunity to target a specific population of subjects in order to make recommendations for impactful change. The pseudonym Hinds County School District will be used throughout this study.

For this study, the researcher was looking for a school within Hinds County School District that met the following criteria:

1. A high school with $9^{\text {th }}-12^{\text {th }}$ grade only.

2. A high school with a student racial demographic of at least $70-100 \%$ AfricanAmerican students.

3. A high school with a high percentage $(>25 \%)$ of African-American instructional staff members.

Given the selection criteria, this study was conducted in one high school within the Hinds County School District. The selected high school will be referred to using the pseudonym Jackson High School throughout this study. Jackson High School was chosen for two reasons. First, Jackson High School's large percentage of African-American students provided the researcher with multiple perspectives of individuals who represent the complexity of experiences within the African diaspora. As Patton (2002) emphasizes in qualitative research, the standard used in choosing participants and sites is whether they are information rich. The researcher believed that Jackson High School's larger number of African-American students provided individuals that differed on perception of culturally responsive teaching as well as differed in their display of Afrocultural learning norms. 
Secondly, with such a large group of schools within the selected school district, the researcher had access to two gatekeepers, an Assistant Principal and a Magnet Coordinator at the school, to access students at Jackson High School. Creswell (2015) defines a gatekeeper as, "An individual who has an official or unofficial role at the site, provides entrance to a site, helps researchers locate people, and assists in the identification of places to study" (p. 210). Having gatekeepers at Jackson High School was pivotal to recruiting study participants because the researcher was an unfamiliar outsider and might encounter difficulty in gaining trust with participants.

This study used a non-probabilistic, purposeful sampling strategy. According to Merriam and Tisdell (2015), "Purposeful sampling is based on the assumption that the investigator wants to discover, understand, and gain insight and therefore must select a sample from which the most can be learned" (p. 96). Purposeful sampling is a popular qualitative sampling method that can be used to gain insight on African-American students' perception of culturally responsive teaching strategies that boost their engagement, understanding and academic success. Specifically, the researcher used maximal variation sampling to recruit 8-10 African-American high school students who were enrolled in the twelfth grade. As Creswell (2015) notes, maximum variation sampling requires "that you identify the characteristic and then find sites or individuals that display different dimensions of that characteristic" (p. 206).

There were limitations to this research study. In this study, the researcher had limited access to high schools with a predominantly African-American student body and a high percentage of African-American instructional staff. In fact, Jackson High School has consistently enrolled the highest percentage of African-American students compared 
to any other high school in Hinds County Public Schools District for the last three years. Jackson High School also has selective admissions, in which students apply and are accepted and/or rejected for academic admission. Therefore, it is important to note that data gathered at Jackson High School in this study may not accurately reflect the findings of all African American high school students enrolled in Hinds County School District. It is also important to note that this study is not generalizable.

\section{Data Collection Process}

\section{Data Sources}

There were four different ways data was collected in this study. Data was collected with the demographic survey (Appendix D), one-on-one semi-structured interviews (Appendix H), participant profile sheet (Appendix I), and the focus group (Appendix J). However, this qualitative study used two primary data sources: a) semistructured individual interviews, and b) two focus groups. The researcher triangulated the data from these two data sources. One-on-one interviews were the first data source in this qualitative study. The researcher utilized an in depth semi-structured interview protocol with 8-10 African-American high school seniors at the selected school site. A semistructured interview process gave participants more flexibility in responses as well as provided the researcher with space for clarifying questions that arose from the responses of the interviewee (Merriam \& Tisdell, 2005).

The semi-structured interview protocol included ten open-ended questions. The interview questions asked participants to describe the teachers who helped them to learn the most and to share their opinions about how these teachers helped them learn. In this study, students were asked to concentrate on expressing what they believe about the 
teacher's instructional strategies and practices that helped them learn best. Interviews were conducted face-to-face. In the event a participant is absent, or did not show up during scheduled participation time, the researcher attempted to invite the participant to another time or date to participate. The actual interview with each participant took approximately 20-45 minutes at the selected school site. Interviews were digitally recorded and transcribed verbatim then the data was be analyzed and coded into themes.

In order to draw thematic conclusions about student perceptions of culturally responsive teaching of African-American students in classrooms and the conditions needed to create those spaces, the researcher conducted two focus groups. Focus groups as defined by Krueger and Casey (2009) are, a "carefully planned series of discussions designed to obtain perceptions on a defined area of interest in a permissive, nonthreatening environment" (p. 5). For this study, the researcher conducted two focus groups with the same participants interviewed during the one-on-one semi structured interviews. Using a focus group with the same participants was the most appropriate data source to gathering data generated from interactive discussion of participants. As Hennink (2014) explains, "During the group discussion participants share their views, hear the views of others, and perhaps refine their own views in light of what they have heard" (Hennink, 2014, p. 2). Given the power of peer influence for high school students, the researcher gained further insight and collected data that was different than the data accessed through individual interviews. Peer influence during the focus group discussion encouraged individuals to share aloud things they feared sharing individually. Peer influence also helped student participants recall events that participants may not have remembered during their individual interviews. The focus group data collection method 
gave the researcher an opportunity to confirm the accuracy of identified themes as well as clarify the participants' standpoints. The focus group gave the participants an opportunity to interact with one another as well as discuss their everyday interactions with the instructional strategies and practices of classroom teachers. The focus group also helped participants further articulate their personal and shared experiences. The focus groups were approximately 30-50 minutes at the selected school site. Participants were given a choice of 2 different time slots to participate in a focus group. The focus groups were digitally audio- and visually-recorded and transcribed verbatim then the data was analyzed and coded into themes.

\section{Recruitment}

Prior to IRB approval, the researcher began preliminary work by speaking with the principal and assistant principal to understand the school schedule, building accessibility, and other nuances unique to the school. Prior to conducting the research, the researcher submitted an application to the University of Louisville Institutional Review Board (IRB) for approval. After obtaining a letter of approval, the researcher submitted an application to Hinds County Schools' District Institutional Review Board (IRB) for approval. After obtaining proper IRB approvals, the researcher contacted the principal at Jackson High School via email (Appendix A- Email to Principal) to request permission to conduct research at the school, under his supervision. Next, the researcher received permission via email from the principal at Jackson High School to conduct the research within the school building, under his supervision. At Jackson High School, seniors are enrolled in a specialized class for their last period of the school day. The last class period of the day with the specialized teachers was deemed as the least disruptive by the 
principal. The principal of Jackson High School was given a Principal Script (Appendix B) to share with the 10 specialized teachers within Jackson High School to recruit students for the study. After five student school calendar days, the principal reminded instructors using the same script.

Next, the Student Recruitment Email (Appendix C) was sent to the identified assistant principal. The assistant principal ensured the email was shared with seniors only at Jackson High School using One Call Now message system. One Call Now is a broadcasting message system that students, parents, guardians and employees are automatically enrolled in. One Call Now messaging is mass-messaging that is traditionally used to communicate important and/or pertinent information. Via their district assigned email addresses, seniors at Jackson High School received a link to the short demographic survey (Appendix D) that was used to recruit study participants. The short demographic survey was voluntary and contained 7 questions. The short demographic survey was used to gather student background attributes (e.g., age, gender identity, race/ethnicity, and learning preference). The last question of the demographic survey asked students to self-select if they would like to be contacted to participate in an individual, one-on-one interview and a small focus group with a researcher.

After collecting all of the demographic surveys (Appendix D), the researcher reviewed all the surveys and identified students who met the following criteria: a) enrolled in twelfth grade, b) identify as Black or African-American, c) have not lived outside of the United States, and d) self-select to willingly participate in an individual, one-on-one interview and a small focus group with a researcher. The researcher wanted 8-10 students who met the outlined criteria. However, there were more than 10 
participants to choose from, therefore, researcher deferred to a predetermined ranking system to achieve maximal variation. First, the researcher selected 8-10 participants by choosing 2 participants from each learning orientation (Appendix D- Demographic Survey, question 5). Secondly, the researcher selected 8-10 participants by choosing 1 participant from each academic program (Appendix D- Demographic Survey, question 4). Lastly, the researcher selected 8-10 participants by choosing participants representative fifty percent male and fifty percent female (Appendix I- Participant Profile Sheet, question 1). Upon identifying 8-10 students, Consent Forms (Appendix E) were sent to each student's parent/guardian(s). In the event students were 18 years old, students were permitted to sign their own consent form (Appendix F). Once consent forms were returned with the proper signatures from the designated participants, the researcher then proceeded with the research study.

Once the consent forms were returned with the proper signatures, the researcher worked with the assistant principal and the magnet coordinator to schedule interview time slots. To accommodate student schedules, the researcher conducted all interviews on the campus of Jackson High School in a closed meeting space provided by the magnet coordinator. The researcher and magnet coordinator aimed to identify the least disruptive time to conduct interviews. The magnet coordinator confirmed with each identified student which date and time worked the best. On the day of the interview, the researcher reviewed the consent form with the participant and provided the participant with an opportunity to ask any questions they may have had about the research study prior to the interview. Each participant received a copy of the consent form for his or her own personal files as well as one for their parents/guardians. All participants under the age of 
18 years old were also provided with an assent form (Appendix G) to confirm their willing participation in the research. Additionally, the researcher detailed the interview process as well as provided a copy of the semi-structured interview protocol (Appendix G) for a personal reference to the participant as the researcher read each question aloud. The copy of the semi-structured interview protocol was collected from the participant at the conclusion of the interview. After the one-on-one semi-structured interview, participants were given a participant profile sheet (Appendix I). The participant profile sheet was used to gather more specific student background attributes (self-identity, physical disability, learning disability, and Free/Reduced lunch eligibility) and academic background attributes (e.g., college aspirations, academic program, and their perception of their academic performance and achievement).

For the focus groups, the researcher used the results from the participant profile sheet (Appendix I) to split participants into 2 focus groups with 4-5 participants in each to achieve maximal variation. Participants were given a choice of 2 different time slots to participate in the focus group interview. In the event, more than 5 participants scheduled the same time slot, the researcher deferred to a predetermined ranking system to achieve maximal variation. The researcher deferred to selecting 4-5 participants for each focus group by choosing participants based upon their neighborhood composition (Appendix I, question 5). Demographic information and attributes gathered from the demographic survey and the participant profile sheet were used later during data analysis to describe participants' shared lived experiences and perspectives. On the day of each focus group, the researcher re-reviewed the consent and assent forms with the participants and provided the participants with an opportunity to ask any questions they may have had 
about the research study prior to the focus group. The researcher also informed participants that their privacy was protected by the use of an assigned pseudonym. The researcher conducted each focus group using the focus group protocol (Appendix J).

\section{Data Collection}

The researcher audio-recorded all semi-structured interviews and the focus groups using a digital voice-recording cell phone application. The focus group was also videorecorded. To strengthen the data analysis and qualitative validity (which will be discussed later), the researcher used the interview protocol (Appendix G) and a field notebook to take notes in addition to audio-recording interviews in the event that the recording equipment fails (Creswell, 2014). Recordings were transcribed using a transcription service, edited and then verified by the researcher and the participant. After receiving the transcriptions, the researcher compared the voice recordings of individual interviews and the focus group to the transcription documents in order to ensure accuracy (Merriam \& Tisdell, 2005).

Before conducting the focus group, the researcher analyzed the individual interviews to note common themes. Commonalities, or themes, were included in focus group questions to confirm the accuracy of identified themes as well as clarify the participants' perspectives and perceptions. The research process used to create the focus group questions was emergent. According to Creswell (2014) an emergent design means, "that the initial plan for research cannot be tightly prescribed, and some or all phases of the process may change or shift after the researcher enters the field and begins to collect data" (p. 186). The focus group protocol (Appendix J) is a sample of questions that will be posed to both focus groups. However, the researcher refined questions based on 
emergent themes gathered during individual interviews. Specifically, scenario \#1 (Appendix J) will be created based on participants' responses from one-on-one semistructured interviews.

Before the focus group begins, the researcher reviewed the assent and confidentiality form. In order to maintain anonymity, pseudonyms were used for the district, the school, the teachers, and other students. For security purposes, the researcher stored all collected data on a password-protected personal laptop hard drive. The researcher transferred and stored all collected data to a personal password-protected external hard drive six months after the conclusion of the study.

\section{Ethical Considerations}

The researcher maintained the integrity prescribed in the ethical standards for conducting research. However, one possible ethical issue that could surface is the potential for this study to impact the relationships between the participants and their teachers. To avoid the potentiality of this ethical issue, the researcher is willing, and open, to sharing the study results with participants, Jackson High School employees, Hinds County School District and any other parties who may be interested after the completion of the study. The study results will not be shared with Jackson High School faculty and staff until all participants have either graduated from Jackson High School with their diploma, transferred to another school, or are un-enrolled from Jackson High School and received their posted final grades. Since all participants will be high school seniors, the impact of the results on the relationship between participants and their teachers will be reduced or eliminated because they will no longer be under teacher supervisor in which they discussed for the study. Other than possible impact to 
relationships between participants and their teachers, there are no foreseeable risks other than possible discomfort in answering personal questions.

\section{Data Analysis}

Creswell (2014) defined a six-step process for analyzing and interpreting data. For this study, the researcher utilized this procedure to analyze and interpret data obtained from the semi-structured individual interviews and from the focus group to better understand the lived experience of African-American high school students and their perceptions of culturally responsive teaching in their classrooms. Although the researcher outlined step-by-step procedures for data analysis, the researcher acknowledged and intended to analyze data using an iterative approach. As Creswell (2015) explains, "The phases are also iterative, meaning that you cycle back and forth between data collection and analysis" (p. 237). Therefore, the researcher collected data and analyze data from the individual interviews and then return to collect more data at the focus group.

The first step in analyzing and interpreting data occurred at the end of each interview. At the conclusion of each interview, the researcher organized and prepared the data for analysis by sending a digital audio recording to a transcription service to be transcribed. Second, the researcher read through each transcription and listened to the audio recording to verify accuracy. The researcher also had each of the subjects review and approve the accuracy of the transcription. Third, the researcher re-read the transcriptions and started coding data. Coding was defined by Creswell (2014) is, "the process of organizing data by bracketing chunks and writing a word representing a category in the margins" (p. 198). Although hand coding was laborious, the researcher hand coded data to better "winnow" the data (Guest, MacQueen, \& Namey, 2012). 
Winnowing data is a way to "aggregate data into a smaller number of themes" (Creswell, 2013). The researcher used the "language of the participants (called an in vivo term)" to create codes (Creswell, 2014, p. 198). The coding procedure used an inductive reasoning approach until interpretations were later formulated or confirmed with participants in the focus group. Emergent codes and themes discovered during the one-on-one interviews were used to create the focus group protocol to add to understanding the essence of the culturally responsive teaching phenomenon as experienced and perceived by AfricanAmerican high school students.

Although qualitative research outputs are less certain, the researcher formatted the discussion of findings by using a phenomenological conceptualization. According to Creswell (2014), "Phenomenological research uses the analysis of significant statements, the generation of meaning, units, and the development of what Moustakas (1994) called an essence description" (p. 196). The essence description involved, "generating categories of information (open coding), selecting one of the categories and positioning it within a theoretical model (axial coding), and then explicating the story from the interconnection of these categories (selective coding)" (Creswell, 2014, p. 196). The researcher used the participants' responses from the individual semi-structured interviews to make meaning of perceived culturally responsive teaching strategies and practices in classrooms. The researcher used the categories developed during coding to capture rich descriptions from the unique experiences of African-American students using their voices to understand teacher dispositions, learning preferences, and culturally responsive teaching practices that enhance academic success. 
After coding, the fourth step for analyzing and interpreting data involved generating themes and descriptions for analysis (Creswell, 2014). During this process, codes were organized into categories, or themes, to build rich descriptions from the unique experiences of African-American students using their voices to understand teacher dispositions, learning preferences, and culturally responsive teaching practices that enhance academic success. Next, the researcher advanced the themes and descriptions by carefully representing data conveyed in the findings of the analysis. Created categories and descriptions will appear as major findings in Chapter 4. Finally, the researcher made interpretations of the findings and results by confirming or refuting past information as well as provided new questions for further research and exploration.

\section{Researcher Positionality}

Among my many identities, the researcher brings attention to her identities as an African-American, who prefers Afrocultural learning norms, and one who only attended and taught in public school institutions. First, the researcher's identity as an AfricanAmerican brings a multi-layered racialized, historical experience between AfricanAmericans and our access to education in the United States. Secondly, the researcher's identity as learner who prefers Afrocultural learning norms conflicts and complicates transactions between my epistemological foundations and the mainstream foundations in which public schools were built. For instance, the mainstream epistemological approach to pedagogy and methodology is parts to whole (inductive reasoning), linear and sequential, whereas, the researcher's Afrocultural epistemological approach to pedagogy and methodology are holistic thinking and critical path analysis, respectively. The researcher's epistemological approach has always been in direct contrast to those in 
mainstream public-school classrooms. Lastly, as a recipient of a solely American, K-12 public school and public post-secondary institution education, the researchers was invested in the success of public schools because it was directly tied to her livelihood through her occupation and professional credibility. The intersectionality of the researcher's identities and years of experiences as a public school educator will influence the ways in which she interpret the outcomes of the study. Milner (2007) best outlines this process of data interpretation through the lens of the researcher's intersecting identities with a framework for a researcher's racial and cultural positionality. The framework intends to guide researchers to work through the, "seen, unseen and unforeseen dangers in the practice of their inquiry: researching the self, researching the self in relation to others, engaged reflection and representation, and shifting from self to system” (pp. 394-395).

\section{Qualitative Validity}

In his book, Research Design Qualitative, Quantitative, and Mixed Methods Approaches, Creswell defined qualitative validity as the means by which, "the researcher checks for accuracy of the findings by employing certain procedures" (Creswell, 2014, p. 201). In this qualitative study, ensuring the accuracy of the findings was of the upmost importance to the researcher. Therefore, Lincoln and Guba's (1985) commonly used approach to qualitative validity used to establish trustworthiness. Reliability was established by checking interview transcriptions for mistakes and errors. Transferability and dependability were established through the descriptive methodological procedures, which, "enable one to repeat a study by using overlapping methods" (Creswell, 2015, p. 258). 
Lastly, the researcher incorporated two specific validity strategies. According to Creswell (2014) to triangulate data one uses, "different data sources of information" to "build a coherent justification for themes" (p. 201). Therefore, to triangulate data for this qualitative research study, the researcher used two different sources of data collection, one-on-one semi-structured interviews and a focus group, to build themes and descriptions on African-American high school students' shared experiences. The themes and descriptions found in the findings of this study were a convergence of, "several sources of data" and multiple African-American students' "perspectives" (Creswell, 2014, p. 201). The second validity strategy that was used was member checking. According to Creswell (2015), "Member checking is a process in which the researcher asks one or more participants in the study to check the accuracy of the account" (p. 259). The researcher took specific shared themes and descriptions found during the coding process of the individual interviews back to the participants during the focus group confirmed and polished major findings. During the focus group, participants had an opportunity to comment on whether the interpretations were accurate, complete, fair and representative of their experience (Creswell, 2015). It should also be noted that the nature of a small study does not allow for generalizability, the purpose of this research will be to focus primarily on gaining new insights into a few cases (Yin, 2014).

\section{Summary}

In summary, Chapter 3 described the research design, context of the study, data sources, data collection, ethical considerations, data analysis, researcher's positionality, and qualitative validity required to conduct this study. Future chapters will include a presentation of research findings accompanied by an analysis, a summary, and the 
implications of finding. This research study is unique in that it identifies culturally responsive instructional strategies and practices from the perspective of AfricanAmerican high school students. It also offers insight into African-American high school students' learning preferences. This research has the potential to offer educators and lawmakers a rich understanding of high school students' preferences as well as highlight innovative instructional strategies to approach to the problem of African-American student underachievement that has persisted for far too long. In conclusion, this research seeks to offer ways in which educators can help African-American students overcome the long-standing tradition of academic underachievement and low sense of belonging in education. 


\section{CHAPTER 4}

\section{FINDINGS}

As stated in Chapter 1, this study examined in detail the possible connection between African-American students' culture and academic achievement. The data analysis in Chapter 4 will answer the overarching research question: How do AfricanAmerican high school seniors perceive culturally responsive teaching in their classrooms? There were three purposes for this study. First, the purpose of this study was to highlight culturally responsive teaching practices that African-American students perceived as contributing to their academic success. Second, the purpose was to help identify if a cultural divergence exists between the instructional practices in U.S. public schools and the learning preferences previously established by African-American students within their homes and communities and if it has any bearing on their academic achievement. Thirdly, the purpose of this study was to offer valuable insight on how to replicate African-American high school students' learning preferences to increase their academic achievement. The organizational framing of Chapter 4 is designed to connect the thematic underpinnings identified in the data to one of the three corresponding purposes posed in Chapter 1. After a thorough analysis of the data, major themes emerged and were extracted, triangulated, and organized within Chapter 4. 


\section{Participants Profiles \& Demographics}

As a popular qualitative sampling method, purposeful sampling was used to gain insight on African-American students' perception of culturally responsive teaching strategies that boost their engagement, understanding, and academic success. Specifically, the researcher used maximal variation sampling to recruit nine AfricanAmerican high school students who are enrolled in the twelfth grade. As Creswell (2015) notes, maximum variation sampling requires "that you identify the characteristic and then find sites or individuals that display different dimensions of that characteristic" (p. 206).

For this study, the researcher used predetermined selection criteria to identify participants at Jackson High School. As outlined in the Methods section (Chapter 3), results from the Demographic Survey (Appendix D) were used to identify nine participants with the following characteristics: a) enrolled in twelfth grade, b) identified as Black or African-American, c) have not lived outside of the United States, and d) who self-selected to willingly participate in an individual, one-on-one interview and a small focus group discussion with the researcher. However, there were more than 10 potential participants to choose from for this study. As outlined in the Methods (Chapter 3), in the event, that there were more than 10 participants to choose from, the researcher would defer to a predetermined ranking system to achieve maximal variation (Creswell, 2015; Lincoln \& Guba, 1985; Robinson, 2014). The researcher's rationale for achieving maximal variation, as cited by Robinson (2014) is that, "any commonality found across a diverse group of cases is more likely to be widely generalizable phenomenon than a commonality found in a homogenous group of cases" (p. 27). Therefore, first the researcher defaulted to selecting 8-10 participants by choosing two participants from each 
learning orientation (Appendix D- Demographic Survey, Question 5). The learning orientations were: a) individualism, b) competition, c) communalism, d) verve, and e) music. Secondly, the researcher defaulted to selecting 8-10 participants by choosing one participant from each academic program (Appendix D- Demographic Survey, Question 4). Lastly, the researcher defaulted to selecting 8-10 participants by choosing participants representative fifty percent male and fifty percent female (Appendix D- Demographic Survey, Question 7). Table 1 reflects participants selected using the predetermined ranking system to achieve maximal variation.

Table 1

Maximal Variation of Participants

\begin{tabular}{|c|c|c|c|c|}
\hline $\begin{array}{l}\text { Student } \\
\text { Name, Self- } \\
\text { Identify }\end{array}$ & Program & $\begin{array}{l}\text { Learning } \\
\text { Preference, } \\
\text { Focus Group }\end{array}$ & $\begin{array}{l}\text { Neighborhood } \\
\text { Composition }\end{array}$ & $\begin{array}{l}\text { F/R } \\
\text { Lunch } \\
\text { Status }\end{array}$ \\
\hline Jessie, F & $\begin{array}{l}\text { Advanced Placement (AP) } \\
\text { College Prep } \\
\text { Law \& Government }\end{array}$ & Verve, 1 & Similar & No \\
\hline Alex, M & $\begin{array}{l}\text { College Prep } \\
\text { Law \& Government }\end{array}$ & $\begin{array}{l}\text { Individualism, } \\
1\end{array}$ & Similar & Yes \\
\hline Amanda, F & $\begin{array}{l}\text { College Prep } \\
\text { Pre-Med } \\
\text { Pharmacy }\end{array}$ & $\begin{array}{l}\text { Communalism, } \\
1\end{array}$ & Mixed & Yes \\
\hline Elise, $\mathrm{F}$ & $\begin{array}{l}\text { Advanced Placement (AP) } \\
\text { Honors } \\
\text { Pre-Med } \\
\text { Pharmacy }\end{array}$ & $\begin{array}{l}\text { Communalism, } \\
1\end{array}$ & Mixed & Yes \\
\hline Tiffany, $\mathrm{F}$ & Law \& Government & $\begin{array}{l}\text { Individualism, } \\
2\end{array}$ & Different & $\begin{array}{l}\text { Not } \\
\text { sure }\end{array}$ \\
\hline Tommie, $\mathrm{F}$ & Law \& Government & Verve, 1 & Similar & Yes \\
\hline Porsche, $\mathrm{F}$ & Nursing & Music, 2 & Mixed & Yes \\
\hline Rafael, M & Technology \& Innovation & Competition, 2 & Mixed & $\begin{array}{l}\text { Not } \\
\text { sure }\end{array}$ \\
\hline Brandon, $\mathrm{M}$ & $\begin{array}{l}\text { Advanced Placement (AP) } \\
\text { Sports Marketing }\end{array}$ & Music, 2 & Similar & Yes \\
\hline
\end{tabular}


Table 2 reflects the results of the demographic descriptors from the Participant Profile Sheet (Appendix I). The sample comprised of three males (33.3\%) and six females (66.7\%). Four of the participants were 17 years old (44.4\%) and five were 18 years old $(55.6 \%)$. Only one participant (11.1\%) identified as a person with a learning disability, while no one identified as a person having a physical disability $(0 \%)$. With regard to likelihood of going to college, the majority of the sample identified as definitely going to college ( $77.8 \%)$, followed by very likely to go to college (11.1\%), and those not likely to go to college (11.1\%). Six participants (66.7\%) received or were eligible to receive Free or Reduced lunch, two (22.2\%) were not sure of their lunch status, and one (11.1\%) was not eligible. In relation to the racial/ethnic composition of each participants' neighborhood, four participants (44.4\%) described the composition (make up) of their neighborhood as similar to themselves, one (11.1\%) described the composition as different from them, and four (44.4\%) described the composition as racially/ethnically mixed. When participants were asked to think about their academic achievement, four participants (44.4\%) thought they were generally at the top of the class, two (22.2\%) thought they were generally at the top middle of the class, two (22.2\%) thought they were generally at the lower middle of the class, and one (11.1\%) preferred not to answer. 
Table 2

Demographic Descriptors

\begin{tabular}{llll}
\hline Profile & Levels & $\begin{array}{l}\text { \# Of } \\
\text { Participants }\end{array}$ & $\begin{array}{l}\% \text { Of } \\
\text { Participants }\end{array}$ \\
\hline Age & 17 & 4 & $44.4 \%$ \\
& 18 & 5 & $55.6 \%$ \\
\hline Physical & Yes & 0 & $0 \%$ \\
Disability & No & 9 & $100 \%$ \\
\hline Learning & Yes & 1 & $11.1 \%$ \\
Disability & No & 8 & $88.9 \%$ \\
\hline Free or & Yes & 6 & $66.7 \%$ \\
Reduced & No & 1 & $11.1 \%$ \\
Lunch & I am not sure. & 2 & $22.2 \%$ \\
\hline Neighborhood & Racially/ethnically similar to me. & 4 & $44.4 \%$ \\
Composition & Racially/ethically different from me. & 1 & $11.1 \%$ \\
& Racially/ethnically mixed. & 4 & $44.4 \%$ \\
\hline Likeliness of & Definitely will go to college. & 7 & $77.8 \%$ \\
going to & Very likely to go to college. & 1 & $11.1 \%$ \\
college & Not likely to go to college. & 1 & $11.1 \%$ \\
\hline Academic & Generally at the top of the class. & 4 & $44.4 \%$ \\
achievement & Generally at the top middle of the class. & 2 & $22.2 \%$ \\
& Generally at the lower middle of the class. & 2 & $22.2 \%$ \\
& I prefer not to answer. & 1 & $11.1 \%$ \\
\hline
\end{tabular}

For the focus groups, the researcher also used the results from the Participant Profile Sheet (Appendix I) to split participants into two focus groups with 4-5 participants in each to achieve maximal variation. Participants were given a choice of two different time slots to participate in the focus group interview. By chance, too many participants (more than five) scheduled the same time slot, so the researcher defaulted to a predetermined ranking system to achieve maximal variation. The researcher selected 45 participants for each focus group by choosing participants based upon their neighborhood composition (Appendix I- Participant Profile Sheet, Question 5). The composition of the focus group members should be noted. In regards to how student would best describe how they learned (Appendix D- Demographic Survey, Question 5) 
focus group 1 was composed of two students who selected communal, two students who selected verve, and one student who selected individualism. Focus group 2 was composed of two students who selected music, one student who selected competition, and one student who selected individualism.

\section{Overview}

The results of participants' responses to the Demographic Survey (Appendix D), the one-on-one open-ended interview questions (Appendix H- Interview Protocol), the Participant Profile Sheet (Appendix I), and the focus group interview (Appendix J- Focus Group Protocol) were analyzed in this chapter and cross-compared to one another to gain a deeper understanding and explanation of how African-American high school seniors perceive culturally responsive teaching in their classrooms. Thirty-two African-American seniors at Jackson High School completed the Demographic Survey (Appendix D) online during the 7-day completion window. The Demographic Survey (Appendix D) was only available to students for 7-days because interviews had to be completed before Jackson High School's senior activities were held and before the school year ended. From the thirty-two respondents, nine students were recruited to participate in this research study. All nine agreed to participate in the study and returned the proper consent (Appendix EParental/Guardian Consent Form and Appendix F- 18 years or older Consent Form) and assent forms (Appendix G- Subject Assent Form). All participants seemed generally interested in sharing their experiences as an African-American student. During her oneon-one interview, one student participant in particular shared how excited she was to share her experience. She stated:

I like this. Because I was like, the Magnet Coordinator gave me some email and I was like, typing away, I was answering them questions. And then she brought me 
down here, and she was like, "Oh, okay." And I was like, "Yes, I will do it." And I signed that paper, and then...I'm here now.

The excitement and willingness of the student participants' to be interviewed not only gives voice to those who are most impacted by culturally responsive teaching but it also supports prior research that advocates for the inclusion of African-American students' voices (Creswell, 2014; Howard, 2001, 2002; Ladson-Billings, 1994).

For each one-on-one interview session, the researcher started by greeting the student participant as they entered into the meeting space and introducing herself in an attempt to establish rapport and acquaintance with the student participant (Miles, Huberman, \& Saldaña, 2014). The researcher also double-checked that each participant had returned his or her signed consent (Appendix E-Parental/Guardian Consent Form and Appendix F- 18 years or older Consent Form) and assent forms (Appendix G- Subject Assent Form) prior to the start of the interview. The researcher gave each student participant a photocopy of his or her signed consent form (Appendix EParental/Guardian Consent Form or Appendix F- 18 years or older Consent Form) and assent form (Appendix G- Subject Assent Form). Also, the researcher verified that each participant was still willing to participate, re-iterated the right to stop participating in the study at any point, and probed for any questions or feedback they might have about the study. Next, the researcher followed the Interview Protocol (Appendix H) as written and proceeded with the one-on-one interview in which students openly answered each question. However, at times, student participant responses were unclear, and more probing (i.e., What do you mean when you say...?) was employed to encourage them share more information in an effort of capture their student voice, which was necessary for in vivo coding (Creswell, 2015). 
During each one-on-one interview, participants shared their perceptions of culturally responsive teaching in their classrooms. The one-on-one interviews included open-ended questions (Appendix H- Interview Protocol) related specifically to the topic of African-American high school seniors' perceptions of culturally responsive teaching, differences between instructional practices used in their homes compared to ones used in their school, and how to replicate their, and other African-American students', learning preferences that they perceived as contributing to their academic success and achievement. Two one-on-one interviews were conducted in the Family Youth Service Center office, five one-on-one interviews were in the Magnet Coordinator's office, and two interviews were conducted in the Principal's office. Interview locations varied due to limited, confidential spaces at designated interview times. Although space was limited, all interviews were conducted behind closed doors and without interruption from others. The one-on-one interviews were scheduled intermittently throughout the school day and after school on two different days to accommodate student participants' class schedule. One-on-one interviews ranged in time length from 21 minutes to 40 minutes long. At the conclusion of each one-on-one interview, the researcher thanked the participant for their time, asked them to complete the Participant Profile Sheet (Appendix I), and reminded the participant about the scheduled focus group.

For each focus group, the researcher started by greeting the student participant as they entered into the meeting space and re-introducing herself in an attempt to establish rapport and acquaintance with the student participant (Miles, Huberman, \& Saldaña, 2014). The researcher also double-checked that each participant had returned his or her signed consent (Appendix E- Parental/Guardian Consent Form and Appendix F- 18 years 
or older Consent Form) and assent forms (Appendix G- Subject Assent Form) prior to the start of the focus group. The researcher verbally reviewed the consent (Appendix EParental/Guardian Consent Form and Appendix F- 18 years or older Consent Form) and assent forms (Appendix G- Subject Assent Form). The researcher did not give each student participant an additional photocopy of his or her signed consent and assent forms. Also, the researcher verified that each participant was still willing to participate, reiterated the right to stop participating in the study at any point, and probed for any questions or feedback they might have about the study. Next, the researcher videorecorded the focus group interview and followed the Focus Group Protocol (Appendix J) as written and proceeded with the focus group interviews in which students openly answered each question. At times, the researcher probed (i.e., What do you mean when you say...?) student participants' when responses were unclear in order to capture the student participants' voices for in vivo coding (Creswell, 2015).

The focus groups included open-ended questions (Appendix J- Focus Group Protocol) that emerged from the preliminary commonalities found by the researcher from one-on-one interviews (Appendix H- Interview Protocol). Focus group interviews were conducted during the regular school day on two different days to accommodate student participants' schedule. Focus group 1 lasted 35 minutes while Focus group 2 lasted 44 minutes. Focus group 1 was composed of five students; four females and one male. Focus group 2 was composed of four students; two females and two males. During each focus group, participants confirmed, modified, or extended the preliminary commonalities identified by the researcher to further explain their perceptions of culturally responsive 
teaching in their classrooms as an African-American high school senior. The detailed analysis of the findings for this study will be further explained below.

\section{Theme 1}

In this research study, the first theme to emerge from the data was that AfricanAmerican high school seniors have preferences for how they would like to be taught new information. In this study, the researcher was able to identify five favorable preferences for how African-American high school seniors would like to be taught new information. Using in vivo codes created from the student participants' voices in the one-on-one interviews, the five favorable preferences identified were: 1) "More hands on," 2) "Keep it interesting," 3) "Use technology," 4) "Give their own touch" and, 5) “One-on-one with the teacher." The in vivo code hands on was described as "hands on," "more hands on," "physical and human nature," "real world," "different methods," and "problem solving." More hands on was described by student participants as an opportunity to learn new information through demonstrations, labs, field trips, and other hands on activities in which a teacher would guide the student learner through a physical and/or visual example(s) as the student followed and learned alongside. For example, one student participant Amanda commented that, "I'd rather watch something than read it. I feel like it will stay in my mind more." She went on extend her explanation by saying, "I feel like if we had done more games, more social, more hands on stuff, it would stick more if we made songs or if we played games than just giving us papers to just memorize in the moment."

When student participants explained how a teacher could "Keep it interesting" students described differentiated instructional strategies that would engage student 
learners. One student participant, Elise explained, "Well, I'm in school. I'm only watching what they put on TV or what I read in this book and it's boring. I can't do it, because it just loses my interest." While describing, "Use technology," the student participants suggested that teachers incorporate opportunities for students to use technological devices to support teacher instruction and foster student learning. Student participants suggested technological devices such as cell phones, computers, different websites, videos, and audiotapes. From the one-on-one interviews, the researcher interpreted "Give their own touch" as student personalization. "Creative" was the word students most frequently associated with "Give their own touch." Student participants expressed a desire to be able to complete learning tasks in unique and creative ways versus "old" and "boring" ways.

The last of the five favorable preferences for how African-American high school seniors would like to be taught new information was one-on-one with the teacher. Student participants described one-on-one with the teacher as individualized instruction where the teacher would "show me," "tell me," or "go into detail" with the student or would allow the student to "talk to another person" when they did not understand. Student participants also described individualized instruction as the ability to ask more questions or have the teacher "explain it some more" when the student did not fully understand. One student participant, Rafael said, "Physically. You showed me how to do it, and of course, hopefully I know how to do it back type learning." Another participant, Brandon said, "Just basically like if I'm doing a worksheet, just come up to the side of me," and "If I ask a question, just come up to the side of me, and then look at the paper and then show me what I did wrong, basically.” 
In analyzing student participants' favorable preferences for how they would like to be taught new information, the researcher in this study was able to tag each in vivo code in this study to the Afrocultural learning orientation verve. In this study, student participants' favorable preferences were tagged to the Afrocultural learning orientation verve because the in vivo codes and descriptions were parallel to vervistic descriptions in Carter, Hawkins, and Natesan (2008). In vivo codes more hands on, keep it interesting, and use technology aligned to vervistic characteristics of "students preferring hands-on, interactive learning tasks" (Carter, Hawkins, \& Natesan, 2008, p. 34). In the descriptors, student participants used multiple action verbs in which they described how they preferred to be more hands on, keep it interesting, and use technology. The use of action verbs signaled having energy and the propensity to remain stimulated and lively. In vivo code keep it interesting aligned to the various differentiated instructional strategies that student participants preferred that allowed for having energy, remaining stimulated, lively, and students trying to work on more than one assignment at a time (Carter, Hawkins, \& Natesan, 2008). In vivo code one-on-one aligned to vervistic characteristics of excessive talking, and students regularly asking assistance from the teacher (Carter, Hawkins, \& Natesan, 2008). In vivo code give own touch aligned to the vervistic characteristics of expressiveness because students expressed a desire to complete learning tasks in creative ways.

In this study, the researcher was able to identify four unfavorable preferences for how students did not like to be taught new information was also identified. The four unfavorable preferences identified were: 1) "Same old boring," 2) "Not interesting," 3) "Lecture hall," and 4) “Expect me to know." Student participants described same old 
boring as teachers who were "not flexible," "not open," those who gave "busywork," "articles, articles, articles, articles, articles," "same old boring bookwork," or "extra work for no reason." However, it should be noted that although students disliked routine assignments, they liked classroom routines that created predictability and structure. When student participants were explaining not interesting one student participant, Porsche, best summarized not interesting as, “The class. It was just dull. It was just boring...I don't know how to say it. It was just dull the whole class. With that, it just made me just feel dull and I didn't want to do nothing." Another student participant, Tommie, explained her dislike for lecture hall when she shared, "I'd rather them do hands on than lecture halls because lecture halls, yeah, they're good, you can go to sleep, put your phone out there and just let it record, you won't learn nothing." Student participants felt as if lecture halls were academically unproductive, not engaging, and allowed students to become easily distracted. Lastly, student participants disliked when their teachers "Expect me to know." The researcher interpreted "Expect me to know" as instances within instruction where a teacher incorrectly assumes a student had background knowledge to perform a learning task but the student did not.

\section{Theme 2}

In this research study, the second theme to emerge from the data was that AfricanAmerican high school seniors have preferences for how they would like to learn content. The learning preferences that African-American high school seniors established, developed, and preferred are heavily rooted in Afrocultural learning orientations. In this study, the researcher found that the participants responded overwhelmingly with a preference to working with others while doing projects. Particularly, participants liked 
shared responsibility to increase efficiency in completing tasks and they liked group projects where all members of the group were responsible for a portion of the whole. For example, one participant Alex explained, "They contribute to a part of the project and I contribute to a part of the project, and then we come together." Shared responsibility to increase efficiency and responsibility for portions of a whole were tagged to the Afrocultural learning orientation communalism because the communal dimensions social orientation and group duty were at play in the student participants' descriptions. Because group projects grades are weighted so heavily student participants placed a premium value on their completion. Student participants' preference to complete such a heavily weighted project that could impact their personal grade with a peer speaks to communalism's group duty dimension in that "group duty places group needs before individual needs" (Boykin, Lilja, \& Tyler, 2004). Student participants expressed a desire to work with others to complete a big task in which the individual student would need to prioritize the completion of their smaller portion (individual need) because it impacted the big group project and grades of other students (group needs).

Participants also had a preference for working with others when they needed help understanding content. They specifically placed a high value on sharing knowledge and teaching one another. The sharing of pooled resources from individuals to benefit the group rather than self, aligned to the communal dimension of sharing (Boykin, Lilja, \& Tyler, 2004; Hurley, 1999). As one participant, Jessie, explained "I like to work with others when it's something like they understand better than I do. I like working with people, if I can help them or they can help me.” Another participant, Porsche, further 
explained the communal process of teaching and learning with a peer in more detailed by saying:

If one of us don't know something, the other one do, then they teach us how to do it. Then it goes back and forth. It goes back and forth. If we don't know how to do it and they know how to do it, then they teach us. If we know how to do it and they don't, then we teach them. We just all go back and forth with teaching each other.

Additionally, participants placed a high value, and preference, for hearing a diversity of ideas and perspectives by sharing, talking, and teaching with their peers, and welcomed the opportunity to do so. As the participant Brandon shared, "I learn a lot because it's many different perspectives. I'm open to learning. Well, open to knowing different opinions on stuff." Student participants' expressing value in diversity of ideas and perspective speaks to the communal dimension of sharing in which pieces, or experiences learned, from individuals are shared to help everyone in a positive way (Boykin, Lilja, \& Tyler, 2004).

In this research study, the researcher found that all of the African-American high school seniors in this research study had a preference for when they preferred to switch tasks. Student participants preferred to switch tasks under three different circumstances: 1) when participants found a task to be challenging, 2) when participants needed to multitask, and 3) when participants felt they mastered a task. When tasks were switched or changed, participants' responses were split on describing how they believed they learned. Student participants' in vivo responses were "ask a question," "think about it," "do it with a group," and "use what I know." "Ask a question" was actualized in the classroom through the use of asking the teacher or peers questions. "Think about it" was actualized in the classroom when students pushed themselves to persist and power 
through the task independently. "Do it with a group" was actualized in the classroom when students worked with others or sought out assistance from peers, a small group, the whole group, or a teacher. "Use what I know" was actualized in the classroom when students used prior background knowledge and anticipated its application in the next task to be completed. With the in vivo "use what I know" student participants operated under the belief that the switched tasks were somehow connected or related to one another.

The student participants' descriptors for this interview question were tagged to the Afrocultural learning orientation verve for three specific reasons. First, the in vivo code "I'd do it with a group" ties to researchers Carter, Hawkins, \& Natesan (2008) highly vervistic classroom descriptor "students asking other students for help" (p. 34). Secondly, in vivo codes "ask for help," "ask the teacher," and "ask a question," tie to researchers Carter, Hawkins, \& Natesan (2008) highly vervistic classroom descriptor "students regularly asking assistance from the teacher" (p. 34). Thirdly, the in vivo codes "know I've got to do something else," "I can move onto the next thing," "completely done with one thing," and "covered everything" ties to Boykin's (1983) descriptor of verve in which one has "a tendency to attend to several concerns at once and to shift focus among them rather than to focus on a single concern or a series of concerns in a rigidly sequential fashion" (p. 345). In vivo codes "know I've got to do something else," "I can move onto the next thing," "completely done with one thing," and "covered everything" also ties to researchers Carter, Hawkins, \& Natesan (2008) highly vervistic classroom descriptor "students trying to work on more than one assignment at a time" (p. 34). In sum, student participants' explanations for how they learned when tasks were switched directly aligned, word for word, with characteristics of highly vervistic classrooms. 
From the data analysis in this research study, the researcher found that all participants had a high propensity towards music. All participants, but one, had a preference for working in the presence of music and rhythm. One participant had a preference for working in the presence of rhythm and movement that he created rather than listening to music. This participant, Rafael explained,

Well, like I said, I play drums by myself, so of course from when I'm doing work, I'm tapping a beat... When I'm working, I'll like tap my feet a little bit. That kind of distracts me I guess, but it feels good.

In contrast to Rafael, all of the other participants preferred to listen to music composed by others and not themselves. Participants' high propensity towards music was best explained by Jessie when she shared, "I like to listen to music and stuff all the time...like maybe have the TV on. I might not be watching it but have it [as] background noise...I'm never really sitting in silence so it feels kind of odd." Jessie was not alone in expressing her preference to working in the presence of music and rhythm. Amanda added, "I feel like I'm more focused with music." While Elise added, "I love listening to music all throughout the day."

Participants also reported various learning tasks in which they preferred to work in the presence of music and rhythm. Participants reported learning in the presence of music and rhythm in three different ways: 1) music increased productivity, 2) music impacted their mood, and 3) music increased their focus. Elise described how music increased her productivity by stating that, "I learned that I'm getting it done. That I can do two things at once...I can listen to music and I can do the project, or I can do this worksheet. Really, multitasking...you're doing it. You're doing two things at once." Tommie explained how music impacted her mood when she explained, "It helps, it copes, 
it helps me cope with school and stress...it just helps. It chills me out, it helps me relax and focus on what I'm doing, and it helps me with myself." Brandon believed music increased his focus and explained, "I'll listen to music to help me focus more in. It just has my brain going... Things just get in my head more easily when I listen to music, so I believe it helps me out." However, it should be noted that the beat of the music (fast tempo versus slow tempo) and the specific learning task being performed dictated student participants' preference toward music and rhythm. In general, participants reported that music with a more upbeat tempo tended to be preferred for low-level cognitive learning activities such as memory recall. Whereas, music with a slower tempo tended to be preferred for tasks that required a higher-level cognition and more focus.

Although African-American high school seniors in this research study had a high propensity towards music, no connection was drawn from the data to the Afrocultural learning orientation movement (music). In order to draw the connection to the Afrocultural learning orientation movement (music), descriptors would have to have referenced learning by music that was "personified by the musical beat" or describe a "multidimensional recurrent pattern that typified one's personal conduct and selfpresentation" but they did not (Boykin, 1983, p. 345). Therefore, a connection between students' preference for music and the Afrocultural learning orientation movement (music) was not supported in vivo codes student participants used to describe how they learned when they worked in the presence of music and rhythm. In this study, all of the student participants' in vivo codes for learning in the presence of music involved participants "listening" to music. In fact, the in vivo code "listen" was most frequently used $(\mathrm{n}=15)$. However, students' propensity to music was tagged to the Afrocultural 
learning orientation verve because student participants' descriptions of "listening" while they completed a learning task. Listening to music while completing a learning task is an example of verve in which an individual is engaged in more than one task at a time and/or switching interchangeably between multiple tasks.

In this research study, data revealed that African-American high school seniors only preferred to work alone when they were studying and/or when they had assignments or projects outside of school. When working alone, participants believed they learned best when they had physical access to the content to manipulate it (i.e., read, jot notes, review videos, and etc.), along with time to process it independently. Working alone and/or independently is aligned to European/Euro-Americans' axiology of memberobject. The member-object axiology lends itself towards competitive and individualistic tendencies and values (Jones \& Nichols, 2013). Within an individualistic value system, intrinsic identity, self-development, achievements, and concern with one's inner circle are highly valued (Jones \& Nichols, 2013). Consequently, preferences for working alone are in direct conflict with the member-member axiology that the African-American student participants held.

\section{Theme 3}

The third theme to emerge from the data in this research study was that AfricanAmerican high school seniors characterized teaching and learning in their homes and communities as catering to their African-American culture and learning style. The three reoccurring commonalities of how teaching and learning in the homes and communities of African-American students catered to their African-American culture and learning style were communal talk, culturally relevant content, and member-member relationships 
with others. During the one-on-one interviews, the in vivo code talk was described as "working together," "together as a group," "we," and "show me." During the focus groups, study participants described the in vivo code talk as "elaborate on things," "verbally, come through their mouth," "asking," and "shows it to me." All of the African-American high school seniors in this research study used talk to describe the delivery method in which a respected individual (a family member, coach, community member or etc.) used to teach them a task they enjoyed learning outside of school. Within the context of the one-on-one interviews, talk was best described as a communal activity in which the student participant and the respected individual worked together through a physical demonstration (hands-on activity) and had verbal commentary exchanged back and forth between the two individuals. Talk was actualized under two specific premises-a verbal exchange between two parties and the respected individual "showing," and/or the student participant "watching."

The talk that student participants described aligned with the Afrocultural learning orientation communalism because their descriptors emphasized how the talk was taking place. In the homes and communities of the African-American participants, talk was being used between the instructor and the student to exchange and share knowledge. Specifically, the instructor was not the only speaker. Instead in the talk used in the homes and communities of African-American students, students were naturally able to question, add their own knowledge, and/or seek further explanation without consequences, and were encouraged, and supported to do so. Study participant Alex explained, "I'm African-American and most of teachers are not. So, that will be a big difference, the way they talk at school is different than the way we talk at home." 
Furthermore, communal learning descriptions in this study were also categorized as communal talk. For this study, student participants used the in vivo codes "we," "working with people," and "together as a group," to describe communal learning. The in vivo code "we" was coded fourteen times during the one-on-one interviews with participants. In the focus groups, talk was described as, "let me show you," "let me tell you," "talk to you," "hear it explained to us," and "show you how to do it." The descriptors for communal learning were aligned to the Afrocultural learning orientation communalism because it emphasized the sharing of knowledge. Sharing, a sub-dimension of communalism is defined by Hurley, Boykin and Allen (2005) as, "knowing that resources are rightfully shared rather than hoarded for individual benefit" (p. 516). The communal learning as described by participants focused on the student and the instructor having a teamwork-like effort to do perform a task together. While the two are performing the new task, the instructor and student are both verbally exchanging back and forth to help the student acquire new knowledge that the instructor already has. One student participant, Amanda, described how communal learning took place between a respected individual at home and/or in the community and an African-American student when she explained,

She did everything hands on with me together. It sticks more. I'm more a motion memorizer than a reader memorizer... She showed me and then it was my turn to do it. We did two steps in one. I had my chance to do my own while she was doing it.

Often times, student participants added that the sharing included a hands-on manipulation or experience, as the respected individual performed a task first while the student watched. Afterwards, the student would perform the same or a similar task independently but in the presence, and/or under the supervision, of the respected individual. 
Culturally relevant content was the second reoccurring commonality in how teaching and learning in the homes and communities of African-American students catered to their African-American culture and learning style. As explained by the student participants, culturally relevant content was actualized through real-world application of learning tasks, student choice in content, and familiarity. Content taught in the real world of the student participants, included, but were not limited to, learning how to cook, purchasing a car, writing a check, cursive writing, paying taxes and etc. As Jessie put it, "At home it's like let me show you how to do it and how you're going to use it in real life." Alex added, "Like what she said. The real life situation that's going to help you succeed." All of these real world experiences resonated with students because they were currently applicable in their individual lives or would be applicable in the near future. Student participants believed that the life lessons learned through these culturally relevant experiences made the learning in their African-American homes more relatable than the content taught at school.

Study participants expressed a heightened pleasure and engagement in having a choice in the content of what they wanted to learn. Student choice in content is directly aligned to the culturally responsive teaching practices that Gay (2013) emphasizes which work to draw a connection between "in-school learning to out of school living" (p. 49). As one student participant Tommie shared, "At home it's more of what you want to learn. And at school it's more what you have to learn." In the focus groups, student participants expressed an ability to choose content that mattered to them. For instance, Elise shared, "My mom taught me how to write a check. School didn't." And Tommie followed by saying, "Yeah, my mom taught me how to write in cursive. School didn't." In the focus 
groups, student participants believed that content taught at home was more relevant to their lives and their current realities as African-American high school seniors.

Culturally relevant content in the teaching and learning within the homes and communities of African-American students was also actualized through familiarity. The researcher interpreted the descriptor "comfortable" as familiarity. During their one-onone interviews, student participants described "comfortable" as, "I can eat while I'm doing work," "We can do whatever we want," "I can dress however I want to," and "I ain't got to be in dress code." The descriptors for "comfortable" speak to how Afrocultural norms in the homes of the African-American are familiar to participants, yet clashes with the Eurocentric norms at school. In the focus groups, student participants also expressed teaching and learning at home was more comfortable. Student participants commented that in their homes and communities they felt "free", and were also encouraged, to be, and learn, authentically without fear of punishment and/or judgment. Specifically, student participants found their homes to be more comfortable because they could, "attend to several concerns at once and to shift focus among them rather than to focus on a single concern or series of concerns in a rigidly sequential fashion" (Carter, Hawkins, Natesan, 2008, p. 31). All in all, teaching and learning at home for AfricanAmerican student participants in this study felt more familiar because they are able to operate within their cultural norms without consequence.

Having member-member relationships with others was the third reoccurring commonality in how teaching and learning in the homes and communities of AfricanAmerican students catered to African-American culture and learning style. In the focus groups, student participants believed that learning at home was different from learning at 
school because of the relationship they had with their "instructor" at home. As captured in this snippet from focus group 1 , students spoke about the relationship they had with their instructor at home:

Jessie: Because your parents care about you.

Alex: Umm...hum. (Affirmative)

Tommie: Yeah, basically, and you're their child so they want you to be prepared no matter what situation you're in or how you get in. At school this is their job, they get paid.

Amanda: They're just doing it for a paycheck.

Tommie: Yeah, that's all. And at home they really mean it from the heart and they want you to learn because that's them.

Elise: I mean don't get me wrong, there are some teachers that if you have a personal relationship with them they might take that extra step but they don't have to. Our parents don't really have to but they kind of have to because they're our parents. They want us to do good. They want to see us go far.

Alex: They love you.

Tommie: Yeah, there's another level that they're on with love.

Jessie: But I mean our moms and dads are still teachers too.

Alex: Umm...hum. (Affirmative)

Jessie: Yeah.

The student participants' prioritization of having a personal relationship with their instructor and how that influences their learning is directly aligned to the membermember axiology of African-Americans within the Philosophical Aspects of Cultural 
Difference Framework. The student participants' beliefs about having a personal relationship with the instructors in their homes were connected to a member-member axiology in which the focus is on community and interconnectedness. Student participants believed that their interconnectedness to their home instructor added to why the learning was different for them in the home compared to learning in school. It should also be noted that instructors in the homes and communities of the student participants were most often parents, extended family members, or coaches.

It should also be noted that the term "trust" was used repeatedly to describe member-member relationships with others. In particular, teaching and learning in the homes and communities of African-American students catered to their AfricanAmericans' cultural value of respect and mutual trust (Jones \& Nichols, 2013). Study participants spoke about their feelings towards the respected individual teaching them in their homes and communities. Student participants felt that they could accept and trust the knowledge being shared with them from the respected individual in their home or community because they knew them. Student participants believed that the respected individual both taught and invested in them precisely because they cared, loved and knew them as an individual. Additionally, student participants believed that trust between themselves and the respected individual in their homes and communities was built through the establishment of a personal relationship.

\section{Theme 4}

In this research study, African-American high school seniors believed teaching and learning in U.S. public schools was quite different from the teaching and learning they experience within their homes and communities. The three reoccurring 
commonalities that African-American high school seniors detailed about teaching and learning in schools were the use of traditional instruction methods, a "more structured" environment, and a culture of "pass the test." In the one-on-one interviews, student participants were able to detail a variety of instructional methods that teachers used to teach them something new at school. As described by the student participants, teachers at school generally use a variety of traditional teaching methods and strategies in their everyday classroom practices. Traditional teaching methods and strategies included, but are not limited to, incorporation of technology, modeling, videos, whole group, independent practice, worksheets, textbook readings, textbook assignments, repeating a skill until student mastery was met, class notes, memorization, reading (aloud and independently), and discussion (whole group and small group).

In this study, when teachers helped the African-American student participants learn something new, the in vivo codes "show me," "walk me," and "the steps" were most frequently used to describe the teaching and learning in their school. Only three of the nine participants did not use the in vivo codes "show me," "walk me," and "the steps." Instead these three participants spoke to the repetition of content as an instructional method used by their teachers in school to teach them something new. Student participants described repetition as, "explain to us more," “do examples a lot," "try it again," and "we did a whole bunch of stuff." Student participants reported that they were typically assessed through homework, usually an extension of unfinished classwork, and quizzes. When student participants sought more individualized instruction at school, students defaulted to an explanation of them staying after school for one-onone time with the teacher. 
Formulaic sequential steps, independent practice, and assessments were instructional methods tagged to mainstream learning orientations. These traditional teaching methods were tagged to mainstream learning orientations because they were parallel to the descriptions of member-object axiological focus, applied knowledge through counting and measuring, and a linear and sequential methodology of European and Euro-American culture. First, as described by student participants, classroom instruction followed the formula of modeling sequential steps for students then releasing them to practice the same skill independently. According to Jones and Nichols' (2013) Philosophical Aspects of Cultural Difference framework, European and Euro-Americans have a member-object axiology. Within a member-object axiology, the value of "self (humanity) is separated from non-self (phenomenal world). There is a "we vs. them" mindset that is consistent with competitive and individualistic and survival strategies" ( $\mathrm{p}$. 38). Secondly, as described by student participants, students are assessed in classrooms through independent practice, worksheets, textbook assignments, repetition of a skill, homework, usually an extension of unfinished classwork, and quizzes. In accordance with a member-object axiological focus, assessing students and giving them numerical values and points (grades) is prioritized. According to Jones and Nichols (2013), within a member-object focus, "the only knowledge that matters is the knowledge that you can count and measure—one only knows through counting and measuring” (p. 49). Lastly, European and Euro-Americans' culture uses linear and sequential methodology (Jones \& Nichols, 2013). "For example Step A, leads to Step B, which leads to Step C, etc. Rarely, does one venture from this sequential pattern of presentation" (Jones \& Nichols, 2013, p. 55). The member-object axiological focus, applied knowledge through counting and 
measuring, and a linear and sequential methodology of European and Euro-American culture directly conflict with the member-member axiological focus, applied knowledge through symbolic imagery and rhythm, and a critical path of analysis methodology of African-Americans culture (Jones \& Nichols, 2013). The findings within this research study are consistent with Jones and Nichols' (2013) Philosophical Aspects of Cultural Difference framework in that African-American student participants believed teaching and learning in U.S. public schools was quite different from the teaching and learning they experience within their homes and communities.

During the one-on-one interviews and focus groups, the discussion of schools' "more structured" environment and a culture of "pass the test" were interconnected for the student participants in this study. The in vivo code more structured was described by student participants as "only teach you enough to where you're able to pass the test," "more reading or writing," "if a teacher is showing me how to do something, then we would use that way," "go off what the teacher is telling me," "make me refer to the notes," "with the facts," "how the teacher wants you to learn it," and "very rigorous." The in vivo code pass the test was used to describe the generic curriculum and content that is pre-set for students to learn in order to pass state, district, and/or classroom assessments. The idea of a pre-set curriculum used in school was best illustrated in the comments of Tommie when she shared:

School I feel like the instruction is like you have to know this so you can pass this test...in school they're going to show you this is what you need to do for the test. That's how the instruction is more so for the test so you can pass.

Just as Tommie explained, student participants believed that teachers at school taught “... what they have to teach" with very little room for student choice. 
Coupled with an emphasis to pass the test was the in vivo code lecturing, which was described by student participants as the primary delivery method of instruction within schools. Jessie explained lecturing as, "So learning in school it's sometimes I feel like teachers, they kind of only teach you enough to where you're able to pass the test." Elise said, “...School is obviously more structured...if a teacher is showing me how to do something, then we would use that way of how they did it...because she's telling us..." Tommie said, “...Inside school is more so lecturing, talking facts than outside of school.” It is important to note that the instructional method lecturing was also described as the exact opposite of the in vivo code student participants used to characterize the teaching and learning in their homes, which was talk. To the student participants, lecturing was delivered primarily as verbal direction or information passed from the teacher, who is the sole source of knowledge, to the student, the one who is in need of the knowledge. The student participants also acknowledged that in schools there was very little room to make errors because they needed to "pass the test." Jessie elaborated on this idea when she said, "At home I guess you're learning from lessons like messing up and learning from it and then at school if you mess up it's your grade, it's on your transcript."

In this research study, although there were primarily three reoccurring commonalities that African-American high school seniors detailed about teaching and learning in schools, it should also be noted that the student participants also detailed, at length and with commonalities, their feelings about how teaching and learning in schools impacted the relationship between African-American students and their teachers. The student participants in this study drew a connection between a pre-set curriculum, a culture of "pass the test," and how it impacted teacher dispositions, which consequently 
impacted their relationship with African-American students. The student participants in this study believed that a pre-set curriculum and a culture of "pass the test" created teacher dispositions that did not prioritize building a personal relationship with students. Instead, student participants in this study believed that a pre-set curriculum and a culture of "pass the test" created teacher dispositions in which job duty and/or responsibility was the priority.

Having no personal relationship with the teacher at school was captured in student comments such as, "teachers teach you the way they wanna teach you," "a teacher you just met for one year, not even a year," and "they just say stuff just to tell you." Teacher dispositions were captured in the student commentary during one-on-one interviews in which they said, "At school this is their job, they get paid," "they might take that extra step but they don't have to," and "They're doing it for a paycheck." In the focus groups, student participants expressed a need to build better relationships with schoolteachers in order to, “...connect with them." They also expressed that teacher dispositions that reflected passion towards teaching were more favorable than dispositions that reflected job duty, or job responsibility. Teachers using phrasing such as, "It's my job," or made references to receiving financial compensation (a paycheck) impacted their relationship with African-American students because student participants felt as if they were not invested in them, or their learning.

All of the descriptors for teacher disposition and having no personal relationship with African-American students speaks directly to the misalignment between Eurocentric learning orientations of public schools and the Afrocultural learning orientations that African-American students develop within their homes and communities. As stated by 
Jones and Nichols (2013), the axiological focus of European and Euro-Americans is member-object. In a member-object axiology, life revolves around one's "relationship to objects and the accumulation of said objects" (p. 38). However, within an AfricanAmerican member-member axiological focus "the highest value lies in the relationships between persons" (p. 37).

\section{Theme 5}

In this research study, the fifth theme to emerge from the data was that AfricanAmerican high school seniors were able to distinguish which teacher practices and dispositions supported their academic achievement. Teacher practices were described as classroom policies and operations, while teacher dispositions were described as student perceived personality traits or behaviors of the teachers. In this study, the student participants were able to distinguish eight teacher practices and dispositions that supported their academic achievement. The eight teacher practices and dispositions that supported African-American students' academic achievement found during the one-onone interviews and focus groups were: 1) invested, 2) "motivated"/“pushed me," 3) culturally responsive, 4) build a personal relationship with students, 5) able to ask questions, 6) positive, 7) acknowledged students' racial identity, and 8) care.

Invested teachers who played the biggest role in supporting student participants' academic achievement were willing to extend themselves to students beyond their expected job duties. Students described beyond expected teacher job duties as letting students "stay after school" to "retake tests," offering "constant support," and those who supported students seeking to transition to their future endeavors. For example, one student participant, Brandon, recounted his invested teachers when he said the following: 
Whenever I had an achievement, I would tell them, and then they would just keep telling me, "Keep going." They was like another parent. They just make sure I just stayed on the right track and just gave me extra motivation.

Invested teachers supported, and encouraged, students to pursue future endeavors by giving "pointers and advice with college and just life." Student participants in this study believed that invested teachers were willing to extend themselves to students beyond their expected job duties because "they want you to succeed."

Invested teachers were helpful in student development and academic success and played a critical role in supporting student participants' academic achievement because they offered "more help or assistance" on learning tasks when students encountered difficulty. "Help" was the in vivo code used to describe how teachers who helped African-American students would actively responds to students' request for help from the teacher. According to the student participants in this study, an invested teacher frequently responded to student requests for help by actually helping them whereas teachers who were not invested were described as, "nonchalant" and "not helping." Invested teachers also gave individualized attention and were willing to offer "more help or assistance on" challenging learning tasks. For example, Amanda said that her invested teacher gave individualized attention when the teacher would, "do a different problem in front of me, and then give me an example to do it by myself and then give me another one."

The second teacher practice and disposition that supported African-American students' academic achievement was a teachers' ability to motivate students or push students. Teachers who "motivated"/ "pushed me," played a crucial role in supporting student participants' academic achievement because they inspired students and held students to high expectations. One student participant, Jessie believed that "motivated"/ 
"pushed me," teachers "seen potential in me that I didn't see...they have confidence in you that you don't have in yourself to make sure you give your full potential." Teachers who "motivated"/ "pushed me," held students to high expectations by pushing students to take challenging courses in high school, or by academically challenging students to complete learning tasks with a higher depth of knowledge. For example, Jessie shared a time when a teacher "motivated"/ "pushed" her when she recalled how she was pleased to receive an 85 on a paper but her teacher felt differently. Jessie shared, "And she would not take that; like she'd give me my paper back and make me fix it...I like the fact that she pushed me to write the best that I could."

The third teacher practice and disposition that supported African-American students' academic achievement was a teachers' incorporation of culturally responsive instructional methods in their classroom. The in vivo codes student participants used to describe culturally responsive instructional methods that supported African-American students academic achievement were "learn it in other ways," "music," and "the classroom sticks us like a team." When student participants explained how they could "learn it in other ways" students explained that teachers who helped African-American students used differentiated instructional strategies that worked well in engaging AfricanAmerican students. Student participants in both focus groups used in vivo codes such as, "free spirit," "to be free," "go in the computer lab," "gets us out in the community," "a lot of different things," "gives more of a variety," "able to talk," "rearrange your desk," "do different stuff, different tasks," "free flowing," "plays music," "jokes around with us," "everyone's in sync with each other," and, "with the plan, it's more fluid" to describe elements of instructional methods that supported African-American students' academic 
achievement. "Music" was the in vivo code used to describe how teachers who helped African-American students allowed students to "listen to music" in class. The researcher categorized the in vivo codes for learn it in other ways and music as an instructional style with high levels of vervistic characteristics that supported African-American students' academic achievement.

While describing the in vivo code, "This classroom sticks us like a team," the student participants suggested that teachers who help African-American students create classroom environments that foster a communal/familial/fictive kinship environment. The student participants in this study felt that within a communal learning environment "people can go far." Student comments such as, "talking to your friend," "express their ideas amongst each other," "feel a connection between their teachers and classmates," "work together," "the help of their classmates, and the teacher," "talks with us," "we can go in there and sit wherever we want," "come up to her desk," "discussions on how we feel about topics," "debate with us," "going to talk," "go back and forth and with your teacher," and "go talk to him" were coded for the Afrocultural learning orientation communalism. One student participant, Elise, even added, "You know you can actually see what comes out of different people whenever you have to work together." It should also be noted that with the in vivo code "This classroom sticks us like a team," student participants acknowledged, and appreciated, how communal learning environments cultivated a diversity of thought.

Fourthly, teachers who "build personal relationship with students" played a key role in supporting student participants' academic achievement because they connected with students. Student participants in this study perceived that these teachers "notice" and 
are "sincere" because they know students personally. While describing "builds relationships with us," the student participants suggested that teachers who supported African-Americans attempted to develop meaningful, personal relationships with African-American students. Teachers who helped African-American students built relationships with students by teasingly joking with students, walking the hallways, "talk to you in class and in the hallways to check up on you," and by getting "to know you personally." Along with building a relationship, student participants also explained that teachers who helped African-American students knew the students they taught because they would "find a teaching style that reaches out to all of them." These teachers were described as, "staying with our culture," "know how to come towards us," "try to relate it to the up and coming," "try to put it into our generation and our feel," "relate things to everybody, like different race," and "talks like us so it's like we understand."

Student participants described the fifth teacher practice and disposition that supported student participants' academic achievement as able to ask questions. The ability to "ask questions" was feeling comfortable enough to approach the teacher with questions. A teacher's disposition was determined to be approachable when student participants felt comfortable to "ask questions" to their teacher and believed that their teacher would welcome and encourage them to do so. The sixth teacher practice and disposition that supported student participants' academic achievement was a positive outlook. While describing "positive" the student participants suggested teachers who supported African-Americans generally held an optimistic outlook on students' academic abilities. Student participants believed that positive teachers supported African-American students because they "make you feel good about yourself" by giving "compliments," 
"verbal reminders," they "never say nothing negative about us [students]," and gave students reassurance when students did not feel confident.

The seventh teacher practice and disposition that supported student participants' academic achievement was when a teacher acknowledged students' racial identity because as student participant Tommie explained, "We're already judged by being our color and being the minority." In this research study, it was clear that African-American high school seniors were well aware of their racial identity and the negative stereotypes, perceptions, and biases towards African-Americans. The student participants in this study believed the negative stereotypes, perceptions, and biases towards African-Americans impacted their and other African-American students' schooling experience in U.S. public school classrooms. For instance, as Amanda articulated in the following:

I feel like more so teachers should be more open to African-Americans. I feel like they put us in a bubble, a stereotype that our highest grade we can get is a D. Like I'm on honor roll. They treat me different than other African-American students. They're like, "Oh, she gets straight A's, but she's Black." I still get treated different from the other races that's on honor roll. They try to put me less because they think I can't do it, but some teachers here, they help me more because they automatically thing that I need it. I don't take that as a threat or anything. I will take the help, but it's like for the other kids that's really not on honor roll, I feel like the teachers...Some teachers just give up on them. "Here's your assignment. If you turn it in, you turn it in. If you don't, you don't." They don't really care if they pass or not.

Like the other student participants, Amanda perceived that many teachers had lower expectations for African-American students because of their race. As a result, student participants in this research study believed teachers should acknowledge students' racial identity when teaching them. For instance, one student participant, Tommie, said, "I just think how they say some things and teach some things, like say history. Lord, that is a hard subject to teach African-American students about slavery and you're a White 
teacher." She went on to explain, "Some of the things they're trying to teach us, we don't agree with cause we know the truth." Another student, Alex, shared the following in regards to his racial identity and instruction:

It's just different skills that your parents teach you versus they teach at school. I mean, I know it's two different things, but some teachers have always taught, will kind of go towards what your parents teach you at home, but some don't...

Another student participant, Tiffany shared, "Like you know how they say that in school, and outside of school you have two different personalities?" Student participants in this study believed that teachers who acknowledged students' racial identity were able to better support African-American students' academic achievement.

Lastly, according to student participants, teachers who support African-American students exhibited "care." "Care" was described as teachers who are just as concerned with student lives outside of the classroom as inside the classroom. An example of the in vivo code "care" was operationalized in Porsche's comments when she said the following:

They're different because I feel like they care more about not just about... They care more about school, but then they care more about outside of school. They get to know you personally...they know what you're going through and what you're going to be in life and stuff. They help you get to that point. Other teachers, they just... They care, but they don't care as much as them teachers do.

In her response to the one-on-one interview, Porsche explains she is aware that teachers generally care. The majority of the study participants also agreed that generally speaking, teachers care. However, like Porsche, the student participants in this study, believed they were able to decipher when a teacher really cared because the teacher was also concerned about their personal life outside of the scope of the classroom. In all, student participants believed that teachers who supported African-American students 
operationalized "care" as concern and attention through observing, learning and understanding students as holistic individuals with consideration to the out-of-school factors impacting their lives and academic performance.

\section{Theme 6}

In this research study, the sixth theme to emerge from the data was that AfricanAmerican high school seniors were able to distinguish which teacher practices and dispositions did not support their academic achievement. In this study, the student participants were able to distinguish 14 teacher practices and dispositions that did not support their academic achievement. The 14 teacher practices and dispositions that did not support African-American students' academic achievement found during the one-onone interviews and focus groups were: 1) unprepared, 2) assigned busy work, 3) repetitive, 4) unclear grading, 5) focused on individualism, 6) had no classroom décor, 7) lack of care, 8) do not push (motivate), 9) personality, 10) language barrier, 11) unapproachable, 12) racially profiling African-American students, 13) power, and 14) disrespect. First, student participants described unprepared teacher practices as, "not knowing anything," "sounded like she didn't know what she was talking about," "not ready to teach others," "not really having a full set up before we go and do whatever that day," "so worried about what was going on besides trying to teach," and "got off topic really easily." Although assigned busy work, repetition, and unclear grading were individuals characteristics of teacher practices, they were also very closely related. Student participants expressed great frustrations with teachers who had unclear grading policies or those who gave unnecessary or repetitive assignments. Student participant Tiffany recounted, "She was just horrible. She didn't know what she was talking about. 
She would give out unnecessary busy work. She wouldn't assign papers to actually help us. She wouldn't tell us what was in mastery and what wasn't in mastery." Another student, Jessie, explained busy work when she recounted:

...we'd get assigned ten pages to read and then during that period of time when we're reading we were expected to do like...I think the first set of flash cards we got was like two hundred words. And I didn't feel like it was really effective because I felt like I was just flipping through the chapter to find the definitions of the two hundred words, so I could have that work done instead of really studying to be prepared for the test we would have in the end.

The fifth teacher practice and disposition that did not student participants' academic achievement were teacher practices that focused on individualism such as, "do this by yourself," "teach yourself," "we just did it ourselves," and "puts them on the board and expects you to learn how to do it" to be equally frustrating when they felt like they needed help understanding. The sixth teacher practice and disposition that did not support student participants' academic achievement was a lack of classroom décor. Details such as, "not colorful," "no pictures or nothing," and "it was just dull in the classroom," played a role in not supporting African-American students' academic achievement.

The seventh teacher practice and disposition that did not support student participants' academic achievement was a lack of care. Teacher dispositions that did not prioritize building a personal relationship with students were categorized as a lack of care. According to the student participants, teachers who lacked care did not, "care personally about the students," and, “ didn't know how us students feel." The eighth teacher practice and disposition was a teacher's failure to "push" them to learn content or a teacher's failure to motivate students played a role in not supporting their academic achievement. For the student participants in this study, the personality of a teacher and language barrier played a smaller role in not supporting African-American students' 
academic achievement. However, the student participants believed that when learning was not effective, both personality and language barrier played the biggest role in their academic unsuccessfulness. Student participants shared that the "thick accent" of teachers whose second language was English made it very difficult for students to understand the teacher. The eleventh teacher practice and disposition that the researcher found that did not support African-American students' academic achievement was unapproachability. In this study, student participants believed that an inability to approach a teacher most often happened when they felt the teacher was vague, not flexible, and/or not lenient.

The twelfth teacher practice and disposition that did not support student participants' academic achievement was racially profiling African-American students. The teacher practice and disposition of racially profiling African-American students and how it did not support student participants' academic achievement was also interconnected to power and respect. The conversation describing racially profiling African-American students began with:

Tommie: I want to say stereotypical teachers. I don't know how to say it without saying they're nonchalant because they stereotype. They've had these type of kids in the past before. They're not going to give that much effort to them because they already know what type of kid they are and what they're going to be. That's another thing I would say that you could put in there is that they have stereotypical... Alex: Profiling kids. 
Tommie: Yeah. They already know what type of student they're dealing with and what class they're dealing with and they know how they're going to move because of how the class is.

In this passage, the student participants were articulating that they believe some teachers have a racial bias towards African-American students. As a result, teachers racially profile and/or stereotype African-American students without taking time to get to know them. The students in focus group 1 continued to tease out this belief as they continued to talk:

Tommie: Say you have a Black male in your class and he don't do nothing. He's like I already know what type of kid he is so I'm not even going to put the effort into him, but maybe he just needs a little bit more motivation but they don't even know that because they already got it made in their head they had kids like that before so they already know what type of student they're going to be so they're going to let them do whatever they want because they have it made up in their mind. They didn't take the extra step to really get to know that person. He might be a Black male and he might be a thug to him or whatever but he actually is smart. He just needed extra umph and they didn't give it to him because he looks the way he looks and he acts the way he acts.

Elise: Or dresses the way he dresses.

Tommie: Yeah, and they're like I already know what type of student. When Tommie was probed about why she used the identity of a Black male for her example, when she had self-identified as a Black female, she responded with the following: 
Tommie: I mean anyone that gets judged the most is Black males and they have a lot of pressure so that's why I used them because they are the number one target. Everyone always targets them. Because if it was a White male, let's be real, they're going to try to get them to do something. I guess they'll be more cooperative than the Black male. That's why I used the Black male because they stereotype them the most just out of everybody.

When the researcher asked the other members of focus group 1 if they felt the same, they unanimously said, "yes." The concepts that focus group 1 communicated demonstrate that the student participants in this study had a clear understanding that their teachers at school were able to, and were actively, making educational decisions for and about African-American students based on stereotypes and bias that teachers held prior to developing a relationship with African-American students. The student participants in this study also communicated a clear understanding that teacher's profiling of students was based on the student's race and behavior, not necessarily the student's academic performance. Lastly, the student participants in this study also understood that schools and society "judge" and profile African-Americans based on their race and gender. Further commentary from focus group 1 focused on how the concept of power, the thirteenth teacher practice and disposition, played a significant role in not supporting the academic achievement of African-American students. In classrooms when learning was not effective, student participants in focus group 1 believed that teachers stopping instruction to address student misbehavior was an issue. Students in focus group 1 explained this power dynamic between teachers and students in the following passage: 
Jessie: I had just said that sometimes teachers just like to prove that they have the power. I mean, "I can write you up, so keep doing silly stuff."

Elise: They [teachers] always say that. That's they best story.

Jessie: Right. Like, "Do you want a referral?"

Elise: "I'm going to write you up." That's they best story.

Tommie: If we got the chance to write them up. Psssssh.

Jessie: Right, the Assistant Principal's list would phat [fat].

Tommie: They would be in stacks...Do you hear me? Piles of referrals. The disrespect.

The concepts of power that focus group 1 communicated demonstrate that the student participants understand that teachers have power over students. The student participants in this focus group also communicated a clear understanding that teachers were able to misuse or abuse their power to the detriment of students. As the student participants in this focus group continued talking, they also discussed how the concept of respect in schools is tied to power, which is different from the concept of respect in their homes. Focus group 1 continued their discussion with:

Elise: Disrespect is huge. I feel like because they feel like they're the adult and if we say something back it's like talking back, getting smart, having an attitude and I feel like we can feel how we want to feel. I mean our tone may be off a little but I'm like you the one that made us feel like this so we have every right to feel what we feel. We should be able to express that to you.

Researcher: Is that what the disrespect is?

Amanda: You can go ahead. 
Researcher: Oh. Sorry, I was going to say, with the disrespect. What is it that's the perceived disrespect?

Tommie: Their tone.

Amanda: Tone.

Elise: Tone.

Jessie: Tone.

Researcher: Tone of voice when they are talking to you?

Amanda: Sometimes they be saying slick stuff too. It's not just how they say it, it's what they say.

Tommie: Yes. It's like the little shots too.

Researcher: So when you say "slick stuff" and "shots" I know what you mean, but what do you mean?

Amanda: Like...umm.

Jessie: "I ain’t ya mama."

Elise: Derogatory. However you say that word. Comments like you know it's about you but they're not going to say it.

Amanda: They're not going to say your name.

Jessie: Shade.

Tommie: Oh yea. Shade. That's a big role in a lot teachers because seniors have senioritis I guess and our attendance is bad. Me personally, I can say my attendance has been terrible since freshman year but hey, I make good grades but teachers always tend to throw shade at students like that. I mean if you missed a lot of days that's on you. My thing is that's my personal privacy. That's my right 
to have my privacy on my attendance and everything and it's not okay for you to blurt that out in front of the class and think that I'm not going to feel some type of way when I'm one of the students that has bad attendance.

Researcher: Gotcha. The disrespect comes in the form when people are speaking to everyone in general but...

Elise: [Interrupts] You know they're talking about you.

Multiple: Yes.

Alex: It's like you're, they being challenged.

Researcher: So general statements but targeted information basically? Jessie: And then teachers expect like...Oh, I'm sorry.

Elise: Then if you go up to them, then they'll be like you might as well just say my name then they want to be like, "Oh, no. I'm not talking about you."

Jessie: "It was general."

Elise: "It was just a general comment to everybody." No, you were talking about me.

From this exchange during focus group 1, student participants felt that teachers spoke disrespectfully to students in coded language. (It should be noted that the descriptor "coded language" might be synonymous with the term "micro-aggression.") Students articulated the coded language of disrespect by using slang terminology. The slang terminology student participants used to describe the coded language of disrespect from teachers who did not support their academic achievement were, "tone," "saying slick stuff," "little shots," "I ain’t ya mama," and "shade." Student participants in this focus group believed that teachers used coded language intentionally to communicate with 
African-American students for several different purposes. First, they believed that teachers chose to use coded language in a passive-aggressive manner to avoid direct communication with African-American students. Second, students perceived their teachers used this passive-aggressive coded language to exert their power over them and as a way to extract automatic respect from students. Consequently, student participants believed that coded language received from teachers to African-American students was a sign of disrespect. Perceived disrespect, the fourteenth and final teacher practice and disposition identified, did not support African-American students' academic achievement. Instead perceived disrespect created conditions that could make AfricanAmerican students defensive towards their teacher. As cited in Jones and Nichols (2013): we recognize the paramount importance of "respect" for those who identify with and are descendants of African cultures. Teachers who disrespect African American children in the classroom will have done more irreparable harm to the relationship than they might have with children from other cultures. When the relationship between the teacher and the African American child shuts down so does the learning (p. 61).

When African-American students perceive disrespect from the teacher, the potential consequence is that not only does the learning process shut down, but the student does too. According to the students in this focus group, this shutting down process that happens as a result of disrespect is why they believed African-American preferred the instruction and learning at home compared to how they are taught at school. As further articulated in this passage: 
Jessie: I've had teachers like that. They want you to treat them how you treat your parents but I'm like mom does not talk to me like you talk to me at all. I don't know. Everybody's mom ain’t like mine. If I say mama, “Ma'am.” My mama says, "Ma'am," to me and you call me "little girl" or sometimes you all don't even be saying my name. So I'm not going to give you the respect I give my mom. It's not the same.

Elise: That's why I feel like it's more comfortable at home. 'Cause it goes back going to be at home, I love to be at home.

Tommie: Cause they really care about you. They wouldn't want to disrespect you, plus they your parents so they know how you are so they know the things that will get you upset, calm you down, how you move, what you like, and these teachers are just out of control sometimes.

In summation, student participants believed that teachers who racially profiled AfricanAmerican students and teachers who believed power should yield respect from students played a role in not supporting African-American students' academic achievement.

\section{Theme 7}

In this research study, the seventh and final theme to emerge from the data was that African-American high school seniors believe the instructional style of AfricanAmerican teachers align to African-American students' learning preferences. In this study, the student participants believed African-American teachers' instructional style was aligned to African-American students' learning preferences because they "personalize" and because they are "more current" with the African-American culture. 
The concept of "personalization" was illustrated within the discussion of focus group 2 when they said the following:

Rafael: People at home break it down more to you. You know they take their time explaining. They can relate it to real life situations in your family, instead of at school.

Tiffany: I agree with him.

Researcher: Okay.

Brandon: I agree too.

Porsche: Me too.

Researcher: Okay.

Porsche: But there are some teachers that, that's something that they do.

Rafael: Yeah.

Tiffany: Black teachers.

Brandon: They personalize. [Cross talk.]

Porsche: Yeah.

Porsche: Black teachers.

Researcher: Are you all saying the Black teachers do that?

Porsche: Yeah.

Rafael: Yeah.

Tiffany: Yeah.

Brandon: [Nods head in affirmative.]

In this conversation, student participants were able to draw a parallel connection between the instructional style within their African-American households and its similarities to the 
instructional style of their African-American teachers. The researcher interpreted "break it down more to you," "take their time explaining," "they can relate it to real life situation in your family," and "personalize" to be aligned to African-American students' learning preferences (theme 1) and instruction at home catering to their African-American culture and learning style (theme 3). The in vivo code "break it down more to you" aligned with the first theme in which African-American students' preferred learning one-on-one with the teacher. The in vivo code "take their time explaining" aligned with the third theme in which communal talk was very prevalent in the teaching and learning done within the homes and communities of African-American students. The in vivo code "they can relate it to real life situation in your family" aligned with the third theme in which culturally relevant content was also very prevalent in the teaching and learning done within the homes and communities of African-American students. Lastly, the in vivo code "personalize" aligned with the first theme in which African-American students' preferred learning where they could "give their own touch." The researcher interpreted the in vivo code "personalization" as a synonym for caters to.

In this study, the student participants believed African-American teachers' instructional style was aligned to African-American students' learning preferences because African-American teachers are "more current" with the African-American culture. While describing "More current with us," the student participants suggested that African-American teachers are more culturally responsive because they know how to relate to African-American students' culture. For example, one student participant, Alex, commented that teachers "may understand, maybe, what we're talking about in order to 
reach us individually." In contrast, he described other teachers who were not current with African-American students in the following way:

They're different because, I would say, they may not understand. So, they're coming from different families their self, so when we say certain things or do certain things then they're confused. They're looking at it like it's wrong, but really it's just how we are.

In this passage, Alex alludes to a perceived difference of cultural values and

understanding between teachers and their African-American students, which leads to classroom practices that do not support African-American students' learning preferences and culture. While answering questions in the one-on-one interviews, student participants acknowledged that teacher to student race played a factor in a teacher supporting AfricanAmerican students. For instance, one student participant, Elise, commented on how her same-race teacher supported African-American students when she said the following:

Well, Coach, he's Black. He's not even from here. So he always says-because if our principal walks in, we have our headphones in, we don't have to take them out in his class, because Mr...Mr... Coach is just kept it real with the principal, and he lets us listen to music in his class while we do our math. And he was just like, "I have to connect with y'all in order for this to go smooth." He said, "I don't want a boring class. I don't want us to just come in here and do bookwork and yadda yadda - “"He said, "I like cutting up with y'all, I like being funny, I like talking about life situations." I mean he brings basketball into his lessons. He tells his basketball players the same things he tells us.

In this passage, Elise describes how her African-American teacher bent the school's rule and allowed students to listen to music with their headphones in his classroom. In this personal anecdote, the student participant described how the African-American teacher modified the school's headphones rules within his classroom because he believed listening to music best supported his African-American students' academic achievement. In essence, the researcher interpreted the actions of this African-American teacher as adjusting the school's norms to tap into student's cultural backgrounds, through the use 
of music, so that he could connect with students ("connect with y'all") and to help the teaching and learning "go smooth." She also detailed how the African-American teacher "kept it real with the principal" when he was asked about knowingly violating the school's policy. The researcher interpreted the student's perception of the AfricanAmerican teacher's communication of "keeping it real" with the principal as a point of advocating on behalf of African-American students and their learning preferences within his classroom. Lastly, Elise also recalls how her African-American teacher expressed a desire to have a member-member relationship/interaction with his students in order to successfully teach them.

Allowing students to listen to music in class, advocating for the incorporation of music, and expressing the desire to have a member-member relationship with students is directly aligned to the Philosophical Aspects of Cultural Difference Framework for African-Americans. It should also be noted that Elise mentioned that the AfricanAmerican teacher is "not even from here," which leads the researcher to believe that the behaviors of this particular African-American teacher are cultural, rather than exclusive to this state or region of the country. Simply put, with the interpretation of in vivo code "more current with us" student participants in this study believed that their same-race teachers helped to support African-American students. Specifically, student participants in this study acknowledged that having African-American teachers helped in supporting African-American students academic achievement.

Along with acknowledging teacher to student race and the factor it played in supporting African-American students, student participants believed their same-race 
teachers held them to higher expectations compared to their different-race teachers. For example, student participant Amanda shared:

I feel like they expect more from the other students than when it comes to me...At first, it used to make me feel some type of way. Like, "That's all you think I can do is a low A?" At first, I didn't care. I was like, "I'll go ahead and get the low A. I've still got my A, though." Then I used to talk to my mom. My mom was like, "No, you have to be better than that." My math teacher now, he always tells our class is mostly Black, but it's a college class. He's like, "You guys have to be better than the pedestal, better than just the average." He made me actually want to do better than just the low A. I actually do better than a low A. My goal every time I do stuff is 100 percent.

In this passage, Amanda explains how "when it comes to me" her different-race teachers expect "a low A" from her but "they expect more from the other students." She goes further to detail how her African-American math teacher held her, and her Black peers to a higher expectations. The African-American teacher communicated high expectations to the African-American students by setting high goals when he told the students, "You guys have to be better than the pedestal," and "better than just the average." The researcher interpreted Amanda's anecdote, and similar comments from other student participants, about managing African-American teachers' high expectations as a "doubleconsciousness" that African-American students battle daily in U.S. public schools. Du Bois (1903/2008) defines double-consciousness as the, "sense of always looking at one's self through the eyes of others, of measuring one's soul by the tape of the world that looks on in amused contempt and pity" (p. 2). Amanda's comments express the burden of bearing two competing identities, one in which she pushes back on the negative stereotypes of African-Americans and low expectation of her different-race teachers, while still wanting to achieve academically to meet her same-race teacher's expectation, 
and her own, by doing better, "than just the low A. I actually do better than a low A. My goal every time I do stuff is 100 percent."

It is important to note that although African-American high school seniors believe the instructional style of African-American teachers align with African-American students' learning preferences, student participants never explicitly stated that differentrace teachers could not support African-American students. Rather, they described the challenges that African-American students experience with different-race teachers. For example, student participant Tiffany said the following:

Yeah, maybe just how can they make it to where it doesn't feel like they're being stereotypical? ...I don't know. They're just scared. It's just like they're walking on eggshells. They don't want to say anything, and they'll turn red if they say something that they think is going to offend us. It doesn't offend us. You can talk to us like how you would talk to your White students or friends or something.

She went on to further explain:

...If you're going to talk to your White students how you...I feel like they should just treat everybody equal. Like, treat the classroom like it would be a White...Like don't talk slang and stuff just because you see Black students in here. If you talk proper to a White class, then you can talk proper to us. I think they're just down when it comes to African-American students. I feel like they think they can just be looser maybe. I don't know. It's confusing. Like they walk on eggshells, but at the same time, they try to fit in maybe. Like they try to please us. But they don't want to slip or anything, but they try to be our friend maybe. They try to like...I don't know. It's weird.

Tiffany even provided a real life example of how to engage with those who are racially different without acting on stereotypes. She explained the following scenario as if she were a Black teacher to a room of White students:

Just be yourself. If I'm a teacher and I have a class of White people, I'm not about to teach them like, "Oh well today, we're going to be learning..." [Spoken mockingly, in a different voice volume and proper English voice after having sat up straight in her chair.] I'm going to talk like my normal self, because I have to sit with y'all for the whole school year. You know? I think that they should just be their selves, because we can notice them trying to be different just because 
we're a different color and they've heard a bunch of stereotypes. Not every Black person is the same. Of course, you do have loud people and stuff, but that's not just Black people. You have loud and angry White people too, or loud and angry Mexicans too. It's not just Black people.

Tommie described the difference in teacher to student race and the in vivo code

stereotype in a much similar way when she shared the following:

I feel like they should not teach by Hinds County Public Schools District, they should teach by the facts and actually urban things. Oh, they should also teach more urban things and more...I don't want to say it. I just feel like they should do more urban stuff.

After Tommie was asked to expand on what she meant by "urban," she went on to say:

I just think we're so used to learning from 'The Man' and that's what I meant by instead of...Instead of that I feel like we should have urban books so we can talk, all of us can know. Cause it can be for Hispanics, Indians, African-Americans, we only know the White-wash of things. We never know our history, like our history. They only give us what they want us to know about our history, but we don't know everything about our history. I think that teachers should take that into consideration when they teach us, because they know. I don't think they understand where we're coming from but they know where we've been. You know? So they should take consideration in some things on their tone and what they teach when it comes to us, like what they teach. And how they say it, the tone.

The two students explicitly mentioned teacher-student race relations and the in vivo code "stereotype" were used most frequently. However, the researcher interpreted both Tiffany and Tommie's comments about different-race teachers racially "stereotyping” AfricanAmerican students as aligning to African-American students managing low expectations from their different-race teachers. As discussed in the literature review, teacher expectations impact student learning (Kuklinski \& Weinstein, 2001). Kuklinski and Weinstein (2001) claim that, “Teachers form expectations about children's future performance. Expectations are communicated to children through differences in teacher behavior, particularly toward high versus low achievers" (p. 1555). Both Tiffany and 
Tommie mentioned "we know" and "we can tell" which translates to the students' ability to distinguish the different-race teachers' expectations of them through a difference in the teachers' behavior towards African-American students who they perceive to be low achievers. As a result, Merton's (1948) "self-fulfilling prophesy" is actualized when African-American students act or behave in ways that meet those expectations.

\section{Summary}

Chapter 4 began with an introduction of the participants' profiles and demographics, an overview, and provides an analysis and interpretation of data collected in this study. This chapter answers the overarching research question: How do AfricanAmerican high school seniors perceive culturally responsive teaching in their classrooms? Through the process of data collection and analysis, themes emerged and were extracted, triangulated, and organized in alignment with seven themes. The thematic underpinnings within the data are most relevant to the research question and the three purposes. In summary, how African-American high school seniors perceive culturally responsive teaching in their classrooms has far-reaching implications for teachers, administrators, district-level, state-level, and federal-level educators. Chapter 5 will provide a discussion of major findings, implications, and recommendations for the findings outlined in this study. 


\section{CHAPTER 5}

\section{DISCUSSION}

\section{Introduction}

The intent of this dissertation study was to examine how African-American high school seniors perceive culturally responsive teaching in their classrooms and to identify which culturally responsive learning preferences needed to be replicated in order to increase their academic success. Specifically, the overarching research question for this study was: How do African-American high school seniors perceive culturally responsive teaching in their classrooms? Culturally responsive learning preferences in this study, particularly those rooted in African-American cultural and learning norms, were defined as the nine dimensions derived from West African beliefs, values, and traditions (Boykin, 1983). The nine dimensions of Afrocultural learning orientation are spirituality, harmony, movement (music), affect, verve, communalism, expressive individualism, social time perspective, and orality (Boykin, 1983). This dissertation study focused only on three Afrocultural orientations-- communalism, verve, and music (movement) because educators are already familiar with them and their observable incorporation into classroom instruction. Data obtained from participants' responses to the Demographic Survey (Appendix D), the one-on-one open-ended interview questions (Appendix HInterview Protocol), the Participant Profile Sheet (Appendix I), and the focus group interview (Appendix J- Focus Group Protocol) were analyzed for the research question and each of the three purposes in the study, and the results were presented in Chapter 4. 
This final chapter will present a summary of the study, discuss key conclusions drawn from the data presented in Chapter 4, and will describe its relevance to existing literature. Recommendations and implications for future research and practice will also be addressed.

\section{Summary of the Study}

In this summary, an outline of how this dissertation study was structured will be reviewed to provide context for the findings. The intent of this dissertation study was to answer the overarching research question: How do African-American high school seniors perceive culturally responsive teaching in their classrooms? Specifically, this dissertation study served three purposes. First, the purpose of this study was to highlight culturally responsive teaching practices that African-American students perceived as contributing to their academic success. Second, the purpose was to help identify if a cultural divergence exists between the instructional practices in U.S. public schools and the learning preferences previously established by African-American students within their homes and communities and if it has any bearing on their academic achievement. Thirdly, the purpose of this study was to offer valuable insight on how to replicate African-American high school students' learning preferences to increase their academic achievement.

Chapter 1 opens with the current state of African-American students' academic achievement and outcomes in the U.S. public-schools system. Current trend data of African-American students' academic achievement and outcomes reveals that despite gains, the academic performance of African-American students in public schools has not measurably increased over the last twenty years (McFarland et al., 2017). The National Center for Education Statistics (NCES) data from 2017 reveals persistent 
underachievement for African-American students compared to their White peers in critical areas such as reading performance, math performance, adjusted cohort graduation rate (ACGR), status dropout rate, and immediate college enrollment rate (McFarland et al., 2017). In the ongoing discussion of persistent academic underachievement of African-American students, some scholars have advocated for the inclusion of more culturally responsive teaching practices that examine the impact of culture on the cognitive performance of African-American students. This study examines an area that has received little attention in professional literature, African-American students' voices about their perceptions of culturally responsive teaching in classrooms (Howard, 2001, 2002; Irving \& Hudley, 2008; Ladson-Billings, 1994; Serpell, Boykin, Madhere, \& Nasim, 2006).

Chapter 2 reviews literature that recounts the plight of African-Americans in the U.S. educational systems, discusses federal and state efforts to address academic achievement gaps for African-American students, and reviews current literature on culturally responsive teaching. Past research revealed that the use of the Afrocultural learning orientations communalism, verve, and music, has produced academic successfulness for African-American students (Carter, Hawkins, \& Natesan, 2008; Cole \& Boykin, 2008; Hurley, Allen, \& Boykin, 2009). Chapter 3 focuses on the methodological approach used for this research study. This study was conducted in a large urban public-school district in the southeastern region of the United States. The research study was restricted to one site, Jackson High School because it met the following criteria:

1. A high school with $9^{\text {th }}-12^{\text {th }}$ grade only. 
2. A high school with a student racial demographic of at least $70-100 \%$ AfricanAmerican students.

3. A high school with a high percentage $(>25 \%)$ of African-American instructional staff members.

A non-probabilistic, purposeful sampling, specifically maximal variation sampling, was used to recruit the nine student participants from their responses to the Demographic Survey (Appendix D). This heterogeneous approach was preferred because heterogeneity of sampling "helps provide evidence that findings are not solely the preserve a particular group, time or place, which can help establish whether a theory developed within one particular context applies to other contexts" (Robinson, 2014, p. 27). Heterogeneous sampling was achieved in this dissertation study in several ways. First, the researcher selected a high school with a student racial demographic of at least $70-100 \%$ AfricanAmerican students. This allowed for greater diversity within the African-American racial group. Secondly, the researcher selected participants with different learning orientations. This allowed for greater diversity within students' learning preferences. Thirdly, the researcher selected participants from different academic programs, which allowed for diversity of student interest. Lastly, the researchers selected participants by choosing fifty percent male and fifty percent female to achieve gender diversity. Once selected to participate, the researcher used open-ended questions to conduct semi-structured one-onone interviews and focus group interviews to collect data in a phenomenological research design.

The data from the one-on-one interviews and focus groups with the student participants were triangulated to identify emerging themes and descriptions of African- 
American high school seniors' shared experiences. It also served to corroborate findings about their perceptions of culturally responsive teaching in their classrooms. The audiorecorded interviews and audio-and video-recorded focus groups were transcribed using Rev Audio - an online service from Rev.com. After transcriptions were received and were reviewed by participants and the researcher for accuracy, the researcher used inductive reasoning to code, analyze and interpret data using Creswell's six-step process (Creswell, 2014). The researcher hand-coded the data to identify emerging themes and patterns and then transferred the data into electronic graphic organizers. This assisted with additional coding for further analysis of the data. Additional themes emerged from this process and were then used to answer the research question and address the three purposes outlined in this dissertation study.

Chapter 4 focuses on reporting the connection between the thematic underpinnings identified in the data to one of the three corresponding purposes posed in this dissertation study. Finally, Chapter 5 provides a discussion of the four major findings for this dissertation study. First, African-American high school seniors perceived their African-American teachers were culturally responsive towards African-American students because their instructional style aligned more closely to African-American students' learning preferences. Second, African-American high school seniors perceived teaching and learning in U.S. public school classrooms to be divergent to AfricanAmerican students' culture and Afrocultural learning orientations. Thirdly, AfricanAmerican high school seniors prefer the utilization of Afrocultural learning orientations in teaching and learning, and believe they contribute to their academic success. Lastly, African-American high school seniors had a preference for teaching and learning 
environments that prioritized member-member relationships and provided vervistic and communalism learning opportunities.

\section{Discussion of Findings}

\section{Research Question}

How do African-American high school seniors perceive culturally responsive teaching in their classrooms?

In this research study, the first finding to emerge from the data was AfricanAmerican high school seniors perceived their African-American teachers were culturally responsive towards African-American students because their instructional style aligned more closely to African-American students' learning preferences. This finding result indicates that African-American high school seniors perceive U.S. public school teachers, who are overwhelmingly White (U.S. Department of Education, 2016), to be racially biased towards African-American students. This finding speaks to the need to recruit more African-American educators in the workforce (Ethridge, 1979; Hawkins, 1994; Holmes, 1990; Irvine, 1988), push for more professional development on culturally responsive pedagogy (Fiedler et al., 2008; Ford \& Kea, 2009, Kozleski, 2011; Phuntsog, 2001), address teachers' low expectations of African-American students and its impact on student achievement (Kuklinski \& Weinstein, 2001; Ramaley, 2014; Reeve \& Jung, 2006, Tucker \& Herman, 2002), and African-American students' sense of belonging in schools (Taliaferro \& DuCuir-Gunby, 2008). Additionally, in discussing pedagogical excellence, education scholar Gloria Ladson-Billings (1995) argued for the need to link schooling and culture. In particular, she acknowledged that culturally relevant teaching "requires that students maintain some cultural integrity as well as academic excellence" 
and that "culturally relevant teachers utilize students' culture as a vehicle for learning" (pp. 160-161).

It is not surprising that African-American high school seniors perceived their African-American teachers to be culturally responsive to African-American students because their instructional style aligned more closely to African-American students' learning preference. The perception that African-American teachers were culturally responsive to African-American students was prevalent throughout themes 2, 3, 5, and 7 . This finding is important in the advocating for the recruitment of more African-American educators in the teaching workforce and African-American students' sense of belonging in schools. Many African-American teachers have had similar schooling experiences as their African-American students, thus they might understand and may have experienced a similar cultural divergence between practices in U.S. public schools and their homes and/or communities. It should also be noted that African-American teachers have often experienced similar racial biases in U.S. public school, and/or from White colleagues, and others, thus they empathize with African-American students and can advocate for, or help African-American students navigate racial insensitivities African-American students may experience in the educational setting.

In this research study, the second finding to emerge from the data is that AfricanAmerican high school seniors perceive teaching and learning in U.S. public school classrooms to be divergent from African-American students' culture and Afrocultural learning orientations. The findings resulting from the research question confirm that U.S. public schools still operate by catering to the dominant culture and appealing to mainstream ideals, values, and pedagogies, like they always have. This finding speaks to 
the industrialization of U.S. public schools in which students are taught and rewarded for their observance of mainstream precepts (Labaree, 2012; Milner \& Lomotey, 2013) while suppressing their own culture in efforts to assimilate to mainstream practices (Boykin, Miller \& Tyler, 2005; Cole \& Boykin, 2008). Teaching and rewarding students for their observance of mainstream precepts speaks to theme 4 because student participants distinguished teaching and learning in schools as parallel to the axiology, epistemology, and logic of European and Euro-American culture. Furthermore, themes 1, 2, and 4 further confirmed that student participants believed a cultural divergence existed between teaching and learning in public schools compared to that within their homes and communities because it paralleled to the axiology, epistemology, and logic of African and African-American culture.

Just as Boykin $(1986,1995)$ and Marryshow et al. (2005) suggest, this study too, found that African-American students underachievement may be the result of rejecting mainstream culture modes, rather than a disdain for academics. Quite possibly, AfricanAmerican students have repeatedly performed far worse than their White peers because assessments are aligned to mainstream learning orientations, ideals, values, and pedagogies. As this study's framework suggests, culture cannot be dismissed in the human setting (Jones \& Nichols, 2013). Therefore, U.S. public schools seeking to increase academic achievement for African-American students need to: 1) acknowledge that some African-American students have developed Afrocultural learning orientations within their homes and communities; 2) acknowledge that U.S. public schools overwhelmingly operate on mainstream values that are regarded as "normal"; 3 ) acknowledge that U.S. public schools are largely void of, and devalue, Afrocultural 
learning orientations; and 4) seek to use African-American students' Afrocultural learning orientations in the service of attaining new competencies.

If U.S. public schools want to increase academic achievement for AfricanAmerican students, then educators must examine student demographics yearly, and adjust the classroom's pedagogy, culture, climate, and instruction to ensure that it corresponds to the axiology, epistemology, and logic of their students in the classroom. Hence, it is not surprising African-American high school seniors felt a cultural divergence between their culture and their teachers' because U.S. public school educators are overwhelmingly White (U.S. Department of Education, 2016) and U.S. public school students are majority students of color (U.S. Department of Education, 2016). Furthermore, if educators and U.S. public schools want to overcome this cultural divergence African-American students feel, educators must adjust their instruction and practice to meet the needs of AfricanAmerican student learners. The cultural divergence African-American students felt in this study spoke to themes 3, 4, and 6 because African-American high school seniors characterized the cultural divergence they experience between the teaching and learning within their homes and communities compared to that within U.S. public schools.

The third finding to emerge from the data in this dissertation study was that African-American high school seniors prefer a utilization of Afrocultural learning orientations in teaching and learning, and believe they contribute to their academic success. This finding indicates that African-American high school seniors have preferences for teaching and learning that are linked to their own Afrocultural orientations and values. This finding extends the findings of Marryshow et al. (2005) and Howard (2002) because older African-American youth also show a clear preference for 
Afrocultural learning orientations over mainstream orientations. Marryshow et al.'s (2005) study included African-American adolescents (ages 10-12), Howard's (2002) participants included African-American students ranging from second to eighth grades were studied, whereas in this study African-American high school seniors (ages 17 and 18) were studied. Like other prior research (Marryshow et al., 2005; Sankofa et al., 2005), the findings of this study also challenge Ogbu (1986) and Fordham (1999) because African-American students do not reject academic achievement but reject mainstream cultural modes.

As a result, U.S. public schools seeking to increase academic achievement for African-American students need to incorporate Afrocultural learning orientations into their instruction and practice. Educators seeking to increase academic achievement for African-American students can be more inclusive by drawing real world connections from in-school learning to out of school living (Gay, 2013). They can also provide African-American students with multiple opportunities to utilize their Afrocultural learning orientation in order to remain in contact with their primary cultural heritage. For example, rather than punishing and/or subliminally forcing African-American students to suppress their Afrocultural learning orientations, educators should encourage, and support, African-American students to use their Afrocultural learning orientations to help them learn, retain content, and continue their development.

The last finding in this dissertation study was that African-American high school seniors had a preference for teaching and learning environments that prioritized membermember relationships and provided vervistic and communal learning opportunities. The research finding for African-American high school seniors' preferring member-member 
relationships fits into previous research finding that places supreme value on the social interconnectedness with others (Albury, 1993; Boykin, 1986; Boykin, Lilja, \& Tyler, 2004; Jones \& Nichols, 2013). African-American high school seniors' high propensity for teaching and learning environments that prioritize vervistic and communal learning opportunities confirms prior research that links students' identity to engagement (Nasir, 2006; Wortham, 2006) and perceived social support from teachers (Reeve \& Jung, 2006). Educators seeking to increase academic achievement for African-American students need to transmit Afrocultural learning orientations and values into their pedagogical practices and the school's culture. Incorporating member-member relationships, vervistic and communalism learning opportunities into the pedagogical practices and the school's culture capitalizes on African-American students' cultural assets to boost their performance. This fourth and final finding of the study spoke to themes 5 and 6 because African-American seniors were able to distinguish which teacher practices and dispositions supported, and did not support, their academic achievement. These four findings have far-reaching implications for policy, practice and recommendations for future research.

\section{Implications for Policy}

Based on the findings of this dissertation study and its alignment with prior research on African-Americans in the U.S. educational system, the achievement gap, culturally responsive pedagogy, and Afrocultural learning orientations, lawmakers and educational leaders should consider three implications for policy. First, policy aimed at increasing the recruitment and retention of African-American teacher candidates and teachers is warranted and necessary. Secondly, policy aimed to create and implement 
yearly, mandatory professional development on culturally responsive teaching practices for all pre-service, practicing, and veteran teachers should be considered. Thirdly, policy aimed at adopting more culturally relevant curriculum and instruction should be considered as well.

Policy focused on increasing the recruitment and retention of African-American teacher candidates and teachers is especially critical given the makeup of U.S. public schools. Currently, nearly half of all U.S. public school students are non-White and their teachers are predominately White (U.S. Department of Education, 2016). The ethnic, racial, and cultural difference between students and their teachers has negative consequences for student learning outcomes (Grissom \& Redding, 2016; U.S. Department of Education, 2016). As found in this dissertation study, African-American high school seniors perceived teaching and learning in U.S. public school classrooms to be divergent to African-American students' culture and Afrocultural learning orientations. This study also found that African-American high school seniors perceived their African-American teachers were culturally responsive towards African-American students because their instructional style aligned more closely to African-American students' learning preferences. Therefore, policy aimed to recruit and retain AfricanAmerican teacher candidates and teachers is a viable solution because African-American educators' have valuable teaching experiences and because all students are able to gain positive academic outcomes from having African-American educators.

The presence of more African-American teachers adds a wealth of knowledge to classrooms, schools, and districts because African-American teachers have valuable experiences in working with African-American students. Many African-American 
teachers are knowledgeable, have had extensive experience with, or may exhibit similar, or identical cultural assets as their African-American students. As described by the student participants in this study, African-American educators were perceived to be culturally responsive towards African-American students because their instructional style aligned more closely with African-American students' learning preferences. Therefore, it is reasonable to suggest that African-American educators use their cultural assets such as Afrocultural learning orientations and their cultural backgrounds in their classroom instruction and practices. It also is reasonable to suggest the instructional style of African-American educators resonates with, and may be familiar to, African-American students resulting in culturally responsive instruction for African-American students. This level of experience that African-American educators have had with African-American students should not be taken lightly, but rather highly valued in the public school setting.

African-American educators' knowledge of African-American students also helps in providing White colleagues with counter-deficit images, addressing biases, and deficit thinking of African-American students. The presence of more African-American educators can also improve the schooling experience of African-American students because African-American teachers have higher expectations for African-American students (Grissom \& Redding, 2016), refer African-American students to gifted programs at significantly higher rate (Grissom \& Redding, 2016), help confront racism in schools (Villegas \& Irvine, 2010), serve as advocates, role models, mentors and cultural interpreters for African-American students (Egalite, Kisida, \& Winters, 2015), and build trusting relationships with African-American students (Villegas \& Irvine, 2010). Lastly, the presence of more African-American educators also improves the schooling 
experience of non-African-American students because non-African-American students are able to: 1) counter negative racial stereotypes of African-Americans, 2) gain exposure to non-dominant, non-mainstream cultures and learning norms, and 3) gain exposure to African-Americans as role models and in positions of power.

As found in this dissertation study, African-American high school seniors perceived teaching and learning in U.S. public school classrooms to be divergent from African-American students' culture and Afrocultural learning orientations. Based on this finding, the second policy aim should focus attention on creating and implementing yearly, mandatory culturally responsive teaching professional development for all preservice, practicing, and veteran teachers. Policy focused on the creation and implementation of yearly, mandatory professional development on culturally responsive teaching practices is a viable solution for two reasons. First, because it addresses insights that African-American students have previously shared. Second, it provides all practitioners with well-defined culturally responsive teaching practices African-American students believe contribute to their academic success.

As stated in prior research, African-American student voices have been limited or excluded in much of academic research (Howard, 2001, 2002; Irving \& Hudley, 2008; Ladson-Billings, 1994; Serpell, Boykin, Madhere, \& Nasim, 2006). However, in this dissertation research study, African-American student voices have been amplified through the use of qualitative interviews, focus groups, and in vivo coding. This research study draws on African-American students' educational literacy as they share their lived experiences in U.S. public school classrooms. In this study, African-American student participants clearly outlined and defined culturally responsive teaching practices that 
contributed to, and hindered, their academic success. Therefore, policy focused on the creation and implementation of yearly, mandatory professional development on culturally responsive teaching practices would support a rationale of educators continuously seeking out student voices that are underrepresented to guide and construct meaning of culturally responsive teaching as experienced by African-American students. In continuously seeking out students' voices, educators can further their understanding of how to best support underrepresented student groups, such as African-Americans, by capturing their voices as it pertains to their educational experiences in public schools by using student feedback through student surveys, student focus groups, and by soliciting parents and communities feedback yearly.

While it is true culturally responsive teaching is necessary, arguably the most significant factor impeding its implementation is educators' knowledge (Fiedler et al., 2008; Ford \& Kea, 2009, Phuntsog, 2001). Therefore, policy focused on the creation and implementation of yearly, mandatory professional development on culturally responsive teaching practices would provide all practitioners with well-defined culturally responsive teaching practices African-American students believe contribute to their academic success. As described by the student participants in this study, culturally responsive teaching of African-American high school students can be defined with five components. According to study participants, the five components that define culturally responsive teaching of African-American high school students include: 1) incorporating Afrocultural learning orientations (specifically vervistic and communal learning opportunities with an emphasis on communal talk) in teaching and learning; 2) building member-member relationships with students; 3) teaching culturally relevant content; 4) acknowledging 
student's racial identities; and 5) challenging mainstream practices in school. Vervistic learning opportunities, communal learning opportunities, building member-member relationships, culturally relevant content, and acknowledging student's racial identities were prevalent throughout themes 1, 2, 3, 5, and 7 of this research study. Importantly, challenging mainstream practices in school was prevalent throughout themes 4 and 6 .

Policy aimed at creating and implementing yearly, mandatory professional development on culturally responsive teaching, with respect to the five well-defined components from this study, benefit African-American students in several ways. First, their Afrocultural learning orientations, which were previously excluded, will be affirmed in a classroom setting. Secondly, African-American students will gain a greater sense of belonging in U.S. public schools by seeing themselves, and other African-Americans, reflected in the content, curriculum, and instruction in their classrooms and learning environment. Thirdly, and most importantly, the academic success and engagement of African-American students should increase because African-American students have provided educators with a clear roadmap of how to best service African-American students.

In using the five defined components of culturally responsive teaching of AfricanAmerican high school students as outlined in this study, non-African-American students are also able to benefit academically. First, non-African-American students will gain another set of valuable competencies and skillsets. When educators begin incorporating culturally responsive teaching of African-American students into instruction, nonAfrican-American students can learn from and develop cultural assets from cultures other than their own. Secondly, when educators begin incorporating culturally responsive 
teaching of African-American students into instruction, non-African-American students will be exposed to counter-narratives to stereotypes of African-Americans. Lastly, mandatory professional development on culturally responsive teaching would help lessen the cultural misunderstandings between teachers and African-American students (Ford \& Kea, 2009), help educators adapt their instruction for students who are not learning (Ladson-Billings, 2009), and address educators' deficit thinking (Ford et al., 2001) by facilitating a growth mind-set (Dweck, 2010).

The third and final policy aim should be the adoption of more culturally relevant curriculum and instruction. This dissertation study found that African-American high school seniors prefer the utilization of Afrocultural learning orientations in teaching and learning, and believe they contribute to their academic success. Importantly, LadsonBillings (1995) affirmed that academic success is the hallmark and foundation for culturally relevant pedagogy. Based on the findings of this study, policy aimed at adopting more culturally relevant curriculum would push educators to challenge their own beliefs, misconceptions, and stereotypes. Additionally, taking and supporting such an approach also can encourage educators to find multiple opportunities to connect the curriculum to the lives and learning orientations of their African-American students. Adopting more culturally relevant curriculum would also be more inclusive of underrepresented groups such as African-Americans, and other people of color. As Gay (2001) explains:

There are several recurrent trends in how formal school curricula deal with ethnic diversity that culturally responsive teachers need to correct. Among them are avoiding controversial issues such as racism, historical atrocities, powerlessness, and hegemony; focusing on the accomplishments of the same few high-profile individuals repeatedly and ignoring the actions of groups; giving proportionally more attention to African-Americans than other groups of color; 
decontextualizing women, their issues, and their actions from their race and ethnicity, ignoring poverty; and emphasizing factual information while minimizing other kinds of knowledge (such as values, attitudes, feelings, experiences, and ethics). (p. 108)

As Gay (2001) suggested, adopting more culturally relevant curriculum provides better representation of cultural diversity. Acknowledging a wider range of contributions that are more inclusive of people of color would help mitigate cultural appropriation and marginalization of accomplishments of people of color as well as provide students with learning opportunities that are more meaningful and representative of themselves and their life experiences. Adopting more culturally relevant instruction improves the schooling experience of all students and helps make schooling much more equitable. Also, culturally relevant instruction improves the schooling experience of AfricanAmerican students because it increases African-American students' sense of belonging and their perceived social support from teachers (see Taliaferro \& DeCuir-Gunby, 2008; Reeve \& Jang, 2006, Wentzel, 1998). Most notably, the adoption of more culturally relevant instruction would alleviate the institutional pressures put on African-American students to suppress their Afrocultural learning orientation to assimilate to mainstream practices used in U.S. public schools (Boykin, Miller \& Tyler, 2005; Cole \& Boykin, 2008).

\section{Implications for Practice}

Based on the findings of this study and its alignment with prior research, districts and schools seeking to bridge policy, practice, and increase the academic achievement of African-American high school students should consider four key implications for practice. The four implications for practice are grounded in two findings from this research study. In the second findings of this study, African-American high school 
seniors perceived teaching and learning in U.S. public school classrooms to be divergent to African-American students' culture and Afrocultural learning orientations. In the fourth finding of this study, African-American high school seniors had a preference for teaching and learning environments that prioritized member-member relationships and provided vervistic and communal learning opportunities. As a result, the four implications for practice were informed by these two major findings.

First, in classroom settings, educators need to acknowledge that AfricanAmerican students have cultural assets that can be leveraged to enhance their academic performance. As cited in the literature review and findings, African-American students have well-developed cultural value systems, understandings, and repertoire of practices that have been developed, refined and transformed through their prolonged participation in their cultural communities (Boykin, 1983; Gutierrez \& Rogoff, 2003; Jones \& Nichols, 2013). The Afrocultural learning orientations and inclinations of African-American students are deeply rooted, dating as far back as their African cultural heritage (Hurley, Boykin, \& Allen, 2005). Therefore, educators' acknowledging, embracing and rewarding a wider range of cultural values and behaviors in classrooms can positively impact efforts to address African-American students' academic achievement and sense of belonging.

Secondly, in classroom settings, educators need to incorporate Afrocultural learning orientations into their instructional practice to provide African-American students with opportunities to leverage cultural competencies learned outside of school in school. When educators incorporate Afrocultural learning orientations into their instructional practice, African-American students' cultural assets and competencies are validated. Validation of cultural values and differences as assets rather than personal 
shortcomings help African-American students feel as though they belong, challenges deficit views of non-dominant culture, and creates more equitable schooling environments (Dumas, 2014; Holme, Diem, \& Welton, 2014; Taliaferro \& DeCuirGunby, 2008). Incorporating Afrocultural learning orientations into instructional practices gives African-American students an opportunity to experience classroom success without having to suppress their own Afrocultural practices and behaviors. There are a variety of ways educators can incorporate Afrocultural learning orientations into their instructional practice. Using the findings of this study and its alignment with prior research, educators can incorporate Afrocultural learning orientations into their practice by doing the following:

- In classroom settings, provide African-American students with multiple opportunities to access academic content in a communal, or collaborative sharing, environment with peers and their instructor.

- In classroom settings, provide African-American students with multiple opportunities to access academic content through vervistic movement and expression independently, with peers, and/or with their instructor.

- Consider revising classroom and building policies that punish or reprimand sharing and interdependence.

- Recognize that member-member axiological focus can be actualized as a fictive kinship relationship among African-American students, parents, and others as a cultural norm and value, not necessarily a biological relationship.

- In all interactions, recognize respect as a central value for African-Americans. 
- Recognize that African-American students are not monolithic; therefore, Afrocultural learning orientations are characteristically manifested in various ways for African-American students.

Thirdly, educators need to give thoughtful consideration to the content taught and the instructional methods used to teach African-American students. Thoughtful consideration of content taught means that educators must intentionally present contributions and comprehensive portrayals of African-Americans', and other underrepresented racial groups', contributions and histories (Gay, 2013). Also, educators must acknowledge the current ways in which institutional racism and oppression operates in systemic and systematic ways to the disadvantage of African-American students. For instance, Dumas (2014) found that schools were rife for Black suffering given that these institutions were understood by his participants "as a site of persistent problems for Black students" (p. 19). Additionally, attention needs to be given to the instructional methods used to teach African-American students. Educators need to make intentional connections from taught content to the real world experiences, or "out of school living" of AfricanAmerican students (Gay, 2013).

Lastly, educators must continuously evaluate classroom and building policies, advocating for, and actively disrupting racial disparities. Educators can advocate for, and actively disrupt racial disparities by acknowledging and challenging systemic and systematic institutional oppression by looking for cultural incongruences that complicate the learning experience for African-American students. One of the most revealing ways to continue disrupting racial disparities in U.S. public schools is by monitoring all data tracking systems within a school and/or district by isolating data according to racial 
demographic. Racial demographic trends and reoccurring patterns in data often reveal educational disparities and helps to identify areas for improvement and growth. Although these are reasonable ideas, they are not directly informed by this research study. However, by intentionally seeking out African-American students' opinions, feedback, and evaluations of teaching and learning in classrooms like the focus of this research study, educators might be able to find similar racial demographic trends and reoccurring patterns in school-wide data in order to make progress in closing the achievement gap. In sum, based on the findings of this study and its alignment with prior research, districts and schools seeking to bridge policy, practice, and increase the academic achievement of African-American high school students, the typology of an invested teacher might be a viable solution. As described by the student participants in this study, an invested teacher played the biggest role in supporting African-American high school students' academic achievement. According to study participants and the findings of this research study, the typology of an invested teacher is one who: 1) is willing to extend themselves to students beyond their expected job duties; 2) motivates and inspires students; 3) is responsive to the varying cultural needs of students; 4) seeks to build personal relationships with students; 5) is approachable; 6) is optimistic; 7) acknowledges students' racial identities; and 8) cares about students' lives inside and outside the classroom. Therefore, it is reasonable to suggest that the practices and disposition of an invested teacher would also meet the necessary disposition of the personnel needed to bridge the culturally responsive policies to practice in classrooms in order to increase the academic achievement of African-American high school students. 


\section{Recommendations for Future Research}

There are a few areas of interest that need to be considered for future research. A limitation of this research study was selecting only nine participants that attended the same high school, Jackson High School in Hinds County Public Schools District. Although the results from qualitative studies tend not to be generalizable (Creswell, 2014), future research should extend this study to other high schools within Hinds County Public Schools District as well as include more participants. Jackson High School is a unique outlier within Hinds County Public Schools District. Jackson High School has a student body racial demographic of at least $70-100 \%$ African-American students and a high percentage ( $>25 \%)$ of African-American instructional staff members. In this regard, African-American students at other area high schools with a lower percentage of AfricanAmerican instructional staff members might have drastically different schooling experiences. Also, African-American students at other area high schools with a lower percentage of African-American students might have drastically different schooling experiences. It is also recommended that another study seeking to replicate the methods in this study should have more African-American student participants. In this regard, the extent to which African-American student voices have been excluded in research about academic achievement would be extended. Also, having more African-American student participants might provide educators with a more comprehensive understanding of how to enhance academic achievement of African-American students.

To properly frame this study, Jones and Nichols' (2013) Philosophical Aspects of Cultural Difference framework was employed. According to Jones and Nichols' (2013), "Tens of thousands years ago, ancestors of African, African-American, Latino, and Arab 
descent thrived in geographical regions where there was an abundance of food" (p. 42). Also, according to Jones and Nichols (2013) because these racial and ethnic groups shared similar natural instinct to survive and thrive, they also share similar worldviews, axiology, epistemology, and logic. A second study seeking to replicate the methods in this study should investigate Hispanic, Latino, and Arab students. It is suggested to replicate this study with Hispanic, Latino, and Arab students because according to Jones and Nichols (2013) Philosophical Aspects of Cultural Difference framework, AfricanAmericans, Africans, Hispanics, Latinos, and Arabs share the same ethnic worldview, while European/Euro American, Asian/Asian American/Polynesian, and Native American have different ethnic worldviews. Therefore, the same or similar research questions should also be helpful in understanding how Hispanic, Latino, and Arab students perceive culturally responsive teaching in the classroom. This would equip educators who are involved with presenting culturally responsive teaching professional developments with additional knowledge about how to support other underrepresented racial groups in U.S. public schools. This information would greatly enhance teacher training to teach diverse student populations.

This present dissertation study is useful in advancing prior research on AfricanAmericans students, the achievement gap, culturally responsive pedagogy, and Afrocultural learning orientations. However, more research is needed to fully understand the dynamic between culturally relevant curriculum and assessment. If educators are moving towards incorporating more culturally responsive teaching and curriculum, there should also be a move towards replacing culturally biased assessments. If not, it would be reasonable to suggest that culturally responsive teaching and curriculum does a disservice 
to students because assessments are not culturally responsive. In essence, educators would be teaching students culturally rich content and encouraging students to utilize non-mainstream learning norms, which in turn would not be on, and could not be used during assessments. Possible next steps in advancing this research might also include: 1) determining if a disconnect exists between curriculum, instruction, assessments, and professional development; 2) evaluating how might assessments be changed to be more culturally responsive; and 3) determining if an achievement gap truly exists or if the use of culturally biased testing is an invalid assessment of students' knowledge.

\section{Conclusion}

In an era in which the closing the achievement gap between African-American and White students remains a priority, recent attention has been given to culturally responsive teaching of African-American students in an effort to boost their academic success. Within this research, however, it is unclear the degree to which AfricanAmerican culture divergences from the culture within U.S. public schools and the role that divergence plays in African-American students' academic achievement. Although arguments on the complex interplay between school expectations and African-American students' culture have been debated since desegregation, little changes have been made to the structure of how U.S. public schools operate (Labaree, 2012). Undergirding these debates is the responsibility of educators to teach all students equitably.

To better understand the lived experience of African-American high school students and their perceptions of culturally responsive teaching in their classrooms, a study was conducted in a large urban public-school district in the southeastern region of the United States. Findings suggested that teaching in classrooms is not culturally 
responsive and that teaching and learning in U.S. public schools is misaligned with African-American students' culture and preferred learning orientations. These results support findings from previous studies examining African-American students perceptions of culturally responsive teaching (Howard 2001, 2002; Ladson-Billings, 2009) and Afrocultural learning orientations (Marryshow et al., 2005; Sankofa et al., 2005).

In conclusion, the responsibility to increase the academic achievement of AfricanAmerican students lies within the power of lawmakers, educational leaders, school districts, schools, educators, and families. But ultimately, education practitioners in the classroom have an opportunity everyday to make the biggest impact in the lives of our African-American students. In order to serve all students and close the achievement gap, culturally responsive teaching of African-American students and Afrocultural learning orientations must be at the forefront of future research and practice. 


\section{REFERENCES}

African American Spirituals. (n.d.) In Library of Congress. Retrieved August 15, 2017, from https://www.loc.gov/item/ihas.200197495/

Albury, A. (1993). Social orientations, learning conditions and learning outcomes among low-income Black and White grade school children. Unpublished doctoral dissertation, Howard University, Washington, DC.

Allen, B., \& Boykin, A. W. (1991). The influence of contextual factors on AfroAmerican and Euro-American children's performance: Effects of movement opportunity and music. International Journal of Psychology, 26(1), 373-387.

American College Testing. (2016). The ACT Profile Report- National 2016. Retrieved from

https://www.act.org/content/dam/act/unsecured/documents/P 99999999 N S N N $\underline{00 \_ \text {ACT-GCPR_National.pdf }}$

Annamma, S. A., Anyon, Y., Joseph, N.M., Farrar, J., Greer, E., Downing, B., \& Simmons, J. (2016). Black girls and school discipline: The complexities of being overrepresented and understudied. Urban Education, 22(1), 1-32.

Arum, R., \& LaFree, G. (2008). Educational attainment, teacher/student ratios and adult incarceration risk among U.S. birth cohorts since 1910. Sociology of Education, $81,387-421$. 
Bailey, C. T., \& Boykin, A. W. (2001). The role of task variability and home contextual factors in the academic performance and task motivation of African American elementary school children. Journal of Negro Education, 70(1-2), 84-95.

Blake, J.J., Butler, B.R., Lewis, C.W., \& Darensbourg, A. (2011). Unmasking the inequitable discipline experiences of urban Black girls: Implications for urban educational stakeholders. Urban Review, 43(1), 90-106.

Boykin, A.W. (1983). The academic performance of Afro-American children. In J. Spence (Ed.), Achievement and achievement motives (pp. 324-337). San Francisco, CA: Freeman.

Boykin, A.W. (1986). The triple quandary and the schooling of Afro-American children. In U. Neisser (Ed.), The school achievement of minority children (p. 57-92). Hillsdale, NJ: Erlbaum.

Boykin, A.W. (1995). Culture matters in the psychosocial experiences of African Americans: Some conceptual, process, and practical considerations. Paper presented at the annual meeting of the American Psychological Association, New York.

Boykin, A.W., Albury, A., Tyler, K.M., Hurley, E.A., Bailey, C.T., \& Miller, O.A. (2004). Culture-based perceptions of academic achievement among low-income elementary students. Cultural Diversity and Ethnic Minority Psychology, 11(4), 339-350.

Boykin, A. W., \& Allen, B. A. (1988). Rhythmic movement facilitation of learning in working-class Afro-American children. The Journal of Genetic Psychology, 149, $335-347$. 
Boykin, A. W., \& Allen, B. A. (2003). Cultural integrity and schooling outcomes of African American schoolchildren from low-income backgrounds. In P. Pufall \& R. Undsworth (Eds.), Childhood revisited. New Brunswick, NJ: Rutgers University Press.

Boykin, A.W., \& Bailey, C. (2000). The role of cultural factors in school relevant cognitive functioning: Synthesis of findings on cultural contexts, cultural orientations and individual differences (Report 42). Washington, DC: Howard University and Johns Hopkins University, Center for Research on the Education of Students Placed At Risk.

Boykin, A. W., \& Cunningham, R. (2001). The effects of movement expressiveness in story content and learning context on the analogical reasoning performance of African American children. Journal of Negro Education, 70(1-2), 72-83.

Boykin, A.W., Lilja, A.J., \& Tyler, K.M. (2004). The influence of communal vs. individual learning context on the academic performance in social studies of grade 4-5 African-Americans. Learning Environments Research, 7(3), 227-244.

Boykin, A.W., Coleman, S.T., Lilja, A.J., \& Tyler, K.M. (2004). Building on children's cultural assets in simulated classroom performance environments (Research Report No. 68). Retrieved from Center for Research on the Education of Students Placed At Risk website: http://files.eric.ed.gov/fulltext/ED484523.pdf

Boykin, A.W., Miller, O.A., \& Tyler, K.M. (2005). In search of cultural themes and their expressions in the dynamics of classroom life. Urban Education, 40(5), 521-549.

Boykin, A.W., \& Mungai, M. (1997). The effect of movement/music expressiveness ontask and off-task contexts on the prose recall of low-African American and 
European American children. Paper presented at the annual meeting of the American Educational Research Association, Chicago.

Boykin, A.W., \& Toms, F.D. (1985). Black child socialization: A cultural framework. In H. P. McAdoo \& J.L. McAdoo (Eds.), Black children: Social, educational, and parental environments (pp. 33-51). Newbury Park, CA: Sage.

Breinin, C. (1981). Too many suspensions? Why not "magnetize" instead? BTF Provocator, p. 11.

Brown v. Board of Education, 350 U.S. 483 (1954).

Carter, N.P., Hawkins, T.N., \& Natesan, P. (2008). The relationship between verve and the academic achievement of African American students in reading and mathematics in an urban middle school. Educational Foundations, 22(1-2), 29-46.

Carter, N.P., \& Larke, P.J. (2003). Examining INTASC standards through the lens of multicultural education: Meeting the needs of underserved students. In N. Carter (Ed.), Convergences or divergence: Alignment of standards, assessment and issues of diversity (pp. 55-70). Washington, DC: American Association of Colleges for Teacher Education.

Cole, J.M. (2000). The effects of music type, movement opportunity, and affect induction on the cognitive task performance and mood ratings of African American school children. Unpublished doctoral dissertation, Howard University, Washington, DC.

Cole, J.M., \& Boykin, A.W. (2008). Examining culturally structured learning environments with different types of music-linked movement opportunity. Journal of Black Psychology, 34(3), 331-335. 
Coleman, J.S., Campell, E.Q., Hobson, C.J., McPartland, J., Mood, A.M., Weinfeld, F.D., \& York, R.L. (1966) Equality of educational opportunity. Washington D.C.: U.S. Government Printing Office.

College Board. (2017). Trends in College Pricing 2017. Retrieved from https://trends.collegeboard.org/sites/default/files/2017-trends-in-collegepricing_1.pdf

Constantine, M.G. (2007). Racial microaggressions against African American clients in cross-racial counseling relationships. Journal of Counseling Psychology, 54(1), 116.

Cook, D.A., \& Dixson, A.D. (2013). Writing critical race theory and method: A composite counterstory on the experiences of Black teachers in New Orleans post-Katrina. International Journal of Qualitative Studies in Education, 26(10), $1238-1258$.

Crenshaw, K., Ocen, P., \& Nanda, J. (2015). Black girls matter: Pushed out, overpoliced and underprotected. African American Policy Forum Center for Intersectionality and Social Policy Studies. Retrieved from https://static1.squarespace.com/static/53f20d90e4b0b80451158d8c/t/54d2d37ce4 b024b41443b0ba/1423102844010/BlackGirlsMatterReport.pdf

Creswell, J.W. (2013). Qualitative inquiry and research design: Choosing among five approaches ( $3^{\text {rd }}$ ed.). Thousand Oaks, CA: Sage.

Creswell, J. W. (2014). Research design: Qualitative, quantitative, and mixed methods approaches. Thousand Oaks, CA: SAGE Publications Ltd. 
Creswell, J.W. (2015). Educational research: Planning, conducting, and evaluating quantitative and Qualitative research ( $5^{\text {th }}$ ed.). Upper Saddle River, NJ: Merrill.

Deming, D.J., \& Figlio, D. (2016). Accountability in US education: Applying lessons from K-12 experience to higher education. The Journal of Economic Perspectives, $30(3), 33-55$.

Deweck, C.S. (2010). Mind-sets and equitable education. Principal Leadership, 10(5), 26-29.

Du Bois, W.E.B. (2008). The souls of Black folk. Retrieved from https://www.gutenberg.org/files/408/408-h/408-h.htm (Original work published 1903)

Duhaime, L. (2013). 1740 Slave code of South Carolina. Retrieved from http://www.duhaime.org/LawMuseum/LawArticle-1494/1740$\underline{\text { Slave-Code-of-South-Carolina.aspx }}$

Dumas, M.J. (2014). Losing an arm: Schooling as a site of Black suffering. Race, Ethnicity, and Education, 17(1), 1-29.

Egalite, A., Kisida, B., \& Winters, M. A. (2015). Representation in the classroom: The effect of own-race teachers on student achievement. Economics of Education Review, 45, 44-52.

Epstein, R., Blake, J.J., \& Gonzalez, T. (2017). Girlhood interrupted: The erasure of Black girls' childhood. Georgetown Law Center on Poverty and Inequality. Retrieved from http://www.law.georgetown.edu/academics/centersinstitutes/poverty-inequality/upload/girlhood-interrupted.pdf 
Ethridge, S.B. (1979). Impact of the 1954 Brown v. Topeka Board of Education decision on Black educators. Negro Educational Review, 30(4), 217-232.

Fiedler, C.R., Chiang, B., Van Haren, B., Jorgensen, J., Halberg, S., \& Bereson, L. (2008). Culturally responsive practices in schools: A checklist to address disproportionality in special education. Teaching Exceptional Children, 40(5), 5259.

Ford, D.Y., Grantham, T.C., \& Whiting, G.W. (2008). Another look at the achievement gap learning from the experience of gifted Black students. Urban Education, 43(2), 216-239.

Ford, D.Y., Harris, J.J., Tyson, C.A., \& Frazier Trotman, M. (2001). Beyond deficit thinking: Providing access for gifted African American students. Roeper Review, 24(2), 52-58.

Ford, D.Y., \& Kea, C.D. (2009). Creating culturally responsive instruction: For students' and teachers' sakes. Focus on Exceptional Children, 41(9), 1-16.

Fordham, S. (1988). Racelessness as a strategy in Black students' school success: Pragmatic strategy or pyrrhic victory? Harvard Educational Review, 58, 54-84.

Fordham, S. (1999). Dissin' "the standard": Ebonics as guerrilla warfare at Capital High. Anthropology \& Education Quarterly, 30(3), 272-293.

Garibaldi, A.M. (1979). Affective contributions of cooperative and group goal structures. Journal of Educational Psychology, 71, 788-794.

Garibaldi, A.M. (1992). Educating and motivating African American males to succeed. Journal of Negro Education, 61, 4-11. 
Gay, G. (2000). Culturally responsive teaching. Theory, research, and practice. New York, NY: Teachers College Press.

Gay, G. (2013). Teaching to and through cultural diversity. The Ontario Institute for Studies in Education of the University of Toronto Curriculum Inquiry, 43(1), 4870.

Grissom, J. A., \& Redding, C. (2016). Discretion and disproportionality: Explaining the underrepresentation of high-achieving students of color in gifted programs. AERA, 2(1), 1-25.

Guest, G., MacQueen, K.M., \& Namey, E.E. (2012). Applied thematic analysis. Thousand Oaks, CA: Sage.

Gutierrez, K.D., \& Rogoff, B. (2003). Cultural ways of learning: Individual traits or repertoires of practice. Educational Researcher, 32(5), 19-25.

Guttentag, M. (1972). Negro-European differences in children's movement. Perceptual and Motor Skills, 35, 435-436.

Hale-Benson, J. E. (1986). African American children: Their roots, culture, and learning style $\left(2^{\text {nd }}\right.$ ed.). Baltimore, MD: The John Hopkins University.

Harris, J.J., Brown, E.L., Ford, D.Y., \& Richardson, J.W. (2004). African Americans and multicultural education: A proposed remedy for disproportionate special education placement and underinclusion in gifted education. Education and Urban Society, 36(2), 304-341.

Hawkins, B.D. (1994). Casualties: Losses among Black educators were high after Brown. Black Issues in Higher Education, 10(23), 26-31.

Hennink, M. M. (2014). Focus group discussions. New York: Oxford University Press. 
Holme, J., Diem, S., \& Welton, A. (2014). Suburban school districts and demographic change: The technical, normative, and political dimensions of response. Education Administration Quarterly, 50(1), 34-66.

Holmes, B.J. (1990). New strategies are needed to produce minority teachers. Elmhurst, IL: North Central Regional Education Laboratory.

Howard, T.C. (2001). Telling their side of the story: African-American students' perceptions of culturally relevant teaching. The Urban Review, 33(2), 131-149.

Howard, T.C. (2002). Hearing footsteps in the dark: African American students' descriptions of effective school learning environments. Journal for the Education of Students Placed At-Risk, 7(4), 425-444.

Hurley, E.A. (1999). The interaction of culture with math achievement and group processes among African American and European American students. Paper presented at the annual meeting of the American Educational Research Association (AERA). New Orleans, LA.

Hurley, E.A., Allen, B.A., \& Boykin, A.W. (2009). Culture and the interaction of student ethnicity with reward structure in group learning. Cognition and Instruction, 27(2), 121-164.

Hurley, E.A., Boykin, A.W., \& Allen, B.A. (2005). Communal versus individual learning of a math-estimation task: African American children and the culture of learning contexts. The Journal of Psychology, 139(6), 513-527.

Hurst, D., Tan, A., Meek, A., \& Sellers, J. (2003). Overview and Inventory of State Education Reforms: 1990 to 2000 (NCES 2003). U.S. Department of Education, 
National Center for Education Statistics. Washington, DC. Retrieved July 13, 2017 from https://nces.ed.gov/pubs2003/2003020.pdf

Irvine, J.J. (1988). An analysis of the problem of disappearing Black educators. The Elementary School Journal, 88(5), 503-513.

Irvine, M.A., \& Hudley, C. (2008). Cultural identification and academic achievement among African American males. Journal of Advanced Academics, 19(4), 676-698.

Jagers, R. (1987). Communal orientation and cooperative learning among African American college students. Unpublished doctoral dissertation, Howard University, Washington, DC.

Johnson, D.W., \& Johnson, R. (1985). The internal dynamics of cooperative learning groups. In R. Slavin, S. Kagan, R.H. Lazarowitz, C. Webb, \& R. Schmuck, (Eds.), Learning to cooperate: Cooperating to learn (pp. 103-123). New York, NY:

Plenum Press.

Jones, B. A., \& Nichols, E. J. (2013). Cultural competence in America's schools leadership, engagement and understanding. Charlotte, NC: Information Age Publishing, Inc.

Kena, G., Hussar, W., McFarland, J., de Brey, C., Musu-Gillette, L., Wang, X., Zhang, J., Rathbun, A., Wilkinson-Flicker, S., Diliberti, M., Barmer, A., Bullock Mann, F., and Dulop Velez, E. (2016). The Condition of Education 2016 (NCES 2016-144). U.S. Department of Education, National Center for Education Statistics. Washington, DC. Retrieved [July 6, 2017] from http://nces.edu.gov/pubsearch. Kozleski, E. B., (2011). Culturally responsive teaching matters. Tempe, AZ: Equity Alliance at ASU. 
Krueger, R.A., \& Casey, M.A. (2009). Focus groups: A practical guide for applied research $\left(4^{\text {th }}\right.$ ed.). Thousand Oaks, CA: Sage.

Kuklinski, M.R., \& Weinstein, R.S. (2001). Classroom and developmental differences in a path model of teacher expectancy effects. Child Development, 72(5), 15541578 .

Kunjufu, J. (1988). To be popular or smart: The Black peer group. Chicago, IL: African American Images.

Labaree, D.F. (2012). Someone has to fail. Harvard University Press.

Ladson-Billings, G. (1994). The dreamkeepers. San Francisco, CA: Jossey-Bass Publishing Co.

Ladson-Billings, G. (1995). But that's just good teaching! The case for culturally relevant pedagogy. Theory Into Practice, 34(3), 159-165.

Ladson-Billings, G. (2001). Crossing over to Canaan: The journey of new teachers in diverse classrooms. San Francisco, CA: Jossey-Bass.

Ladson-Billings, G. (2009). The dreamkeepers: Successful teachers of African American children $\left(2^{\text {nd }}\right.$ ed.). San Francisco, CA: Jossey-Bass.

Lincoln, Y.S., \& Guba, E.G. (1985). Narrative inquiry. Newbury Park, CA: Sage.

Littlebear, R. (2009). Understanding American Indian culture. In L.S. Warner \& G. E. Gipp (Eds.) Tradition and culture in the millennium: Tribal colleges and universities (pp. 89-92). Charlotte, NC: Information Age Publishing, Inc.

Lucker, G.W., Rosenfield, D., Sikes, J., \& Aronson, E. (1976). Performance in the interdependent classroom: A field study. American Educational Research Journal, 13, 115-123. 
Marryshow, D. (1992). The impact of learning orientation on African American children's attitude toward high achievers. Unpublished master's thesis, Howard University, Washington, DC.

Marryshow, D., Hurley, E.A., Allen, B.A., Tyler, K.M., \& Boykin, A.W. (2005). Impact of learning orientation on African American children's attitudes toward highachieving peers. The American Journal of Psychology, 118(4), 603-618.

Mason, J. (1993). Cultural competence self-assessment questionnaire. Portland, OR: Portland State University, Multicultural Initiative Project.

McFarland, J., Hussar, B., de Brey, C., Snyder, T., Wang, X., Wilkinson-Flicker, S., Gebrekristos, S., Zhang, J., Rathbun, A., Barmer, A., Bullock Mann, F., and Hinz, S. (2017). The Condition of Education 2017 (NCES 2017-144). U.S. Department of Education. Washington, DC: National Center for Education Statistics. Retrieved from https://nces.ed.gov/pubs2017/2017144.pdf .

McLaurin v. Oklahoma State Regents, 339 U.S. 637 (1950).

Merriam, S.B., \& Tisdell, E.J. (2015). Qualitative research: A guide to design and implementation. John Wiley \& Sons.

Merton, R.K. (1948). The self-fulfilling prophecy. Antioch Review, 8, 193-210.

Miles, M.B., Huberman, A.M., \& Saldaña, J. (2014). Qualitative data analysis: A methods sourcebook ( $3^{\text {rd }}$ ed.). London: SAGE.

Milner, H.R. (2006). The promise of Black teachers' success with Black students. Educational Foundations, 20, 89-104.

Milner, H.R. (2007). Race, culture, and researcher positionality: Working through dangers seen, unseen, and unforeseen. Educational Researcher, 36(7), 388-400. 
Milner, H.R., \& Lomotey, K. (2013) Handbook of Urban Education. Retrieved from https://books.google.com/books?id=IeAkAgAAQBAJ\&printsec=frontcover\&sour

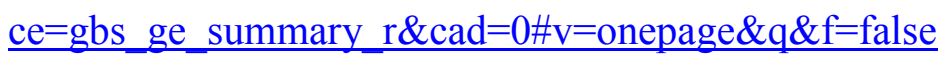

Missouri ex rel. Gaines v. Canada, 305 U.S. 637 (1938).

Morgan, H. (1990). Assessment of students' behavioral interactions during on-task classroom activities. Perceptual and Motor Skills, 70, 46-73.

Morris, E.W., \& Perry, B.L. (2016). The punishment gap: School suspension and racial disparities in achievement. Social Problems, 63(1), 68-86.

Moustakas, C. (1994). Phenomenological research methods. Thousand Oaks, CA: Sage. Muhammad, S. (2003). How to teach math to Black students. Chicago, IL: African American Images.

Murrell, P.C. (2002). African-centered pedagogy: Developing school of achievement for African American children. New York: State University of New York Press.

Nasir, N. (2006, August.) But when is an identity: Challenges and tensions in operationalizing identity in the study of learning. Paper presented at the meeting of the International Society for Cultural and Activity Research, Seville, Spain.

National Center for Educational Statistics. (n.d.) In National Center for Educational Statistics. Retrieved June 26, 2017, from https://nces.ed.gov/about/

Neal, L.I., Davis McCray, A., \& Webb-Johnson, G. (2001). Teachers' reactions to African American students' movement styles. Intervention in School and Clinic, $36,168-174$. 
Neal, L.I., Davis McCray, A., Webb-Johnson, G., \& Bridgest, S.T. (2003). The effect of African American movement styles on teachers' perceptions and reactions. The Journal of Special Education, 33(1), p. 49-57.

Nichols, E. J. (1986). Cultural foundations for teaching Black children. In O. M. T. Rattery (Ed.), Teaching mathematics: Volume 1, culture, motivation, history and classroom management (pp. 1-7). Washington, DC: Institute for Independent Education.

Nichols, E. J. (1995). Cultural competence in leadership. Washington, DC: Nichols \& Associates.

Ogbu, J.U. (1986). The consequences of the American caste-system. In U. Neiser (Ed.), The school achievement of minority children: New perspectives. Hillsdale, NJ: Erlbaum.

Ogbu, J.U. (1990). Minority status and literacy in comparative perspective. Daedalus, 119(2), 141-168.

Ogbu, J.U., \& Simons, H.D. (1998). Voluntary and involuntary minorities: A culturalecological theory of school performance with implications for education. Anthropology \& Education Quarterly, 29, 21-55.

Patton, M.Q. (2002). Qualitative research and evaluation methods ( $3^{\text {rd }}$ ed.). Thousand Oaks, CA: Sage.

Phuntsog, N. (2001). Culturally responsive teaching: What do selected United States elementary school teachers think? Intercultural Education, 12(1), 51-64.

Plessy v. Ferguson, 163 U.S. 537 (1896). 
Ramaley, J.A. (2014). Educating for a changing world: The importance of an equity mindset. Metropolitan Universities, 25(3), 5-15.

Reeve, J., \& Jang, H. (2006). What teachers say and do to support students' autonomy during a learning activity. Journal of Education Psychology, 98(1), 209-218.

Reynolds, G. A., Thernstrom, A., Gaziano, T., Heriot, G., Kirsanow, P. N., Melendez, A. D., Taylor, A.L., \& Yaki, M. (2009) Minorities in special education. Washington D.C.: U.S. Government Printing Office.

Roberts v. City of Boston, 59 Mass. (5 Cush.) 198 (1850).

Robinson, O. (2014). Sampling in interview-based qualitative research: A theoretical and practical guide. Qualitative Research in Psychology, 11(1), 25-41.

Robinson, R. (2000). The debt: What America owes to Blacks. New York, NY: Dutton Books.

Rogoff, B. (1993). Children's guided participatory appropriation in sociocultural activity. In R. H. Wozniak \& K. W. Fischer (Eds.) Development in context: Acting and thinking in specific environments. Hillsdale, NJ: Lawrence Erlbaum.

Sambol-Tosco, K. (2004). The slave experience: education, arts \& culture historical overview. Retrieved from http://www.pbs.org/wnet/slavery/experience/education/history.html

Sankofa, B.M., Hurley, E.A., Allen, B.A., \& Boykin, A.W. (2005). Cultural expression Black students' attitude toward high achievers. The Journal of Psychology, 139(3), 247-259.

Scholastic Aptitude Test. (2016). 2016 College-Bound Seniors Total Group Profile Report. Retrieved from https://reports.collegeboard.org/pdf/total-group-2016.pdf 
Serpell, Z.N., Boykin, A.W., Madhere, S., \& Nasim, A. (2006). The significance of contextual factors in African American students' transfer of learning. Journal of Black Psychology, 32(4), 418-441.

Serpell, Z., \& Cole, J. (2008). Move to learn: Enhancing story recall among urban African American children. Journal of Urban Learning, Teaching, and Research, $4,73-85$.

Slavin, R.E. (1983). When does cooperative learning increase student achievement? Psychological Bulletin, 94, 429-445.

Span, C. M. (2005). Learning in spite of opposition: African Americans and their history of education exclusion in antebellum America. The Politics of Curricular Change: Race, Hegemony, and Power in Education, 131, 26-53.

Spence, J. (1985). Achievement American style: The rewards and costs of individualism. American Psychologist, 40(12), 1285-1295.

Staton-Salazar, R. (1997). A social capital framework for understanding the socialization of racial minority children and youths. Harvard Educational Review, 67(1), 1-41.

Sweatt v. Painter, 339 U.S. 629 (1950).

Taliaferro, J. D., \& DeCuir-Gunby, J. (2008). African American educators' perspectives on the advanced placement opportunity gap. The Urban Review, 40(2), 164-185.

Tatum, B.D. (1997). “Why are all the Black kids sitting together in the cafeteria?": And other conversations about race. New York, NY: Basic Books.

Toldson, I.A., \& Lewis, C.W. (2012). Challenge the status quo: Academic success among school-age African American males. Washington, D.C.: Congressional Black Caucus Foundation, Inc. 
Tucker, C. M., \& Herman, K. C. (2002). Using culturally sensitive theories and research to meet the academic needs of low-income African American children, American Psychologist, 57, 762-773.

U. S. Department of Education. The National Commission on Excellence in Education. (1983). A nation at risk: The imperative for educational reform. Retrieved from http://files.eric.ed.gov/fulltext/ED226006.pdf

U. S. Department of Education. Every Student Succeeds Act (ESSA). Retrieved May 20, 2017 from https://www.ed.gov/essa? $\mathrm{src}=\mathrm{rn}$

U.S. Department of Education, Office of Planning, Evaluation and Policy Development, Policy and Program Studies Service. (2016). The state of racial diversity in the educator workforce. Retrieved from https://www2.ed.gov/rschstat/eval/highered/racial-diversity/state-racial-diversityworkforce.pdf

U.S. Department of Education, Office of Special Education and Rehabilitative Services, Office of Special Education Programs. (2016). $38^{\text {th }}$ Annual Report to Congress on the Implementation of the Individuals with Disabilities Education Act, 2016, Washington, D.C. 2016.

Vasquez, C. (2005). The perceptions of intervention assistance team members on the impact of the intervention assistance teams (IATs) in reducing special education referrals in urban elementary schools. Unpublished doctoral dissertation, Texas A\&M University, College Station, Texas.

Villegas, A. M., \& Irvine, J. J. (2010). Diversifying the teaching force: An examination of major arguments. The Urban Review, 42, 175-192. 
Weller, C. E., Ajinkya, J., \& Farrell, J. (2012). The state of communities of color in the U.S. economy: Still feeling the pain three years into the recovery. Washington, D.C.:Center for American Progress.

Welton, A.D., \& Martinez, M.A. (2014). Coloring the college pathway: A more culturally responsive approach to college readiness and access for students of color in secondary schools. The Urban Review, 46, 197-223.

Wentzel, K.R. (1998). Social relationships and motivation in middle school: The role of parents, teachers, and peers. Journal of Educational Psychology, 90(2), 202-209. Wertsch, J. V. (1991). Voices of the mind: A sociocultural approach to mediated action. Cambridge, MA: Harvard University Press.

Wortham, S. (2006). Learning identity: The joint emergence of social identification and academic learning. New York, NY: Cambridge University Press.

Yin, R.K. (2014). Case study research: Design and methods. Thousand Oaks, CA: Sage Publications. 


\section{APPENDIX A}

\section{Email to Principal}

Dear Principal

My name is Whitney M. Stewart. I am an Ed.D. doctoral candidate in Educational

Leadership and Organizational Development with a superintendent concentration at the University of Louisville. I am currently writing a dissertation entitled: Student Voices: African-American High School Seniors' Perception of Culturally Responsive Teaching.

The purpose of this qualitative phenomenological study is to gain understanding of African-American students' perceptions of culturally responsive teaching in their classrooms. By gathering the insights of African-American students, educational leaders within the district may adopt more culturally responsive teaching practices that help positively impact the academic success of African-American high school students.

I am requesting permission to conduct my research at your school. Specifically, I am interested in inviting your African-American students who are seniors to participate in my dissertation research study. I will inform the students selected for the research that their participation will help me understand how African-American students learn best and their perceptions of the teachers who have helped them learn best.

I would like to submit a recruitment email for your approval asking seniors to complete a short demographic survey in order to identify study participants. Please see the email attachment of the electronic demographic survey that will be used to select study participants. As a study participant, students will be asked to complete a one-on-one individual interview and participate in a small focus group with other student interviewees.

You, your staff, and your students will not be placed at any risk. All interviews will remain confidential. Any names of person, school sites, or districts used in the study will be pseudonyms. As compensation for the student participants' time, an afternoon snack of pizza will be provided to the participants at the conclusion of the focus group.

At the conclusion of the study, I would be more than happy to share the findings of my research with any interested parties. In the event you need additional information, my email address is wmstew01@1ouisville.edu and my phone number is (502)-643-8317. The Advisor for this study is Dr. Mary Brydon-Miller. Her email address is mary.brydonmiller@louisville.edu and her phone number is (502)-852-6887. I look forward to your response and I thank you for your time.

With Highest Regards,

Whitney M. Stewart, Ed.D. Candidate

Educational Leadership and Organizational Development 
University of Louisville

Mary Brydon-Miller, Ph.D.

Professor, Educational Leadership, Evaluation, and Organizational Development

ELOD Ph.D. Program Director

College of Education and Human Development

University of Louisville 


\section{APPENDIX B}

\section{Principal Script}

Prompt: Teachers, a graduate student researcher will be conducting her dissertation study research within our school building with our senior students. The graduate student researcher's name is Whitney M. Stewart from the University of Louisville. Her dissertation aims to better understand and capture African-American students' voices on their perceptions about teaching that help them learn best. All seniors will be emailed a link to a short 7-question demographic survey via our One Call Now system to their district provided email. Please encourage and allot time for seniors to complete the short survey in your class. The demographic survey is voluntary and results will be used to identify student participants for further research. Please read the following prompt below to your students.

\section{Teacher Prompt:}

"Seniors, you are invited to complete a short 8-question demographic survey online to assist a graduate student with her doctoral research. The demographic survey is completely voluntary. Please check your district assigned email address to access a link to the demographic survey. If you need help accessing your district assigned email address, please let me know and I can help you login. You will be given access to the Internet and in class time to complete the demographic survey if you choose to participate. Please complete the demographic survey by [Date]." 


\section{APPENDIX C}

\section{Student Recruitment Email}

Dear Assistant Principal,

Below you will find the email I would like shared with the seniors for my research.

Hi seniors,

The purpose of this email is to request your assistance with my dissertation research study designed to better understand and capture African-American students' voices on their perceptions about teaching that help them learn best. This research will contribute to the scholarship regarding teaching African-American high school students within the school district so that we, as educators, are in a better position to serve students and by extension, enhance learning. As a study participant, students will be asked to complete a one-on-one individual interview and participate in a small focus group with other student interviewees.

To participate, please cut and paste the link below into your web browser and complete a short 7-question demographic survey by [Date].

\section{https://goo.gl/forms/nCkeODIXkflCzQ263}

I am hopeful that you will agree to participate in this unique and exciting research opportunity. Please do not hesitate to contact the principal investigator at (502)-852-6887 Mary.brydon-miller@louisville.edu or Whitney M. Stewart at (502)-643-8317 or at whitney.stewart@louisville.edu if you have questions or concerns.

With Highest Regards,

Mary Brydon-Miller, Ph.D.

Professor, Educational Leadership, Evaluation, and Organizational Development

ELOD Ph.D. Program Director

College of Education and Human Development

University of Louisville

Whitney M. Stewart, Ed.D. Candidate

Educational Leadership and Organizational Development

University of Louisville 


\section{APPENDIX D}

\section{Demographic Survey}

Please respond to the following set of questions. You will notice many of the questions have multiple options. For those questions, please select the option(s) you feel are applicable to you and please check the "Not listed" option if you feel the options provided do not adequately represent your identity or identities.

1. What is your age? (Please enter in numeric digits.)

2. What is your race/ethnicity? (Circle response.)
a. American Indian or Alaska Native
b. Asian
c. Native Hawaiian or Pacific Islander
d. Black or African-American
e. Hispanic or Latino/a
f. Two or More Races
g. White
h. Not listed.
i. I prefer not to answer

3. Have you ever lived outside of the United States?
a. Yes
b. No

4. Please circle all the academic programs that you are involved with:
a. Advanced Placement (AP)
b. Honors
c. College Prep
d. Montessori
e. Technology and innovation
f. Law and government
g. Nursing
h. Pre-Med
i. Veterinary
j. Dental
k. Business
1. Sports Marketing
m. Pharmacy
n. Not listed
o. None of the above

5. How you would describe how you learn best? (Circle only one response.) 
a. I prefer to learn from teachers who use independent work to motivate students to learn.

For example, most assignments are completed individually and showcase what I know.

b. I prefer to learn from teachers who use friendly competition to motivate students to learn.

For example, most assignments are completed with incentives awards when I score high.

c. I prefer to learn from teachers who use a community-focus where everyone helps and works together to motivate students to learn.

For example, I am expected to share and work other students to complete most assignments.

d. I prefer to learn from teachers who use a variety of teaching methods to motivate students to learn.

For example, I am expected to multitask between multiple assignments and tasks at the same time to complete most assignments.

e. I prefer to learn from teachers who use music, rhythm, and movement to motivate students to learn.

For example, most assignments are completed with performance gestures, catchy phrases, and/or beat making to showcase what I know.

6. Would you be willing to participate in an individual, one-on-one interview and a small focus group interview with a researcher to help researchers understand the characteristics and classroom practices of teachers from whom you learn the most?

a. Yes

b. No

7. If you responded, "Yes," you would be willing to participate in an individual, one-on-one interview and a small focus group interview with a researcher to help researchers understand the characteristics and classroom practices of teachers from whom you learn the most. Please type your legal first and last name so you can be contacted. 
APPENDIX E

\section{Parental/Guardian Consent Form}

Project Title:

\section{STUDENT VOICES: AFRICAN AMERICAN HIGH SCHOOL SENIORS' PERCEPTION OF CULTURALLY RESPONSIVE TEACHING}

Principal Investigator:

Mary Brydon-Miller, Ph.D.

College of Education and Human Development

University of Louisville

1905 South $1^{\text {st }}$ Street

Louisville, KY 40292

Mary.brydon-miller@,1ouisville.edu

Investigator(s) name \& address:

Whitney M. Stewart

University of Louisville

1905 South $1^{\text {st }}$ Street

Louisville, KY 40292

Wmstew01@1ouisville.edu

Site(s) where study is to be conducted:

Phone number for subjects to call for questions: Dr. Mary Brydon-Miller 502-852-6887

and/or Whitney M. Stewart 502-643-8317

\section{Introduction and Background Information}

Your child is invited to participate in a research study. The study is being conducted by Dr. Brydon-Miller and Whitney M. Stewart. The study is sponsored by the University of Louisville, Department of Leadership, Evaluation, and Organizational Development. The study will take place at their high school. Approximately 8-10 subjects will be invited to participate.

\section{Purpose}

The purpose of this study is to understand and capture African-American students' voices on their perceptions about teaching that help them learn best.

\section{Procedures}


In this study, your child will be asked to participate in a one-on-one individual interview, complete a participant profile sheet after their individual interview, and participate in a small focus group with other students. The individual interview should take approximately 20-40 minutes. The participant profile sheet should take 5 minutes to complete. The focus group should take approximately 30-90 minutes. During the individual interview and focus group, your child will be asked questions that help the researcher to better understand the characteristics and classroom practices of teachers from whom African-American students learn from best. The interviews will be audio recorded. Your child may decline to answer any questions that make him/her feel uncomfortable.

\section{Potential Risks}

There are no foreseeable risks other than possible discomfort in answering personal questions.

\section{Benefits}

The possible benefits of this study include contributions to educational research regarding teaching African-American high school students within the school district so that we, as educators, are in a better position to serve students and by extension, enhance learning.

\section{Payment}

Your child will not be compensated for his/her time or inconveniences while he/she is in this study.

\section{Confidentiality}

Total privacy cannot be guaranteed. We will protect your child's privacy to the extent permitted by law. If the results from this study are published, your child's name will not be made public. Once your information leaves our institution, we cannot promise that others will keep it private.

Your child's information may be shared with the following:

- The University of Louisville Institutional Review Board, Human Subjects Protection Program Office, Privacy Office, others involved in research administration and compliance at the University, and others contracted by the University for ensuring human subjects safety or research compliance.

\section{Conflict of Interest}

This study involves no foreseeable conflict of interest.

\section{Security}


Your child's information will be kept private by using pseudonyms throughout this study. Interviews will be audio recorded and then secured on a password-locked computer along with professional transcriptions of those interviews. All data will be stored on a password-protected computer and at the conclusion of the study all data will be transferred to a password-protected external hard-drive.

\section{Voluntary Participation}

Taking part in this study is voluntary. Your child may choose not to take part at all. If your child decides to be in this study, your child may stop taking part at any time. If your child decides not to be in this study or if your child stops taking part at any time, your child's grades or ability to participate in school activities or events will not be affected.

\section{U.S. Department of Education (DOE) Funded Studies}

Because this study is funded by the U.S. DOE or this school system receives funding from the DOE, we are required to tell you the following information.

The information we collect from the education or study records of you or your child may only be used to meet the purposes of the study as stated in this consent. We will conduct this study in a manner that does not allow identification of you or your child by anyone other than study team members or others who may have a legitimate reason to know. All instructional materials or survey instruments used for the research, including teachers' manuals, films, tapes, or other supplementary instructional material used in connection with this study, are available for you to see before the study begins if you ask to see it. If you want to see any of this information, please contact Whitney M. Stewart, (502)-6438317 and they will give you a date and time where it will be available for you to review. Once we have completed this study, we are required by the U.S. Department of Education to destroy or return to the school system all personally identifiable information when no longer needed for the purposes of the study. We expect this study to last for six months and when the study is finished, we will delete any identifying information. All audio recordings will be destroyed by 2020 and all transcriptions will be destroyed by 2030.

\section{Contact Persons}

If you have any questions, concerns, or complaints about the research study, please contact the principal investigator at (502)-852-6887 Mary.brydon-miller@louisville.edu or Whitney M. Stewart at (502)-643-8317 or at whitney.stewart@,louisville.edu.

\section{Research Subject's Rights}

If you have any questions about your child's rights as a research subject, you may call the Human Subjects Protection Program Office at (502) 852-5188. You may discuss any questions about your child's rights as a research subject, in private, with a member of the 
Institutional Review Board (IRB). You may also call this number if you have other questions about the research, and you cannot reach the study doctor, or want to talk to someone else. The IRB is an independent committee made up of people from the University community, staff of the institutions, as well as people from the community not connected with these institutions. The IRB has approved the participation of human subjects in this research study.

\section{Concerns and Complaints}

If you have concerns or complaints about the research or research staff and you do not wish to give your name, you may call the toll free number 1-877-852-1167. This is a 24 hour hot line answered by people who do not work at the University of Louisville.

\section{Acknowledgment and Signatures}

This informed consent document is not a contract. This document tells you what will happen during the study if you choose for your child to take part. Your signature indicates that this study has been explained to you, that your questions have been answered, and that you agree for your child to take part in the study. You are not giving up any legal rights to which you are entitled by signing this informed consent document. Your child will be given a copy of this consent form to keep for your records.

Subject Name (Please Print)

$\overline{\text { Signature of Subject } \quad \text { Date Signed }}$

Printed Name of Legally

Authorized Representative (if applicable)

Signature of Legally Date Signed

Authorized Representative

Authority of Legally Authorized Representative to act on behalf of Subject

*Authority to act on behalf of another includes, but is not limited to parent, guardian, or durable power of attorney for health care.

Printed Name of Person $\quad$ Explaining Consent Form

Printed Name of Investigator
Signature of Person Explaining Date Signed

Consent Form (if other than the Investigator)

Signature of Investigator Date Signed 
List of Investigators:

Mary Brydon-Miller

Whitney M. Stewart
Phone Numbers:

(502)-852-6887

(502)-643-8317 


\section{APPENDIX F}

\section{8 years or older Consent Form}

Project Title:

\section{STUDENT VOICES: AFRICAN AMERICAN HIGH SCHOOL SENIORS' PERCEPTION OF CULTURALLY RESPONSIVE TEACHING}

Principal Investigator:

Mary Brydon-Miller, Ph.D.

College of Education and Human Development

University of Louisville

1905 South $1^{\text {st }}$ Street

Louisville, KY 40292

Mary.brydon-miller@1ouisville.edu

Investigator(s) name \& address:

Whitney M. Stewart

University of Louisville

1905 South $1^{\text {st }}$ Street

Louisville, KY 40292

Wmstew01@,louisville.edu

Site(s) where study is to be conducted: University of Louisville and

Phone number for subjects to call for questions: Dr. Mary Brydon-Miller 502-852-6887

and/or Whitney M. Stewart 502-643-8317

\section{Introduction and Background Information}

You are invited to participate in a research study. The study is being conducted by Dr. Brydon-Miller and Whitney M. Stewart. The study is sponsored by the University of Louisville, Department of Leadership, Evaluation, and Organizational Development. The study will take place at their high school. Approximately 8-10 subjects will be invited to participate.

\section{Purpose}

The purpose of this study is to understand and capture African-American students' voices on their perceptions about teaching that help them learn best.

\section{Procedures}

In this study, you will be asked to participate in a one-on-one individual interview, complete a participant profile sheet after their individual interview, and participate in a 
small focus group with other students. The individual interview should take approximately 20-40 minutes. The participant profile sheet should take 5 minutes to complete. The focus group should take approximately 30-90 minutes. During the individual and focus group interview, you will be asked questions that help the researcher to better understand the characteristics and classroom practices of teachers from whom African-American students learn from best. The interviews will be audio recorded. You may decline to answer any questions that make you feel uncomfortable.

\section{Potential Risks}

There are no foreseeable risks other than possible discomfort in answering personal questions.

\section{Benefits}

The possible benefits of this study include contributions to educational research regarding culturally responsive teaching of African-American high school students within the school district so that we, as educators, are in a better position to serve students and by extension, enhance learning.

\section{Payment}

You will not be compensated for your time or inconveniences while you are in this study.

\section{Confidentiality}

Total privacy cannot be guaranteed. We will protect your privacy to the extent permitted by law. If the results from this study are published, your name will not be made public. Once your information leaves our institution, we cannot promise that others will keep it private.

Your information may be shared with the following:

- The University of Louisville Institutional Review Board, Human Subjects Protection Program Office, Privacy Office, others involved in research administration and compliance at the University, and others contracted by the University for ensuring human subjects safety or research compliance.

\section{Conflict of Interest}

This study involves no foreseeable conflict of interest.

\section{Security}

Your information will be kept private by using pseudonyms throughout this study. Interviews will be audio recorded and then secured on a password-locked computer along with professional transcriptions of those interviews. All data will be stored on a 
password-protected computer and at the conclusion of the study all data will be transferred to a password-protected external hard-drive.

\section{Voluntary Participation}

Taking part in this study is voluntary. You may choose not to take part at all. If you decide to be in this study you may stop taking part at any time. If you decide not to be in this study or if you stop taking part at any time, your grades or ability to participate in school activities or events will not be affected.

\section{U.S. Department of Education (DOE) Funded Studies}

Because this study is funded by the U.S. DOE or this school system receives funding from the DOE, we are required to tell you the following information.

The information we collect from the education or study records of you or your child may only be used to meet the purposes of the study as stated in this consent. We will conduct this study in a manner that does not allow identification of you or your child by anyone other than study team members or others who may have a legitimate reason to know. All instructional materials or survey instruments used for the research, including teachers' manuals, films, tapes, or other supplementary instructional material used in connection with this study, are available for you to see before the study begins if you ask to see it. If you want to see any of this information, please contact Whitney M. Stewart, (502)-6438317 and they will give you a date and time where it will be available for you to review. Once we have completed this study, we are required by the U.S. Department of Education to destroy or return to the school system all personally identifiable information when no longer needed for the purposes of the study. We expect this study to last for six months and when the study is finished, we will delete any identifying information. All audio recordings will be destroyed by 2020 and all transcriptions will be destroyed by 2030.

\section{Contact Persons}

If you have any questions, concerns, or complaints about the research study, please contact the principal investigator at (502)-852-6887 Mary.brydon-miller@louisville.edu or Whitney M. Stewart at (502)-643-8317 or at whitney.stewart@,louisville.edu.

\section{Research Subject's Rights}

If you have any questions about your rights as a research subject, you may call the Human Subjects Protection Program Office at (502) 852-5188. You may discuss any questions about your rights as a research subject, in private, with a member of the Institutional Review Board (IRB). You may also call this number if you have other questions about the research, and you cannot reach the study doctor, or want to talk to someone else. The IRB is an independent committee made up of people from the University community, staff of the institutions, as well as people from the community not 
connected with these institutions. The IRB has approved the participation of human subjects in this research study.

\section{Concerns and Complaints}

If you have concerns or complaints about the research or research staff and you do not wish to give your name, you may call the toll free number 1-877-852-1167. This is a 24 hour hot line answered by people who do not work at the University of Louisville.

\section{Acknowledgment and Signatures}

This informed consent document is not a contract. This document tells you what will happen during the study if you choose to take part. Your signature indicates that this study has been explained to you, that your questions have been answered, and that you agree to take part in the study. You are not giving up any legal rights to which you are entitled by signing this informed consent document. You will be given a copy of this consent form to keep for your records.

Subject Name (Please Print)

Signature of Subject Date Signed

Printed Name of Person Explaining Consent Form

Signature of Person Explaining Date Signed Consent Form (if other than the Investigator)

Printed Name of Investigator

Signature of Investigator Date Signed

\section{List of Investigators:}

Mary Brydon-Miller

Whitney M. Stewart
Phone Numbers:

(502)-852-6887

(502)-643-8317 


\section{APPENDIX G}

\section{Subject Assent Form}

\section{STUDENT VOICES: AFRICAN AMERICAN HIGH SCHOOL SENIORS' PERCEPTION OF CULTURALLY RESPONSIVE TEACHING}

I am invited to be in a research study being done by Dr. Brydon-Miller and Whitney M. Stewart. When a person is in a research study, they are called a "subject". I am invited because I am enrolled in twelfth grade, b) I identify as Black or African-American, c) I have not lived outside of the United States, and d) I self-selected to willingly participate in an individual, one-on-one interview and a small focus group discussion with a researcher.

This means that I will participate in a one-on-one semi-structured interview, complete a participant profile sheet, and participate in a focus group. There are no foreseeable risks other than possible discomfort in answering personal questions.

The individual interview should take approximately 20-40 minutes. The focus group should take approximately 30-90 minutes. The benefit to me for participating in this study is to receive validation to my actual experience as an African American student as well as contribute to the educational research regarding teaching African-American high school students.

My family, the school administrators, teachers, and classmates will know that I'm in the study. If anyone else is given information about me, they will not know my name. A number or initials will be used instead of my name.

I have been told about this study and know why it is being done and what I have to do. My parent(s) have agreed to let me be in the study. If I have any questions I can ask Dr. Mary Brydon-Miller or Whitney M. Stewart. She will answer my questions. If I do not want to be in this study or I want to quit after I am already in this study, I can tell the researcher and she will discuss this with my parents.

Printed Name of Subject

Signature of Subject

Date Signed

Printed Name of Parent/Guardian

Printed Name of Investigator

Signature of Investigator

Date Signed 


\section{APPENDIX H}

\section{Interview Protocol}

\begin{tabular}{|l|l|}
\hline $\begin{array}{l}\text { Time of } \\
\text { Interview: }\end{array}$ & \\
\hline Date: & \\
\hline Place: & \\
\hline Interviewer: & \\
\hline Interviewee: & \\
\hline Pseudonym: & \\
\hline Review consent forms: Yes or No \\
\hline
\end{tabular}

Prompt: I am going to ask you a series of questions one at a time. For these questions, I want you to reflect on your high school experience. This one-on-one interview will help me to better understand the characteristics and classroom practices of teachers from whom African-American students learn from best. This interview will last approximately 20-40 minutes. I will audio record this interview for accuracy. The recording will be transcribed (your words typed out) and you will have an opportunity to review and approve what you have spoken. After your approval, I will use your words as data. I will not share your recording with anyone from the school. The recording will be collected on my password-protected cell phone and later stored on my personal, password-protected computer. After my research findings are complete, the recordings will be destroyed. Please feel free to be open and honest.

[Turn on audio recording device and test it.]

Prompt: You were selected to participate in this interview because of your demographic survey responses. You identified yourself as Black or African-American twelfth grader whom has never lived outside of the United States. Is this correct? Can you tell me a little bit more about yourself? How would you describe yourself? How would you describe your learning?

1. Think about something you enjoyed learning outside of school recently. Tell me about how you were taught and how you learned at home or within your community.

2. Tell me about a time when a teacher helped you learn something new. How were you taught and how did you learn from the teacher at school?

3. How would you describe how you are taught a new skill outside of school compared to how you are taught a new skill at school by a teacher? Is learning at school and home the same or different? How so? 
4. Do you have a preference for how you would like to be taught new information?

a. When do you prefer to work alone? How do you learn when you work alone?

b. When do you prefer to work with others? How do you learn when you work with others?

c. When you are learning, when do you prefer to switch tasks (break routine, mix it up, or vary from the current task)? How do you learn when tasks are switched or changed?

d. When do you prefer to work in the presence of music and rhythm? How do you learn when you work in the presence of music and rhythm?

5. Think about teachers you've had in the past when learning was not as effective. How would you describe that teacher(s)? What did they do or what have they done that played the biggest role in NOT supporting your academic achievement?

6. Think about teachers you've had in the past. Tell me about a teacher, or teachers, who have really helped you learn. What did they do or what have they done that played the biggest role in supporting your academic achievement?

7. If I were a new teacher, what are some things you would advise me to do in order to help support African-American students' academic achievement?

8. Teachers teach many different kinds of students that learn in many different ways. Tell me about the teachers who work well with you and other African-American students. What do they do to help you and other African-American students? How are they different from the other teachers that do not help (or that do not work well with) you and other African-American students?

9. Are there any questions I may not have asked that you believe are relevant to understanding how African-American student learn best in the classroom?

10. Are there any questions I may not have asked that you believe are relevant to understanding how teachers can best instruct African-American students?

Prompt: Last thing before you leave. Could you answer a few more demographic questions about yourself? [Give students post participant profile sheet.]

Prompt: Thank you for your cooperation and participation in this interview. Your responses will remain confidential and you will be given an opportunity to verify your responses. Once your recording has been transcribed (your words typed out), you will 
have an opportunity to review and approve what you have spoken. I will meet with you next week to review the transcriptions. Do you have any questions for me? See you then.

[End audio recording.] 


\section{APPENDIX I}

\section{Participant Profile Sheet}

Please respond to the following set of questions. You will notice many of the questions have multiple options. For those questions, please select the option(s) you feel are applicable to you and please check the "Not listed" option if you feel the options provided do not adequately represent your identity or identities.

1. How do you self-identify? (Circle response.)
a. Female
b. Intersex
c. Male
d. Transgender
e. Not listed
f. I prefer not to answer

2. Do you identify as a person with a physical disability? (Circle response.)
a. Yes
b. No
c. I prefer not to answer

3. Do you identify as a person with a learning disability? (Circle response.)
a. Yes
b. No
c. I prefer not to answer

4. Do you receive or are your eligible to receive Free or Reduced lunch? (Circle response.)
a. Yes
b. No
c. I am not sure.
d. I prefer not to answer

5. In relation to your racial/ethnic identity, how you would describe the racial/ethnic composition (make up) of your neighborhood?
a. The majority of my neighborhood is racially/ethnically similar to me.
b. The majority of my neighborhood is racially/ethnically different from me.
c. The majority of my neighborhood is racially/ethnically mixed.
d. Not able to determine
e. I prefer not to answer

6. How likely are you to go to college? (Circle response.) 

a. Definitely will go to college.
b. Very likely to go to college.
c. Somewhat likely to go to college.
d. Not likely to go to college.
e. Will not go to college.
f. I prefer not to answer

7. Where do you think you are in terms of academic achievement? (Circle response.)
a. Generally at the top of the class.
b. Generally at the top middle of the class.
c. Generally at the lower middle of the class.
d. Generally at the bottom of the class.
e. I am unsure.
f. I prefer not to answer 


\section{APPENDIX J}

\section{Focus Group Protocol}

\begin{tabular}{|l|l|}
\hline Time of & \\
Focus & \\
Group: & \\
\hline Date: & \\
\hline Place: & \\
\hline Interviewer: & \\
\hline Participants: & \\
\hline Pseudonym: & \\
\hline Review consent forms: Yes or No \\
\hline
\end{tabular}

Prompt: I am going to ask the group a series of questions one at a time. For these questions, I want you to reflect on your high school experience. This focus group will help me to better understand the characteristics and classroom practices of teachers from whom African-American students learn from best. This interview will last approximately 30-90 minutes. I will audio and video record this interview for accuracy. The recording will be transcribed (your words typed out). I will use your words as data. I will not share your recording with anyone from the school. The recording will be collected on my password-protected cell phone and with a video camera. Later, both recordings will be stored on my personal, password-protected computer. After my research findings are complete, the recordings will be destroyed. Please feel free to be open and honest.

[Turn on audio recording device and test it.]

Prompt: Thank you for agreeing to participate in this focus group. I'm going to ask the group some questions. Please answer them aloud to the group. Feel free to talk to or respond to another participant or you can direct your comments to me. Try to speak loudly so everyone can hear you and so that your thoughts will be captured on the recording.

1. Think about something you enjoyed learning outside of school recently. Tell me about how you were taught and how you learned at home or within your community.

2. Think about teachers you've had in the past when learning was not as effective. How would you describe that teacher(s)? What did they do or what have they done that played the biggest role in NOT supporting your academic achievement?

3. If I were a new teacher, what are some things you would advise me to do in order to help support African-American students' academic achievement?

Prompt: In our one-on-one interviews, I asked all the participants what advice they would give to a new teacher. I compiled all of your answers together to make an "ideal" teacher. Here is what the classroom would be like. 
[Scenario \#1] Ms. Moorman believes learning happens during lively discussions and spontaneous participation. In Ms. Moorman's class, students spend time sharing with one another and with the teacher. Ms. Moorman's students are expected to talk, move around, and exchange ideas and thoughts with one another to complete assignments. Most of the time, there are a variety of tasks or assignments. [Further explanation: Rarely are the assignments and tasks the same. They can vary from lecture, small group work, class discussion, written work, problem solving to Q\&A.] In Ms. Moorman's classroom, student desks are often re-arranged depending on the assignment or task. Student voice volume is typically medium to high. Ms. Moorman thinks breaking the routine, trying new things, and being creative is the best way to learn. She tends to constantly move around the classroom, talking and listening with students.

4. From your experience, do you think learning in this class would support AfricanAmerican students' academic achievement? Why or why not?

5. In this classroom setting, how would you describe your motivation to learn?

6. Reflecting on your high school career, how has having teachers with an instructional style similar to Ms. Moorman impacted African-American students' learning?

7. What changes would you suggest to Ms. Moorman to help African-American students learn better?

8. Are there any questions I may not have asked that you believe are relevant to understanding how African-American student learn best in the classroom?

Prompt: Thank you for your cooperation and participation in this focus group. Your responses will remain confidential. Once the recordings have been transcribed (your words typed out), I will use your words as data for my research. Do you have any questions for me?

[End audio recording.] 


\section{CURRICULUM VITAE}

Whitney M. Stewart

(502)-643-8317

Stewart.whitneym@gmail.com

\section{EDUCATION:}

Doctoral Student, Education Leadership and Organizational Development August 2015-present University of Louisville Masters of Education in Instructional Technology July 2011 University of Louisville

Bachelors of Science in Early Elementary Education with Concentration in Middle School Science
May 2010
University of Louisville

\section{RESEARCH INTEREST:}

Educational leadership $\square$ Culturally responsive teaching $\square$ Afrocultural learning orientations $\square \square$ African-American students K-12 $\square$ Instructional technology

\section{PROFESSIONAL EXPERIENCE:}

08/14-present College Access Resource Teacher South Park and Westport TAPP

Schools

Jefferson County Public School Louisville, KY

08/11-08/14 Seventh Grade Science Teacher

Jefferson County Public School

Stuart Middle School

Louisville, KY

06/10-08/11 Graduate Teaching Assistant

University of Louisville

University of Louisville

Louisville, KY

05/11-05/11 Technology and Science Teacher

Independence High School

Red Bank and Independence, Belize

01/08-05/11 Certified Substitute Teacher

Jefferson County Public School Louisville, KY

08/10-12/10 Instructional Technology Practicum Student

Newburg Middle School Louisville, KY 
01/10-04/10 Student Teacher Jefferson County Public School

04/06-08/06 Classroom Assistant

Promised Land Childcare
Wheeler Elementary School

Louisville, KY

Louisville, KY

\section{PROFESSIONAL LEADERSHIP:}

- Professional Growth and Effectiveness System (PGES)

Jefferson County Public Schools

- Solution Tree Leadership NOW Summit Las Vegas, Nevada

- Leveraged Adolescent Literacy and Learning Initiative (LALLI/ALP)

- Apprentice Push Program University of Louisville

- Budget Committee Stuart Middle School

- Professional Development Committee Stuart Middle School

- School Website Design Stuart Middle School Stuart Middle School

PRESENTATIONS:

2017 Ignite Presenter, University Council of Educational Administration (UCEA) Denver, Colorado

2017 Paper Co-Presenter, University Council of Educational Administration (UCEA) Denver, Colorado

2017 GSS Co-Paper Presenter, University Council of Educational Administration (UCEA) Denver, Colorado

2017 Co-Presenter, Deeper Learning Symposium Louisville, Kentucky

2014 Co-Presenter, Collaborative Center for Literacy Development Lexington, Kentucky

2013 Co-Presenter, Collaborative Center for Literacy Development Lexington, Kentucky

\section{HONORS \& AWARDS:}

Woodford R. Porter Scholar-Scholarship Recipient and Participant Minority Teacher Recruitment Program- Scholarship Recipient and Participant Stuart Middle School's First Spotlight Teacher of the Month February 2013

\section{PROFESSIONAL ORGANIZATIONS:}

Delta Sigma Theta Sorority, Inc.

Women Scholars of Color, University of Louisville 